\title{
EQUAÇÕES DE EXPORTAÇÃO PARA O AÇÚCAR BRASILEIRO: UM MODELO DE AUTO-REGRESSÃO VETORIAL
}

\author{
Mauro Virgino de Sena e Silva
}

Bacharel em Ciências Econômicas

Orientador: Profa. Dra. MIRIAM RUMENOS PIEDADE BACCHI

Dissertação apresentada à Escola Superior de Agricultura "Luiz de Queiroz", Universidade de São Paulo, para obtenção do título de Mestre em Ciências, Área de Concentração: Economia Aplicada.

P I R A C I C A B A

Estado de São Paulo - Brasil

Julho -2005 
Dados Internacionais de Catalogação na Publicação (CIP) DIVISÃO DE BIBLIOTECA E DOCUMENTAÇĀO - ESALQIUSP

Silva, Mauro Virgino de Sena e

Equações de exportação para o açúcar brasileiro: um modelo de auto-regressão vetorial / Mauro Virgino de Sena e Silva. - - Piracicaba, 2005.

$124 p$

Dissertaçăo (Mestrado) - - Escola Superior de Agricultura Luiz de Queiroz, 2005.

Bibliografia.

1. Açúcar 2. Análise de séries temporais 3. Exportação 4. Oferta I. Título

CDD 338.476641

"Permitida a cópia total ou parcial deste documento, desde que citada a fonte - 0 autor" 
Dedico a meus pais, Antonio Virgino e Antonia de Sena, por toda uma vida de apoio incondicional, incentivo e amor.

Ofereço as minhas irmãs, Neuma, Maria e Edna, ao meu sobrinho Julio César e a minha querida namorada Ana Cecília. 


\section{AGRADECIMENTOS}

Aos meus pais, especialmente a minha mãe, pelo constante apoio, incentivo e amor desde sempre. As minhas irmãs Neuma, Maria e Edna pela torcida e confiança que depositam em mim. A minha namorada Ana Cecília pelo amor, dedicação e companhia.

Aos meus amigos, caiçaras e do interior. A despeito da distância vocês são, assim como minha família, nas palavras de Vinicius de Moraes, "parte indispensável ao meu equilibrio vital, porque (...) fazem parte do mundo que eu, tremulamente construí e se tornaram alicerces do meu encanto pela vida". Não poderia deixar de mencionar alguns: os irmãos Fernando e Fabiano Xavier, Adriano, Vandinho, os irmãos Marcel e Maurílio, Paulo Camuri, Fernando Pereira, Bruno Cortina, Willy, Fabiana de Cássia, Luiz Camarani, Cássio, Alessandra, Rosângela e Érica Baron. Sou grato também à Lia, minha professora de Inglês que tornou uma amiga muito estimada. Meu muito obrigado pelo apoio, incentivo e pelas memoráveis histórias que têm me proporcionado nesses anos todos de amizade. Aos colegas e amigos de pós-graduação sou grato pela cordialidade na convivência diária e pela companhia, principalmente no primeiro ano do curso. Menção especial ao doutorando Lucílio, pela ajuda com o programa RATS no início dessa pesquisa;

Faço um agradecimento muito especial à Profa. Dra. Mirian Rumenos Piedade Bacchi, um ser humano incrível e uma profissional plenamente consciente do seu papel como educadora e do sentido que a palavra orientacão encerra. Serei eternamente grato pela oportunidade de aprendizado que me proporcionou e pela disposição a ajudar, demonstrada desde o primeiro momento. Espero que um dia eu possa retribuir tudo isso. Deixo aqui meu muito obrigado! 
À Profa. Dra. Heloísa Lee Burnquist, à Profa. Dra. Silvia H. Galvão de Miranda e à Dra. Marta Majorta-Maistro pela atenção, críticas e contribuições a esse trabalho. Menção especial à Profa. Dra. Silvia H. Galvão de Miranda pela supervisão na monitoria da disciplina Economia e Comércio Internacional no segundo semestre de 2004;

À Maielli, secretária do Programa de Pós Graduação em Economia Aplicada (PPG/EA), pela incansável disposição e paciência em esclarecer as nossas dúvidas e competência no cumprimento de suas funções, sempre com muita simpatia;

Ao Álvaro e à Ligiana, ambos da Divisão de Biblioteca e Documentação da ESALQ-USP, não só pelo apoio e agilidade no atendimento, mas também pela gentileza e cordialidade ao fazê-lo;

Ao Departamento de Economia da Universidade Estadual Paulista "Julio de Mesquita Filho" (UNESP) por ter me proporcionado sólidas bases para seguir adiante na carreira de economista. Agradecimentos especiais ao Prof. Dr. Carlos A. Cinquetti, ao Prof. Dr. Renato P. Colistette e à Profa. Dra. Luciana T. de Almeida, pelos ensinamentos e incentivos à carreira acadêmica;

À Escola Superior de Agricultura "Luiz de Queiroz" da Universidade de São Paulo, ao Departamento de Economia, Administração e Sociologia e ao Programa de Pós Graduação em Economia Aplicada (PPG/EA) por me proporcionar tão boas condições de estudo e aperfeiçoamento profissional;

Ả Fundação de Amparo à Pesquisa do Estado de São Paulo (FAPESP) pelo apoio financeiro a esse trabalho e ao seu parecerista anônimo pelas sugestões e críticas;

À DEUS, a quem palavras podem ser redundantes... 


\section{SUMÁRIO}

Página

LISTA DE FIGURAS ......................................................................... viii

LISTA DE QUADROS …......................................................................... ix

LISTA DE TABELAS …...................................................................

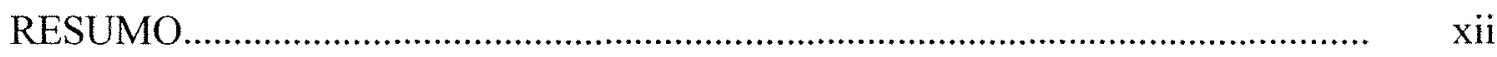

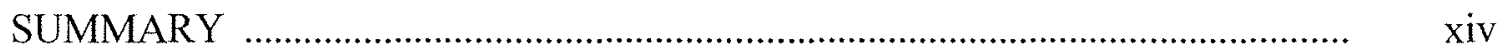

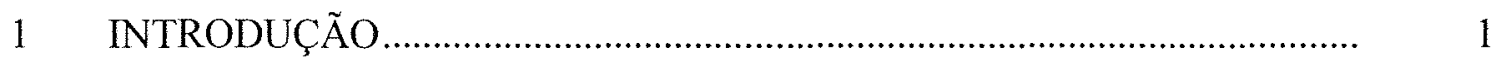

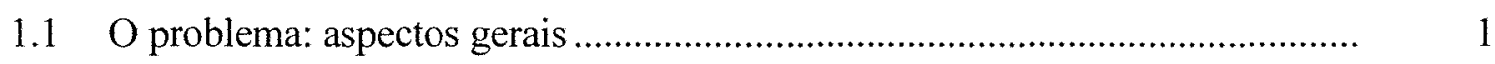

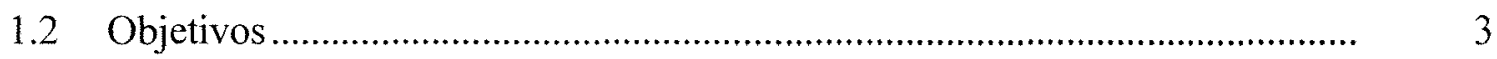

1.3 Importância do estudo....................................................................... 3

1.4 Organização da dissertação................................................................... 5

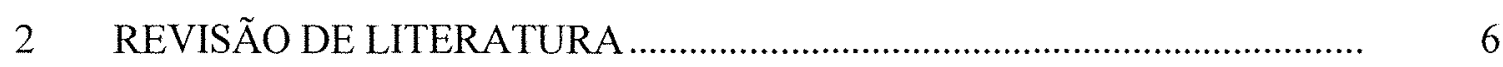

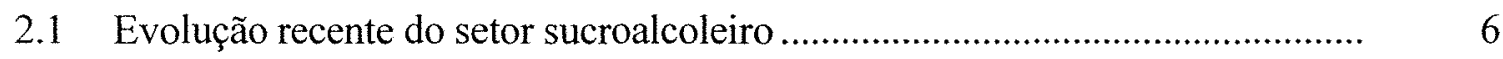

2.1.1 O complexo agroindustrial canavieiro brasileiro: um breve histórico do período anterior à desregulamentação ......................................................... 6

2.1.2 Panorama atual do setor sucroalcooleiro no Brasil ........................................ 9

2.1.3 O mercado de açúcar brasileiro pós-desregulamentação ............................ 13

2.2 Um panorama do Brasil no mercado internacional do açúcar ...................... 17

2.2.1 Uma caracterização dos principais países demandantes do açúcar brasileiro no mercado internacional ................................................................ 24

2.3 A estimação de equações de exportação: uma revisão teórica........................ 28

2.3.1 Considerações gerais sobre a estimação de equações de exportação................ $\quad 28$

2.3.1.1 A construção de um modelo econométrico: as formas estrutural e reduzida ... 29

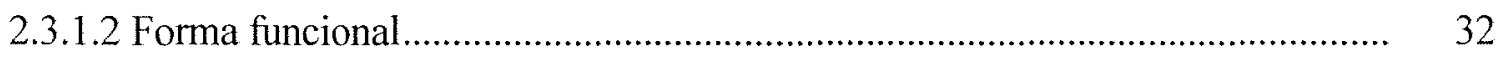


2.3.1.3 A escolha da variável dependente................................................................ 33

2.3.1.4 A escolha das variáveis explicativas ............................................................ 34

2.3.2 Formas de especificação de um modelo de comércio ....................................... 40

2.3.3 As diferentes abordagens nos estudos sobre equações de exportação........... 41

3 PROCEDIMENTOS METODOLÓGICOS E O MODELO ECONÔMICO

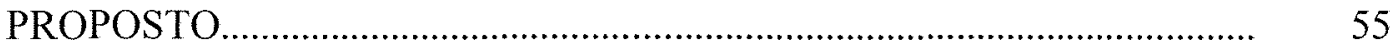

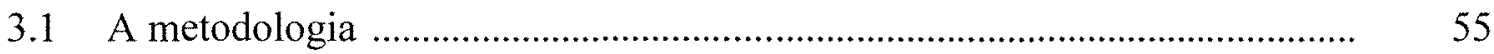

3.1.1 Aspectos gerais: variáveis estacionárias e não-estacionárias ......................... 55

3.1.2 Testando estacionariedade: a função de autocorrelação e o teste de raízes unitárias .................................................................................................. 57

3.1.3 Análise econométrica utilizando Vetores Auto-Regressivos (VAR) ............ 64

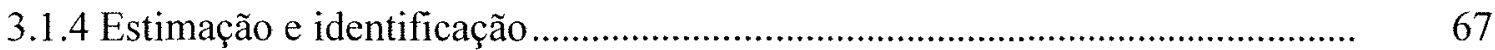

3.1.5 A função de resposta a impulso .................................................................

3.1.6 Decomposição da variância do erro de previsão ..................................................

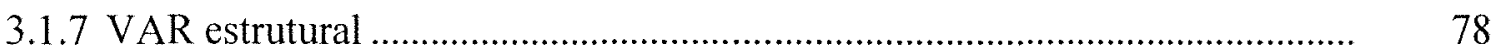

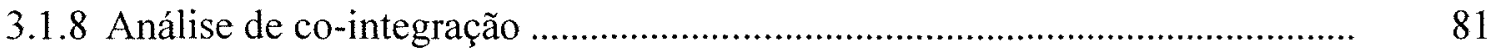

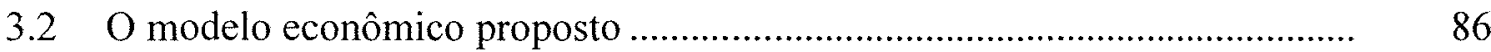

3.2.1 Modelo proposto para as exportações de açúcar branco ....................................... 86

3.2.2 Modelo proposto para as exportações de açúcar bruto ........................................ 92

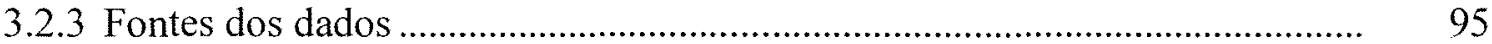

$4 \quad$ RESULTADOS E DISCUSS ÃO …………………….................................. 98

4.1 Testes de raiz unitária ....................................................................................... 99

4.2 Resultado dos modelos de Auto-Regressão Vetorial para o quantum de exportação de açúcar bruto e branco ................................................................. 101

4.2.1 Equação de exportação para o quantum exportado de açúcar bruto ................. 102

4.2.2 Equação de exportação para o quantum exportado de açúcar branco ............. 106

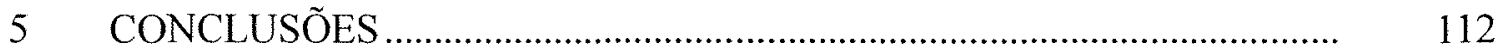

REFERÊNCIAS BIBLIOGRÁFICAS ........................................................... 117 


\section{LISTA DE FIGURAS}

Página

1 Brasil: rendimento médio da lavoura da cana-de-açúcar (toneladas por hectare) - período 1994 a 2003/04

2 Empregos na lavoura de cana-de-açúcar segundo grandes regiões $-2002 \ldots$

3 Participação relativa dos principais estados produtores de açúcar na safra $2002 / 03$

4 Função de resposta das exportações de açúcar bruto (lnXbrut.) a um impulso na renda a Rússia (lnYr.)

5 Função de resposta das exportações de açúcar bruto (lnXbrut.) a um impulso no preço doméstico de açúcar $(\ln P d$. $)$

6 Função de resposta das exportações de açúcar bruto (lnXbrut.) a um impulso na taxa de câmbio $(\operatorname{lnC}$.

7 Função de resposta das exportações de açúcar branco (lnXbco.) a um impulso na renda dos países Árabes e Africanos (lnYa.)

8 Função de resposta das exportações de açúcar branco (lnXbco.) a um impulso no preço doméstico do açúcar $(\operatorname{lnPd})$

9 Função de resposta das exportações de açúcar branco (lnXbco.) a um impulso na renda do Brasil $(\ln Y b)$

10 Função de resposta das exportações de açúcar branco (lnXbco.) a um impulso na taxa de câmbio $(\operatorname{lnC})$ 


\section{LISTA DE QUADROS}

Página

1 Brasil: principais países concorrentes no mercado internacional de açúcar do tipo bruto

2 Brasil: principais países concorrentes no mercado internacional de açúcar do tipo branco

3 Definição das variáveis utilizadas no modelo ajustado para o açúcar bruto e fontes dos dados

4 Definição das variáveis utilizadas no modelo ajustado para o açúcar branco e fontes dos dados 


\section{LISTA DE TABELAS}

Página

1 Brasil: importância do setor sucroalcooleiro (2003) .........................................

2 Brasil: produção de cana, açúcar e álcool - período de 1975/76 a 1990/91 .... 8

3 Brasil: safra colhida por principais culturas (em hectare) - período de 2002/03 a $2003 / 04$

4 Brasil: área plantada, quantidade produzida e rendimento médio da lavoura da cana-de-açúcar segundo regiões - 2002/03

5 Brasil: produção de cana, açúcar e álcool - Safras 1990/91 - 2002/03........... 14

6 Brasil: participação relativa na produção de açúcar por principais regiões período de 1990/01 a 2002/03 .................................................................. 15

7 Mundo: volume de produção e exportação de açúcar (em 1000 toneladas) Período 1999/200 a 2003/04.

8 Mundo: principais países produtores de açúcar (em 1000 toneladas) - Período 1999/00 a 2003/04.

9 Brasil: exportações de açúcar por principais estados (em 1000 toneladas) 2003

10 Mundo: principais exportadores de açúcar no mercado internacional (em 1000 toneladas) - Período 1999/00 a 2003/04

11 Mundo: principais importadores de açúcar (em 1000 toneladas) - Período $1999 / 00$ a $2003 / 04$

12 Brasil: dez maiores importadores de açúcar (em 1000 toneladas) - Período 2001 a 2002

13 Brasil: exportação de açúcar bruto por país de destino (1000 toneladas) Período 1995 a 2003 
14 Brasil: exportação de açúcar branco por país de destino (1000 toneladas)-

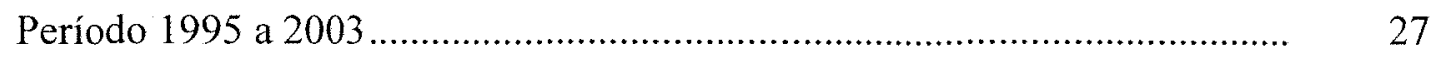

15 Descrição das variáveis utilizadas na pesquisa. ................................................ 99

16 Resultados dos testes de raiz unitária de Dickey-Fuller Aumentado (ADF). 100

17 Resultados dos testes de co-integração de Johansen entre as séries $\ln \mathrm{Xbrut}$

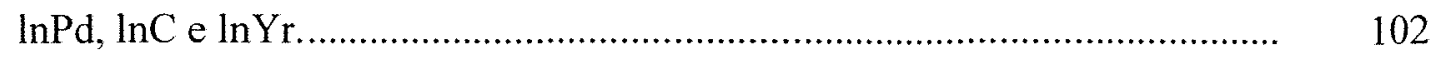

18 Estimativa da matriz de coeficientes de relações contemporâneas. ............... 103

19 Decomposição histórica da variância do erro de previsão para a quantidade exportada de açúcar bruto. ........................................................................ 104

20 Resultados dos testes de co-integração de Johansen entre as séries $\operatorname{lnXbco}$,

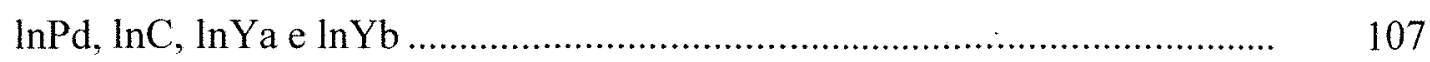

21 Estimativa da matriz de coeficientes de relações contemporâneas................ 108

22 Decomposição histórica da variância do erro de previsão para a quantidade exportada de açúcar branco 


\title{
EQUAÇÕES DE EXPORTAÇÃO PARA O AÇÚCAR BRASILEIRO: UM MODELO DE AUTO-REGRESSÃO VETORIAL
}

\author{
Autor: MAURO VIRGINO DE SENA E SILVA \\ Orientadora: Profa. Dra. MIRIAM RUMENOS PIEDADE BACCHI
}

\section{RESUMO}

O objetivo da presente pesquisa é estimar equações de exportação que expliquem o comércio internacional do açúcar brasileiro, com a finalidade de identificar as principais determinantes do desempenho exportador dessa commodity. Os modelos são estimados a partir de dados trimestrais para o período entre o quarto trimestre de 1995 e o quarto trimestre de 2003. A metodologia adotada é a análise de Auto-Regressão Vetorial, sendo consideradas as propriedades de integração e co-integração das séries utilizadas. Os testes de raiz unitária de Dickey-Fuller são utilizados para determinar a ordem de integração das séries, e o procedimento de Johansen para testar co-integração e propiciar as estimativas do(s) termo(s) de correção de erro. São ajustados modelos diferenciados por tipo de açúcar: branco e bruto. Uma vez que a produção doméstica de açúcar bruto se destina exclusivamente ao mercado externo e a Rússia é o principal destino para esse produto, ajustou-se um modelo reduzido baseado na definição das curvas de oferta e demanda de exportação, incluindo a renda da Rússia como a variável deslocadora da demanda externa por esse produto. Da mesma forma, dado que os países Árabes e africanos são os principais demandantes do açúcar branco, incluiu-se a renda desses países na função de demanda por exportações dessa commodity. No caso do 
açúcar branco, o modelo de exportação foi definido de forma a considerar as condições internas, uma vez que esse produto é também consumido no mercado doméstico. Os sinais da matriz de coeficientes de relações contemporâneas no modelo estimado para o açúcar bruto apresentam sinais consistentes. O resultado da decomposição da variância do erro de previsão mostra que as variáveis de mercado externo, renda da Rússia e taxa de câmbio, são as que explicam a maior parte das variações no quantum exportado de açúcar bruto. Os sinais dos coeficientes da matriz de relações contemporâneas do modelo de vendas externas para o açúcar branco também apresentam-se todos de acordo com o esperado, com exceção da variável renda do Brasil. Esse resultado deve estar relacionado à proxy utilizada, o PIB, que pode estar captando a forte influência das exportações sobre o crescimento da economia brasileira nos últimos anos. Como esperado, as variáveis de mercado interno, renda do Brasil e preço doméstico, explicam a maior parte das variações no quantum exportado de açúcar branco. A despeito do número reduzido de observações disponíveis para o ajustamento dos modelos propostos, considerado uma limitação do presente trabalho, o objetivo principal, identificar os impactos de importantes condicionantes do desempenho exportador do açúcar brasileiro, foi alcançado. 


\title{
EXPORT EQUATIONS FOR THE BRAZILIAN SUGAR: A VECTORIAL AUTOREGRESSION MODEL
}

\author{
Author: MAURO VIRGINO DE SENA E SILVA \\ Adviser: Profa. Dra. MIRIAM RUMENOS PIEDADE BACCHI
}

\section{SUMMARY}

The aim of the present research is to estimate equations of exports which explain the Brazilian sugar international trade, with the purpose of identifying the main determinant of the exporting performance of this commodity. These analyses are carried out from quarter data for the period between the fourth quarter of 1995 and the forth quarter of 2003. The applied methodology is the analysis of vectorial Auto-regressions, being considered the integration and co-integration properties of the used series. DickeyFuller unity root tests are used to determine the series integration order, and Johansen procedure to test co-integration and to estimate error correction term. Specific models differed by sugar type are adjusted: raw and refined sugar. Due to the fact that the domestic production of raw sugar is directed exclusively to external markets and Russia is the main destination for this product, a reduced model for raw sugar exports based on supply and demand curves for exports was adjusted, including Russian income as the dislocating variable of the external demand for this product. In the same way, due to de fact that the Arabian and African countries are the main purchaser of the Brazilian refined sugar, their income was included in the function of demand for exports. Regarding the refined sugar, the exports model was adjusted in a way to consider the internal conditions, because this product is also consumed in the internal market. The 
coefficient matrix signals of contemporary relations in the model for the raw sugar presented consistent signals. The decomposition result of the forecast error variance shows that the external market variable, Russian income and exchange rate, are the ones which explains most of the variations in the exported quantum of raw sugar. The matrix coefficient signals of contemporary relations of the external sales model for the refined sugar are also shown according to what was expected, except for the Brazilian income variable. This result must be related to the proxy used, the Brazilian GDP, which may be receiving strong influences from the exports on the growth of the Brazilian economy in the last years. As expected, the internal market variables, Brazilian income and internal price, explain most of the variations in the exported quantum of refined sugar. In the spite of the reduced number of available observations to the proposed model adjustment, considered as limitation to this study, the main goal, to identify the impacts of important variables on the Brazilian sugar exporting performance, was reached. 


\section{INTRODUÇÃO}

\subsection{O problema: aspectos gerais}

Em fins da década 1980, mais marcadamente a partir de 1990, a economia brasileira rompeu com uma longa tradição de protecionismo, iniciando um amplo processo de liberalização comercial. A queda do protecionismo ao longo dos anos de 1990 é ilustrada pela firme redução do valor médio e da mediana das tarifas de importação, assim como da amplitude e do desvio padrão das mesmas, apontando para uma convergência de todos os setores para um mesmo padrão de proteção (Kume, 1998).

O objetivo desta abertura comercial era intensificar a concorrência sobre os produtores locais e ampliar o acesso às melhores práticas internacionais, quer pelas importações de produtos, quer pela importação de tecnologias (Gonçalves, 1998). Outro resultado deste processo, ao apontar os setores da economia local que tinham vantagens comparativas, e os que não tinham, era reorientar os recursos locais dos últimos para os primeiros, elevando a eficiência alocativa.

Um setor cujas desvantagens comparativas logo se explicitaram com a abertura comercial foi o das indústrias produtoras de bens de capital (Rezende \& Anderson, 1999). Entre 1991 e 1996, o coeficiente de importação (importação/produção) deste setor passou de $33,3 \%$ para $61,5 \%$, enquanto o coeficiente de exportação (exportação/produção) evoluiu apenas de $14,7 \%$ para $16,5 \%$ no mesmo período (Moreira, 1997). É certo que este desempenho comercial foi também decorrente da valorização cambial desde a implantação do Plano Real, em 1994. 
A redefinição do papel do Estado na economia afetou também o setor agrícola brasileiro, o qual passou de um regime de política agrícola concebido para uma economia fechada, com forte intervenção estatal, para um regime desenhado para uma economia aberta e com um menor papel do Estado. No entanto, como mostram Helfand \& Rezende (2001), a liberalização do comércio exterior para o setor agrícola apresentou resultados diversos daqueles observados para a média do setor de bens de capital. A alteração dos preços relativos dos insumos, aliado ao maior acesso a insumos importados e de alta qualidade, levou a produção doméstica de agrícolas a uma maior competitividade internacional.

Para os países em desenvolvimento, como o Brasil, e particularmente para aqueles que enfrentam dificuldades de acesso aos mercados financeiros internacionais, os recursos proporcionados pelas exportações assumem papel fundamental. Considerando-se que esses recursos apresentam-se, em diversas instancias, como estratégicos para manter o fluxo de importações de bens de capital e de energia para assegurar o desenvolvimento econômico, torna-se necessário conduzir estudos que proporcionem subsídios para o entendimento dos fatores que explicam o desempenho das exportações (Barros et al., 2002).

Barros et al. (2002) apontam que o agronegócio nacional tem contribuído de maneira decisiva na geração de saldos positivos na balança comercial do Brasil e tem respondido positivamente à necessidade de redução do déficit no balanço de pagamentos, principalmente quando comparado às exportações de industriais.

As exportações de agropecuários e agroindustriais brasileiros, como mostram Tomich, et al. (2001), estão concentradas em um grupo reduzido de produtos que é responsável por cerca de $70 \%$ a $80 \%$ das exportações do setor. Dentre os produtos tradicionais, o açúcar aparece como um dos que têm posição de destaque em termos de competitividade comercial.

A participação do açúcar brasileiro no mercado internacional cresceu durante toda a década de 1990, o que sugere que o Brasil deslocou importantes ofertantes desse produto no mercado internacional, como Austrália e Cuba (Waak \& Neves, 1998). Tais 
ganhos de competitividade estariam associados ao processo de desregulamentação por que passou o setor nos anos de 1990.

\subsection{Objetivo}

O objetivo deste estudo é estimar equações de exportação que expliquem o comércio internacional do açúcar brasileiro, com a finalidade de identificar as principais determinantes do desempenho exportador dessa commodity.

As estimativas foram feitas a partir de dados trimestrais para o período compreendido entre o quarto trimestre de 1995 e o quarto trimestre de 2003. Diferentemente da maior parte dos estudos realizados anteriormente para o açúcar, propôs-se a definição e o ajustamento de equações de exportação diferenciadas por tipo do produto: branco e bruto. Vale ressaltar desde já que na especificação dos modelos que explicam as exportações de açúcar brasileiro foi considerada uma variável representativa da renda dos principais mercados demandantes dessa commodity brasileira ${ }^{1}$, o que não foi feito em estudos anteriores.

\subsection{Importância do estudo}

A relevância de se estudar os determinantes do desempenho comercial do açúcar brasileiro, foco desta dissertação, está na grande importância que esse setor tem para a economia brasileira.

A Tabela 1 apresenta alguns indicadores da importância do setor sucroalcooleiro para a economia nacional e da posição do Brasil no mercado internacional do açúcar e do álcool. Destacam-se o volume de empregos gerados pelo setor (3,6 milhões) e a quantidade produzida e exportada de açúcar na safra 2002/03, 24 e 13,5 milhões de

\footnotetext{
'Os mercados importadores considerados são dois: a Rússia e um grupo de nove países chamados genericamente de Árabes e Africanos, devido ao fato de a maioria ser do Oriente Médio e da África.
} 
toneladas, respectivamente, o que faz com que o Brasil seja o maior produtor e exportador mundial desse produto. Esses dados evidenciam, portanto, a importância estratégica do setor sucroalcooleiro na geração de divisas, emprego e renda, o que justifica o desenvolvimento de estudos que auxiliem no entendimento das condicionantes das exportações desse setor.

Ademais, a maior parte dos estudos empíricos que tratam da estimação de equações de oferta e demanda de exportação para o Brasil o faz considerando setores agregados. Desse modo, com o objetivo de preencher a lacuna existente na literatura sobre o assunto, é que se propõe o ajuste de equações de oferta e demanda de exportações para os diferentes tipos de açúcar produzidos no Brasil.

Tabela 1. Brasil: importância do setor sucroalcooleiro (2002/03)

\begin{tabular}{ll}
\hline Item & Valor \\
\hline Movimentou: & $R \$ 36$ bilhões \\
Representou: & $3,5 \%$ do PIB \\
Gerou: & 3,6 milhões de empregos \\
Envolveu: & 70,000 mil agricultores \\
Moeu: & 340 milhões de toneladas de cana \\
Produziu: & 24 milhões de toneladas de açúcar \\
Produziu: & 14,5 bilhões de litros de álcool \\
Exportou: & 13,5 milhões de toneladas de açúcar \\
Exportou: & 690 milhões de litros de álcool \\
Recolheu: & $\mathrm{R} \$ 4,5$ bilhões em impostos e taxas \\
Investiu: & $\mathrm{R} \$ 3,5$ bilhões por ano \\
Compõem-se de: & 302 usinas e destilarias \\
\hline
\end{tabular}

Fonte: Jornal da Cana (2004)

Além disso, como discutido em Barros et al. (2002), a estimação de equações de oferta e demanda de exportação possibilita verificar ex ante os resultados de políticas de 
incentivos e/ou alterações nas variáveis condicionantes, permitindo análises prospectivas sobre o comportamento do comércio externo do País. Esse tipo de análise pode servir de suporte no processo de definição de políticas comerciais e de programas econômicos de ajustamento do setor externo. Adicionalmente, o conhecimento das elasticidades de oferta e demanda de exportação pode auxiliar os agentes ligados a esse setor na tomada de decisão sobre produção e comercialização.

\subsection{Organização da dissertação}

O presente trabalho está organizado em cinco capítulos, incluindo esta introdução. O Capítulo 2 está dividido em três subcapítulos. No primeiro subcapítulo faz-se uma breve discussão sobre a evolução do setor sucroalcooleiro brasileiro, destacando as principais transformações que ocorreram nesse setor no período recente. O segundo subcapítulo traz uma análise da posição do Brasil no mercado internacional do açúcar, apontando os principais mercados de destino do açúcar brasileiro, bem como os principais concorrentes do País nesses mercados. No terceiro subcapitulo faz-se uma discussão acerca das principais formulações teóricas que podem ser testadas para a análise empírica das determinantes do comportamento das exportações de um país. Além disso, é feita uma revisão sobre diversos estudos que buscaram explicar o desempenho do comércio exterior brasileiro, o que auxiliou na definição dos modelos econômicos propostos. O Capítulo 3 está dividido em dois subcapítulos. No primeiro subcapítulo são discutidos os procedimentos metodológicos que envolvem a pesquisa com séries temporais e, mais especificamente, com vetores auto-regressivos. No segundo subcapítulo são apresentados os modelos econômicos propostos para o presente estudo, bem como as fontes dos dados. No Capitulo 4 faz-se a apresentação e discussão dos principais resultados obtidos na presente pesquisa. Finalmente, o Capítulo 5 traz as principais conclusões deste estudo, bem como uma discussão sobre seu alcance e limitações.As Referências Bibliográficas constam ao final do trabalho. 


\section{REVISÃO DE LITERATURA}

\subsection{Evolução do setor sucroalcooleiro brasileiro}

\subsubsection{O complexo agroindustrial canavieiro brasileiro ${ }^{1}$ : um breve histórico do período anterior à desregulamentação}

Introduzida em Pernambuco logo após o descobrimento do Brasil e posteriormente em São Paulo, a cultura da cana-de-açúcar aparece como a atividade econômica não extrativa mais antiga do Brasil.

Em 1933 houve a criação do Instituto do Açúcar e do Álcool (IAA). Segundo Carón (1986), a criação desse instituto significou a unificação da intervenção governamental no setor sucroalcooleiro, até então exercido por diversos órgãos de emergência que tinham caráter provisório. $\mathrm{O}$ objetivo do IAA era o de regulamentar e gerenciar as atividades do setor sucroalcooleiro. No que se refere ao açúcar, o principal instrumento à disposição do IAA era a determinação das quotas individuais de produção, tendo por base a capacidade instalada de cada unidade e as previsões de evolução do mercado. Tal mecanismo era complementado pela atribuição do IAA em regular o mercado de açúcar, comprando os excedentes de produção de forma a garantir um preço

\footnotetext{
' Segundo Shikida (1997), o complexo agroindustrial canavieiro pode ser conceituado como um conjunto de atividades produtivas e comerciais que envolvem os produtores de insumo; a produção de cana-deaçúcar propriamente dita; e a transformação industrial, geradora de produtos (açúcar e álcool) e subprodutos (bagaço, vinhoto, etc.), que, conforme sua especificação, destinam-se ao mercado interno e/ou externo.
} 
remunerador aos produtores e usando seus estoques para garantir o abastecimento no caso de falta de produto (Moreira, 1997).

Durante séculos a cana destinou-se quase que exclusivamente à produção de açúcar. Devido às crises do petróleo na década de 1970 houve a necessidade de se reduzir a dependência externa brasileira desse produto. A experiência acumulada na produção e uso de álcool em todo o País desde a década de 20 (álcool anidro para mistura à gasolina) possibilitou ao Brasil buscar no álcool combustível uma alternativa para diminuir sua vulnerabilidade energética e economizar divisas. Em 1975, apenas dois anos após o primeiro choque do petróleo, foi instituído o Programa Nacional do Álcool Combustível - PROALCOOL, um programa de investimentos que permitiu a diversificação da indústria açucareira, com grandes investimentos por parte dos setores público e privado, apoiados pelo Banco Mundial. Esse programa possibilitou a ampliação da área plantada de cana-de-açúcar e a implantação de destilarias de álcool autônomas ou anexas às usinas de açúcar existentes (Jornal da Cana, 2004).

Visando estabilizar o preço doméstico de açúcar e garantir oferta adequada de cana-de-açúcar para produção de álcool e açúcar, o IAA centralizava as operações de exportação do açúcar brasileiro, sendo a única instituição autorizada a comprar açúcar no mercado doméstico e a estabelecer contratos de exportação (Ramos, 1999).

Desde a época das capitanias hereditárias, passando pela criação do IAA e pela instituição do PROALCOOL, percebe-se que a trajetória da agroindústria canavieira do Brasil é marcada por forte intervenção estatal.

Na Tabela 2 são apresentados dados de produção de cana-de-açúcar, açúcar e álcool desde a instituição do PROALCOOL, em 1975/76, até o auge da crise desse programa, em 1990/91. 
Tabela 2. Brasil: produção de cana, açúcar e álcool - Período de 1975/76 a 1990/91

\begin{tabular}{lcccc}
\hline Ano & $\begin{array}{c}\text { Cana } \\
(\mathrm{em} \mathrm{1000} \mathrm{t.)}\end{array}$ & $\begin{array}{c}\text { Cana para açúcar } \\
(\%)\end{array}$ & $\begin{array}{c}\text { Açúcar } \\
(\mathrm{em} \mathrm{1000} \mathrm{t.})\end{array}$ & $\begin{array}{c}\text { Álcool } \\
\left(\mathrm{em} 1000 \mathrm{~m}^{3}\right)\end{array}$ \\
\hline $1975 / 76$ & 91,525 & 86,28 & 6,017 & 556 \\
$1980 / 81$ & 148,651 & 55,01 & 7,843 & 3,706 \\
$1985 / 86$ & 224,364 & 27,87 & 7,819 & 11,820 \\
$1990 / 91$ & 222,163 & 26,86 & 7,365 & 11,783 \\
\hline
\end{tabular}

Fonte: UNICA (2004)

Nota-se que na safra 1975/76 do total de cana-de-açúcar produzido, mais de $86 \%$ foi destinado à produção de açúcar. Já na safra de 1980/81 esse percentual se reduz para aproximadamente $55 \%$ e em $1985 / 86$ cai para pouco menos de $28 \%$. Fica evidente, portanto, a influência da consolidação do PROALCOOL sobre a opção dos agentes do setor sucroalcooleiro. Verifica-se que de 1975/76 a 1990/91, o resultado desse programa foi o estímulo à produção do álcool.

Apesar de até os primeiros anos da década de 1990 cerca de 2/3 da produção total de cana-de-açúcar ter se destinado à produção de álcool, desde meados da década de 1980 o PROALCOOL foi marcado pela retirada gradual da participação dos investimentos públicos. O resultado foi o desequilíbrio entre a oferta e a demanda de álcool combustível e a conseqüente necessidade de importação do produto a partir de 1989 (Shikida, 1997). Essa situação ia contra os propósitos iniciais do PROALCOOL, uma vez que ao invés de economizar divisas, reduzindo a dependência externa brasileira de petróleo, criou-se um mercado de álcool combustível de tamanho considerável a ser suprido por fontes internas ou externas ${ }^{2}$.

Como parte da política de desregulamentação que marcou o início do governo Collor, tem-se a extinção do IAA, em março de 1990. O término das quotas e preços administrados no setor transformaram o agronegócio sucroalcooleiro. A partir de então,

\footnotetext{
${ }^{2}$ Segundo Shikida (1997), 96\% dos carros vendidos no Brasil em 1985 eram com motores a álcool.
} 
a comercialização do açúcar passou a acontecer sem a intervenção ou subsídios do governo. Em relação às exportações, o Estado deixou de deter o seu monopólio e estas passaram a ser feitas diretamente e por conta e risco dos produtores e/ou tradings.

$\mathrm{O}$ resultado foi o estabelecimento de um ambiente mais competitivo na agroindústria como um todo, dado que os preços passaram a ser determinados de acordo com as regras do livre mercado. Esse novo ambiente colocava o Brasil como uma exceção no mercado internacional do açúcar, uma vez que a interferência estatal no setor no âmbito internacional é generalizada. Por outro lado, deu ao setor sucroalcooleiro brasileiro as condições de mercado necessárias para que o Brasil se transformasse no maior produtor e exportador de álcool e açúcar do mundo.

\subsubsection{Panorama atual do setor sucroalcooleiro no Brasil}

Em 2003 o agronegócio sucroalcooleiro movimentou cerca de $\mathrm{R} \$ 36$ bilhões, com faturamentos diretos e indiretos, o que correspondeu a aproximadamente $3,5 \%$ do PIB brasileiro no período. Além de ser um dos setores que mais empregam no país, cerca de 3,6 milhões de empregos diretos e indiretos, o agronegócio sucroalcooleiro se destaca também pelo volume de impostos recolhidos anualmente: cerca de R\$4,5 bilhões (Jornal da Cana, 2004).

Da cana-de-açúcar se extrai principalmente o açúcar, o álcool anidro (aditivado à gasolina) e o álcool hidratado para os mercados interno e externo. No entanto, a indústria sucroalcooleira gera diversos subprodutos no seu processo produtivo como, por exemplo, o bagaço, a vinhaça e a torta de filtro. Sousa \& Burnquist (1999) afirmam que a exposição do setor sucroalcooleiro a incentivos de mercados tem aguçado a capacidade empresarial dos agentes ligados a esse setor, que têm buscado expandir suas alternativas e capacidade de gerar receitas adicionais a partir de subprodutos. Miranda-Stalder \& Burnquist (1996) afirmam que o bagaço da cana usado como combustível na geração de energia elétrica tem sido identificado como o subproduto com maior potencial de 
aumento de receita na indústria sucroalcooleira, seja pela venda, seja pelo uso nas próprias unidades de produção.

A tabela 3 apresenta dados sobre a área colhida das principais culturas nas safras de 2002/03 a 2003/04. Através dessa tabela pode-se notar que a cana-de-açúcar ocupa posição de destaque em relação às principais culturas, em termos de área colhida nos anos analisados. Observa-se que a cultura da cana-de-açúcar, com 5.336,985 ha de área colhida em 2003/04, ficou atrás apenas da cultura da soja, que no mesmo ano apresentou uma área colhida de $18.447,669$ ha. Na safra de 2003/04, por exemplo, a área colhida de cana-de-açúcar correspondeu a aproximadamente $10 \%$ da área total colhida no País e apresentou um crescimento de cerca de $2,5 \%$ em relação à 2002/03.

Tabela 3. Brasil: safra colhida por principais culturas (em hectare) - periodo de $2002 / 03$ a $2003 / 04$

\begin{tabular}{lcc}
\hline Produtos Agrícolas & $\begin{array}{c}\text { Colhida em } \\
2002 / 3\end{array}$ & Colhida em 2003/04 \\
\hline Soja & $16.382,035$ & $18.447,669$ \\
Cana-de-açúcar & $5.206,736$ & $5.336,985$ \\
Trigo & $2.158,831$ & $2.495,392$ \\
Arroz & $3.175,772$ & $3.186,822$ \\
Café & $2.429,206$ & $2.395,584$ \\
\hline
\end{tabular}

Fonte: IBGE (2004)

Além do aumento da área plantada, tem-se observado também um crescimento significativo da produtividade da cultura da cana-de-açúcar no período recente. Segundo a Confederação da Agricultura e Pecuária do Brasil (CNA) isso se deve à significativa renovação dos canaviais, resultando no aumento expressivo do rendimento do Açúcar Total Recuperável (ATR). 
A Figura 1 apresenta a evolução do rendimento médio da lavoura de cana-deaçúcar, em toneladas por hectare, para as safras de 1994/95 à 2003/04. Observa-se que o rendimento médio dessa cultura passa de pouco mais de 65 toneladas por hectare, na safra de 1994/95, para aproximadamente 74 toneladas por hectare na safra de 2003/04.

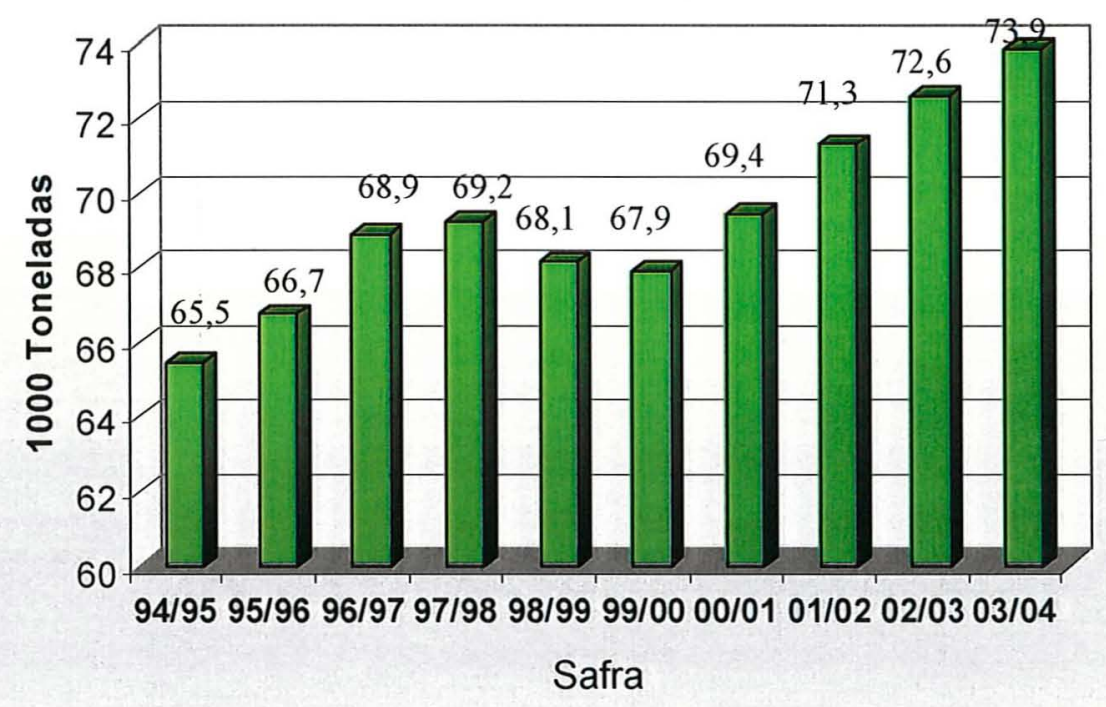

Figura 1 - Brasil: rendimento médio da lavoura da cana-de-açúcar (toneladas por hectare) 1994 a 2003/04

Fonte: CNA (2004)

Em termos da distribuição regional, costuma-se dividir a cultura da cana-deaçúcar em duas grandes regiões produtoras, quais sejam, a Centro-Sul e a NorteNordeste $^{3}$. A Tabela 4 apresenta dados sobre área plantada, quantidade produzida e rendimento médio por hectare da cultura de cana-de-açúcar para a safra de 2002/3. Nesta tabela pode-se notar que a principal região produtora de cana-de-açúcar é a Centro-Sul, responsável por $77,8 \%$ da área plantada, por $83,4 \%$ da quantidade total produzida e pelo melhor rendimento médio, mais de 75 toneladas por hectare.

\footnotetext{
${ }^{3}$ A região Centro -Sul corresponde aos estados produtores das regiões Centro-Oeste, Sudeste e Sul, enquanto que a região Norte-Nordeste é formada pelos estados do Norte e Nordeste do Brasil.
} 
Tabela 4. Brasil: área plantada, quantidade produzida e rendimento médio da lavoura da cana-de-açúcar segundo regiões - 2002/03

\begin{tabular}{lccc}
\hline Região & Área plantada (ha) & $\begin{array}{c}\text { Quantidade } \\
\text { produzida }(\mathrm{t})\end{array}$ & $\begin{array}{c}\text { Rendimento médio } \\
(\mathrm{t} / \mathrm{ha})\end{array}$ \\
\hline Centro-Sul & $4.049,829$ & $303.870,447$ & 75,09 \\
Norte-Nordeste & $1.156,907$ & $60.520,569$ & 57,15 \\
Brasil & $5.206,736$ & $364.391,016$ & 71,444 \\
\hline
\end{tabular}

Fonte: IBGE (2004)

Além disso, vale salientar que dentro da região Centro-Sul, o destaque é o estado de São Paulo, responsável na safra $2002 / 03$ por mais de $84 \%$ da área total plantada de cana-de-açúcar da região, $88,2 \%$ do total produzido, possuindo, ainda, o maior rendimento médio por hectare, $79,94 \mathrm{t} / \mathrm{ha}$.

Segundo Stalder (1997), um dos aspectos mais salientados para diferenciar as regiões Norte-Nordeste e Centro-Sul são os custos de produção. Tais custos são mais elevados para o Norte-Nordeste. Uma outra característica que diferencia essas regiões é o cultivo menos tecnificado e, conseqüentemente, níveis de eficiência inferiores na região Norte-Nordeste frente à região Centro-Sul. Além disso, a autora aponta que tais regiões se diferenciam também pela própria evolução histórica da cultura e por apresentarem épocas de colheita distintas, propiciando oferta de cana-de-açúcar ao longo de todo o ano.

A Figura 2 mostra o número de empregos gerados na lavoura da cana-de-açúcar por regiões. Comparando-se estes dados com os já apresentados na Tabela 4, fica evidente o maior nível de tecnificação da lavoura canavieira na região Centro-Sul do Brasil. 


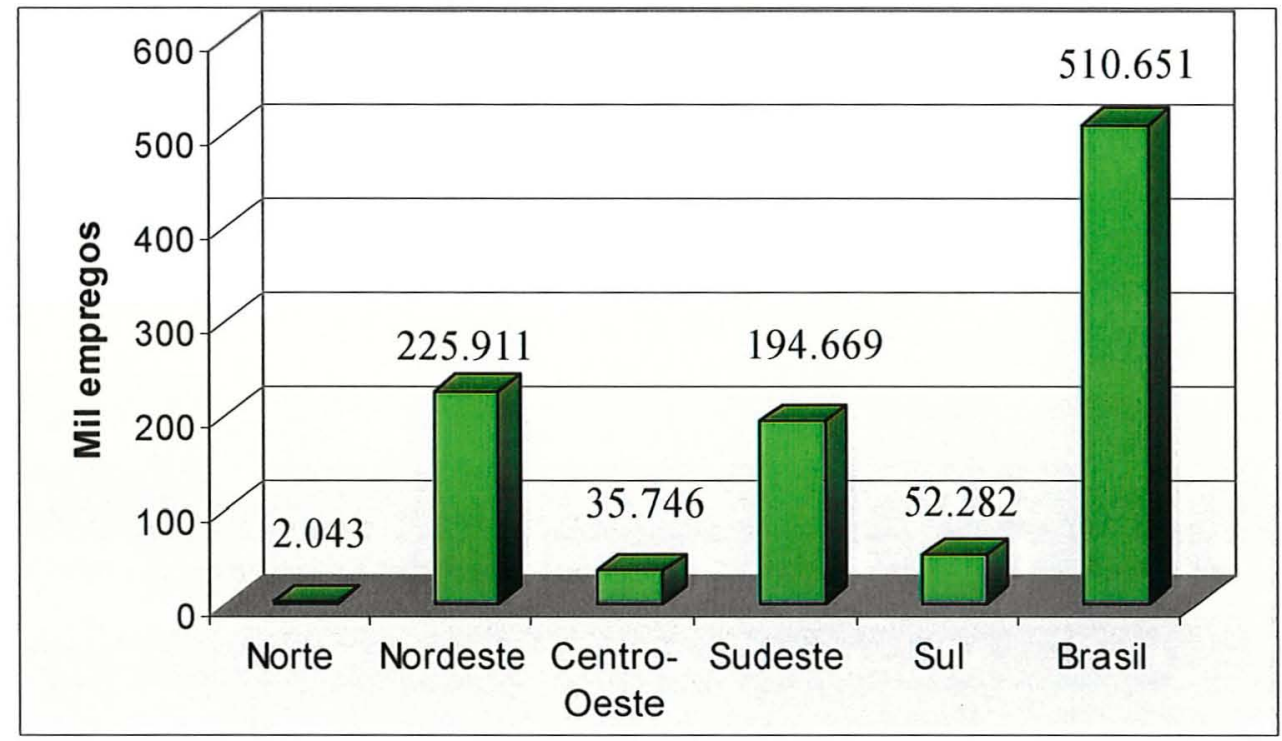

Figura 2 - Brasil: empregos na lavoura de cana-de-açúcar segundo grandes regiões $-2002 / 3$

Fonte: CNA (2004)

Enquanto a região Centro-Sul apresenta uma área plantada e um volume de produção respectivamente 3,5 e 5 vezes maior que o da região Norte-Nordeste, o volume de empregos gerados na região Centro-Sul é apenas $24 \%$ maior que o da região NorteNordeste, o que evidencia maior nível de mecanização da lavoura canavieira na região Centro-Sul do País frente à região Norte-Nordeste.

\subsubsection{O mercado de açúcar brasileiro pós-desregulamentação}

A maior parte do açúcar brasileiro é produzido por meio de centrífugação que gera, por cristalização, um açúcar marrom impuro conhecido como açúcar bruto ou VHP (Value Hight Polarization). Esse açúcar pode ser processado, resultando no açúcar do tipo branco (cristal e refinado). A Tabela 5 apresenta dados sobre o mix de produção do setor sucroalcooleiro para as safras entre 1990/91 e 2002/03. Na safra 1990/91, o produtor destinou quase $2 / 3$ do total produzido de cana-de-açúcar à produção de álcool, 
conforme já mencionado. Somente a partir da safra 2000/01 é que se verifica que do total de cana-de-açúcar produzido, os percentuais destinados à produção de açúcar e à produção de álcool passaram a ser praticamente equivalentes.

Tabela 5 - Brasil: produção de cana, açúcar e álcool - Safras 1990/91 - 2002/03

\begin{tabular}{rcccc}
\hline Ano & $\begin{array}{c}\text { Cana } \\
(1000 \text { ton. })\end{array}$ & $\begin{array}{c}\text { Cana para } \\
\text { açúcar } \\
(\%)\end{array}$ & $\begin{array}{c}\text { Açúcar } \\
(1000 \text { ton. })\end{array}$ & $\begin{array}{c}\text { Álcool - } \\
\left(1000 \mathrm{~m}^{3}\right)\end{array}$ \\
\hline $1990 / 91$ & 222,163 & 26,86 & 7,365 & 11,783 \\
$1995 / 96$ & 251,346 & 37,92 & 13,235 & 13,235 \\
$2000 / 01$ & 257,969 & 46,91 & 16,221 & 10,615 \\
$2001 / 02$ & 291,924 & 48,96 & 19,095 & 11,502 \\
$2002 / 03$ & 320,683 & 51,21 & 22,533 & 12,638 \\
\hline
\end{tabular}

Fonte: UNICA (2004)

Enquanto a produção de açúcar na safra de 1990/91 foi de um pouco mais de 7 milhões de toneladas, na safra de 2002/03 esta passou para mais de 22,5 milhões de toneladas, um aumento de mais de $300 \%$ no período. Em relação à produção de álcool, por outro lado, tem-se um aumento de apenas 7,3\% passando de 11,783 milhões de $\mathrm{m}^{3}$ para 12,638 milhões de $\mathrm{m}^{3}$, no mesmo período. Em termos gerais, pode-se afirmar que a mudança na opção do produtor, nos anos noventa, entre produzir álcool ou açúcar está associada tanto ao fim dos incentivos à produção de álcool combustível, como ao aumento na demanda externa pelo açúcar brasileiro. O resultado foi o aumento na produção de açúcar em detrimento à produção de álcool combustível.

Para complementar os dados da Tabela 5 , dividiu-se a produção de cana-deaçúcar destinada ao fabrico do açúcar entre as regiões Centro-Sul e Norte-Nordeste. A Tabela 6 apresenta o resultado desta participação relativa. Através dessa tabela é possível observar que ao longo das safras de 1990/91 a 2002/03 ocorre aumento na 
participação relativa da região Centro-Sul. O declínio da participação da região NorteNordeste no total de açúcar produzido fica mais evidente a partir da safra de 1998/99, em que a participação dessa região cai abaixo dos $20 \%$. A única exceção foi a safra de $2000 / 01$.

Tabela 6 - Brasil: participação relativa na produção de açúcar por principais regiões $1990 / 91$ a $2002 / 03$

\begin{tabular}{ccc}
\hline Safra/ Região & Centro - Sul (\%) & Norte - Nordeste (\%) \\
\hline $1990 / 91$ & 61,22 & 38,78 \\
$1995 / 96$ & 73,62 & 26,38 \\
$1998 / 99$ & 84,51 & 15,49 \\
$1999 / 00$ & 87,17 & 12,83 \\
$2000 / 01$ & 77,76 & 22,24 \\
$2001 / 02$ & 83,09 & 16,91 \\
$2002 / 03$ & 83,55 & 16,45 \\
\hline
\end{tabular}

Fonte: UNICA (2005)

A Figura 3 traz a participação relativa dos principais estados produtores de açúcar na safra 2002/03. Através destes dados, fica evidente a importância do estado de São Paulo, responsável por $63 \%$ da produção total de açúcar do Brasil. Além de São Paulo, os principais estados produtores de açúcar são: Alagoas (9\%), Paraná (7\%), Pernambuco (5\%) e Minas Gerais (5\%). Os estados de Goiás (3\%) e Mato Grosso (2\%) passaram a se destacar na produção de açúcar mais notadamente na última década. 


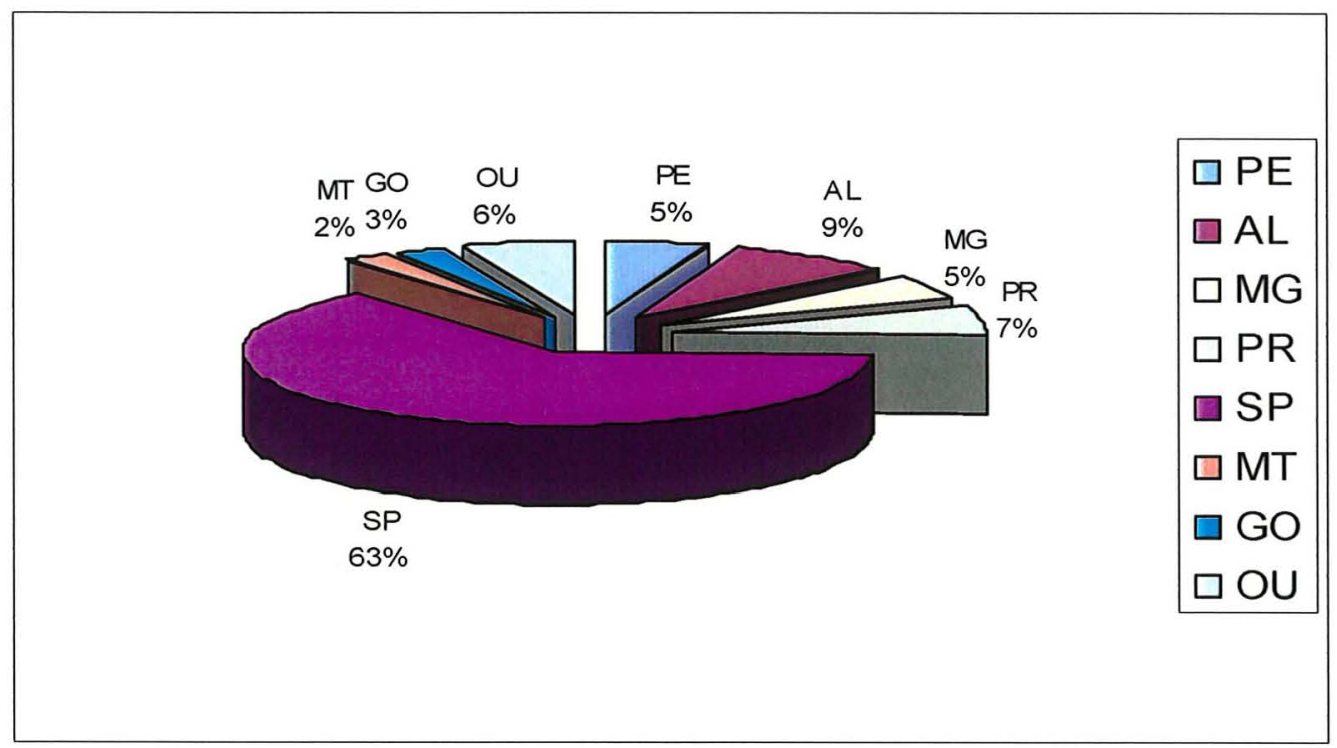

Figura 3 - Brasil: participação relativa dos principais estados produtores de açúcar na safra - 2002/03

Fonte: UNICA (2005)

O consumo doméstico de açúcar possui uma demanda inelástica em relação à renda (Caruso, 2002). Nesse sentido, a ampliação na demanda pelo açúcar brasileiro dependerá do aumento da demanda externa pelo produto e/ou aumento das aquisições da indústria alimentícia, cuja demanda tende a ser mais elástica em relação à renda. Portanto, se por um lado o aumento na demanda pelo açúcar industrial depende do crescimento da economia brasileira, por outro, a ampliação do mercado externo para essa commodity depende do rompimento das barreiras protecionistas impostas ao mercado de açúcar, as quais, como coloca Burnquist \& Bacchi (2002), envolvem tanto grandes importadores e consumidores, como grandes produtores e exportadores de açúcar. 


\subsection{Um panorama do Brasil no mercado internacional do açúcar}

O mercado internacional de açúcar conta com a participação de cerca de 120 países produtores. Conforme definido por Abbott (1990), citado em Stalder (1997), esse mercado se caracteriza por apresentar diversos tipos de estruturas. Segundo o autor, um primeiro tipo de estrutura é a dos mercados controlados, que engloba os Acordos Internacionais de Açúcar (AIAs). A finalidade desses acordos é controlar e regulamentar as operações de mercado, visando torná-las mais estáveis no que se refere aos preços. A formação de estoques reguladores e a fixação de cotas de exportação são os principais instrumentos utilizados com essa finalidade. Uma segunda categoria compreende os mercados preferenciais e garantidos, incluindo os acordos bilaterais e especiais entre países importadores e exportadores. Os exemplos mais conhecidos são os arranjos entre Cuba e os países da Europa Oriental, e o Protocolo do Açúcar do Acordo de Lomé entre a União Européia (EU) e as suas ex-colônias da África, Caribe e Pacífico. Já o terceiro tipo de estrutura é o Mercado Livre Mundial caracterizado pela instabilidade de preços, os quais são refletidos nas bolsas de commodities, de acordo com a demanda e a oferta.

A Tabela 7 mostra a participação das exportações mundiais de açúcar no total produzido dessa commodity no período recente. Pode-se notar que esta relação pouco variou durante o período analisado (da safra de 1999/00 a safra de 2003/04), ficando em torno de $30 \%$. Porém, ao analisar separadamente cada variável que compõe esta relação, observa-se que, em quatro anos, a produção mundial de açúcar aumentou em mais de 8 milhões de toneladas, sendo que aproximadamente 3,65 milhões de toneladas foram destinadas à exportação. 
Tabela 7. Mundo: volume de produção e exportação de açúcar (em 1000 toneladas) 1999/2000 a 2003/04

\begin{tabular}{llllll}
\hline Item & $1999 / 00$ & $2000 / 01$ & $2001 / 02$ & $2002 / 3$ & $2003 / 04$ \\
\hline Produção (A) & 136,531 & 130,495 & 134,888 & 147,336 & 144,635 \\
Exportação (B) & 41,448 & 37,686 & 41,228 & 45,724 & 45,107 \\
(B)/(A) em \% & 30,36 & 28,88 & 30,57 & 31,03 & 31,19 \\
\hline
\end{tabular}

Fonte: USDA (2004)

A Tabela 8 apresenta dados sobre os principais países produtores de açúcar. Observa-se que atualmente o Brasil é o maior produtor mundial de açúcar, tendo produzido, na safra 2003/04, 24,780 milhões de toneladas do produto. Índia, EUA e União Européia são também grandes produtores mundiais de açúcar. Vale destacar ainda que um conjunto de apenas quatro países tem sido responsável pela produção de uma porção considerável do total de açúcar produzido no mundo. Ao longo do período analisado, safras de 1999/00 à 2003/04, a participação relativa desse grupo de países ficou em torno de $40 \%$ do total.

Tabela 8. Mundo: principais países produtores de açúcar (em 1000 toneladas) - 1999/00 a $2003 / 04$

\begin{tabular}{lccccc}
\hline País & $1999 / 00$ & $2000 / 01$ & $2001 / 02$ & $2002 / 03$ & $2003 / 04$ \\
\hline Brasil (A) & 20,100 & 17,100 & 20,400 & 23,810 & 24,780 \\
Índia (B) & 20,219 & 20,480 & 20,475 & 22,100 & 19,880 \\
EUA (C) & 8,203 & 7,956 & 7,174 & 7,600 & 8,070 \\
UE (D) & 6,138 & 6,607 & 4,793 & 5,600 & 4,900 \\
Outros & 81,871 & 78,352 & 82,046 & 88,226 & 87,005 \\
Total (E) & 136,531 & 130,495 & 134,888 & 147,336 & 144,635 \\
(A+...D)/(E) & $40,03 \%$ & $39,96 \%$ & $39,18 \%$ & $40,12 \%$ & $39,84 \%$ \\
\hline
\end{tabular}

Fonte: USDA (2004) 
Em 2003, o mercado livre mundial de açúcar foi estimado em 42 milhões de toneladas, o que correspondeu a aproximadamente $30 \%$ do consumo mundial do produto, que é de cerca de 138 milhões de toneladas anuais. O Brasil, com aproximadamente 13,4 milhões de toneladas exportadas, ocupou cerca de $30 \%$ do mercado livre mundial de açúcar (UNICA, 2004).

Segundo a Organização Internacional do Açúcar (OIA), em um cenário conservador em que o Brasil aumentaria sua área plantada de cana-de-açúcar em torno de 4\% ao ano, até 2010, o País alcançaria um excedente exportável de açúcar de 18 milhões de toneladas, prevendo-se assim a manutenção da liderança brasileira na produção mundial de açúcar até pelo menos 2010.

Conforme discutem Stalder (1997) e Marjotta-Maistro (1998), até o início dos anos noventa o Brasil figurava apenas em quinto lugar entre os maiores exportadores de açúcar do mundo. Burnquist et al. (2002) afirma que a suspensão do sistema de quotas de exportação por parte do Brasil, em 1994, pode ter contribuído para incrementar a importância desse setor no mercado internacional. Uma evidência disso é que já na safra de 1995/96 o Brasil se destacou como o maior exportador dessa commodity no mercado internacional, exportando, segundo a OIA, cerca de 6,30 milhões de toneladas.

Complementando a análise anterior, Stalder (1997) argumenta que a evolução do comércio de açúcar brasileiro com o exterior após 1990 permite supor que as medidas políticas de desregulamentação, aliadas à indefinição das novas diretrizes para o programa do álcool, possibilitaram maior flexibilidade na comercialização e produção do açúcar e do álcool, e, portanto, melhores oportunidades de participar no mercado externo. A autora argumenta ainda que além do acesso mais fácil do produtor e exportador brasileiro ao mercado externo, outros fatores contribuíram para incentivar o crescimento das exportações brasileiras de açúcar e o aumento da demanda por esse produto, quais sejam, existência de diferenciais de preços internos e externos favoráveis ao segundo na safra de 1994/95 e quebra de safra de grandes produtores como Índia, China e Cuba.

A Tabela 9 apresenta os cinco principais estados brasileiros que participaram do comércio internacional do açúcar em 2003, o total exportado nesse mesmo ano e os tipos 
de açúcares comercializados. Através da Tabela 9 observa-se que a principal região exportadora, tanto do açúcar do tipo bruto como o do tipo branco, é a Centro-Sul. Em 2003, os principais estados exportadores dessa região foram responsáveis por cerca de $87 \%$ do açúcar branco exportado pelo Brasil e por 78,8\% do total exportado de açúcar do tipo bruto. O estado de São Paulo aparece como o maior exportador brasileiro de açúcar, tendo sido responsável por quase $68 \%$ do total exportado pelo Brasil em 2003. Além disso, esse Estado apresenta expressiva participação no comércio total de ambos os tipos de açúcares, branco e bruto. Merece destaque também o estado do Paraná, o qual tem incrementado sua participação no total de açúcar exportado pelo País e em 2003 superou um tradicional estado exportador desse produto, o Pernambuco. Quase a totalidade do açúcar exportado pela região Norte-Nordeste em 2003 foi o do tipo bruto. O principal destaque da região é o estado de Alagoas, que em 2003 participou com pouco mais de $12 \%$ das exportações totais desse produto.

Tabela 9. Brasil: exportações de açúcar por principais estados (1000 toneladas) - 2003

\begin{tabular}{lcccc}
\hline Estado & Branco & Bruto & Total & $\%$ \\
\hline São Paulo & 3,766 & 5,006 & 8,772 & 67,93 \\
Alagoas & 230 & 1,343 & 1,573 & 12,18 \\
Paraná & 74 & 1,112 & 1,186 & 9,19 \\
Minas Gerais & 124 & 462 & 586 & 4,55 \\
Pernambuco & 169 & 316 & 485 & 3,75 \\
Demais & 195 & 113 & 309 & 2,4 \\
Total & 4,560 & 8,353 & 12,914 & 100 \\
\hline
\end{tabular}

Fonte: Brasil (2004)

A Tabela 10 mostra os quatro maiores exportadores mundiais de açúcar nas safras de 1999/00 a 2003/04. Através desse tabela observa-se que o Brasil é o maior exportador de açúcar do mundo. Na safra de 1999/00, o volume de açúcar exportado 
pelo Brasil foi mais de 2,3 vezes maior que o segundo maior exportador, a União Européia, alcançando a cifra de 12,472 milhões de toneladas. A despeito da brusca queda no volume de açúcar exportado pelo Brasil na safra de 2000/01, o País continuou líder nas exportações desse produto, alcançando na safra de 2003/04 um volume exportado de 13,311 milhões de toneladas. As exportações mundiais da União Européia têm se mantido razoavelmente constantes ao longo do período analisado. Vale chamar a atenção para a inversão de posição no ranking dos maiores exportadores mundiais de açúcar que tem ocorrido entre a Tailândia e a Austrália nos anos analisados. É interessante observar que apenas quatro países têm sido responsáveis por aproximadamente $60 \%$ de todo o açúcar exportado nos anos analisados.

Tabela 10. Mundo: principais exportadores de açúcar no mercado internacional (em 1000 toneladas) $-1999 / 00$ a 2003/04

\begin{tabular}{lccccc}
\hline País & $1999 / 00$ & $2000 / 01$ & $2001 / 02$ & $2002 / 03$ & $2003 / 04$ \\
\hline Brasil (A) & 12,472 & 6,692 & 11,528 & 13,852 & 13,311 \\
UE (B) & 5,261 & 6,311 & 6,392 & 4,723 & 5,066 \\
Tailândia (C) & 3,379 & 4,241 & 3,335 & 4,204 & 5,350 \\
Austrália (D) & 4,189 & 4,172 & 3,551 & 3,436 & 2,402 \\
Outros & 17,200 & 18,662 & 17,874 & 19,403 & 15,873 \\
Total (E) & 42,501 & 40,078 & 42,680 & 45,618 & 42,002 \\
(A+...D)/(E) & $59,5 \%$ & $53,4 \%$ & $58,1 \%$ & $57,4 \%$ & $62,2 \%$ \\
\hline
\end{tabular}

Fonte: FAO (2004)

Após verificar os principais países exportadores de açúcar do mundo, a Tabela 11 apresenta os principais importadores mundiais dessa commodity. Através dessa tabela pode-se observar que a Rússia é o principal importador mundial desse produto. No entanto, de 1999/00 a 2003/04 houve um pequeno decréscimo no volume total de açúcar importado por esse país. Enquanto na safra de 1999/00 a Rússia importou mais de 5,9 
milhões de toneladas dessa commodity, ao final do período analisado, na safra de 2003/04, esse volume se reduziu para pouco mais de 4,2 milhões de toneladas. Ainda assim, nessa safra, a Rússia importou duas vezes mais açúcar que o segundo maior importador, a União Européia, que na safra de 2003/04 importou aproximadamente 2 milhões de toneladas. Finalmente, vale notar que a participação dos quatro maiores importadores de açúcar no total mundial importado desse produto tem ficado em torno de $25 \%$.

Tabela 11. Mundo: principais importadores de açúcar (em 1000 toneladas) - 1999 a 2003

\begin{tabular}{lccccc}
\hline País & $1999 / 00$ & $2000 / 01$ & $2001 / 02$ & $2002 / 03$ & $2003 / 04$ \\
\hline Rússia (A) & 5,912 & 4,841 & 5,566 & 4,618 & 4,276 \\
UE (B) & 1,963 & 1,832 & 1,913 & 2,145 & 2,063 \\
EUA (C) & 1,704 & 1,413 & 1,344 & 1,418 & 1,528 \\
Indonésia (D) & 2,323 & 1,654 & 1,375 & 1,028 & 1,540 \\
Outros & 27,902 & 26,963 & 29,898 & 30,686 & 31,092 \\
Total (E) & 39,804 & 36,703 & 40,096 & 39,895 & 40,499 \\
(A+...D)/(E) & $29,9 \%$ & $26,53 \%$ & $25,43 \%$ & $23,08 \%$ & $23,27 \%$ \\
\hline
\end{tabular}

Fonte: FAO (2004)

A Tabela 12 apresenta o ranking dos dez maiores importadores do açúcar brasileiro. Comparando-se esses dados com os já apresentados na Tabela 11, nota-se que dos quatro maiores importadores de açúcar no mercado mundial nas últimas safras, apenas a Rússia aparece como um grande importador desse produto do Brasil. O fim dos acordos de preferências entre Cuba e os países da Europa Oriental, vinculados a afinidades políticas, permitiu ao Brasil a conquista de porção importante do mercado de açúcar russo e fez com que o País se tornasse, desde então, o principal fornecedor desse produto a Rússia. 
Em relação aos demais importantes importadores de açúcar no mercado internacional, apresentados na Tabela 11, pode-se destacar a política comercial extremamente restritiva desses países como sendo pelo menos parte da explicação para a baixa penetração do açúcar brasileiro nesses mercados. A União Européia, por exemplo, se utiliza fortemente de cotas tarifárias, principalmente para as ex-colônias. Além disso, cobra tarifas de $€ 339 / \mathrm{t}$ sobre o açúcar cru para refino e $€ 419 / \mathrm{t}$ sobre os demais. As cotas tarifárias são também muito comuns nos EUA, sendo a cota mínima de 1.117.195 tm/ano para o açúcar cru para refino e $22 \mathrm{tm} /$ ano para outros açúcares. Finalmente, a Indonésia tem suas importações de açúcar controladas pelo governo, incluindo ainda determinadas especificações técnicas para o açúcar importado (UNICA, 2004).

Tabela 12. Brasil: dez maiores importadores de açúcar (1000 toneladas) - 2001 a 2002

\begin{tabular}{lcclcc}
\hline País & 2001 & $\%$ & País & 2002 & $\%$ \\
\hline Rússia & 3,679 & 32,9 & Rússia & 3,521 & 26,36 \\
Nigéria & 1,021 & 9,13 & Nigéria & 1,118 & 8,37 \\
Em. Árabes & 775 & 6,93 & Em. Árabes & 989 & 7,40 \\
Romênia & 431 & 3,85 & Egito & 871 & 6,52 \\
Egito & 727 & 6,5 & Canadá & 608 & 4,55 \\
Irã & 442 & 3,95 & Marrocos & 671 & 5,02 \\
Marrocos & 441 & 3,94 & Irã & 572 & 4,28 \\
Canadá & 342 & 3,06 & A. Saudita & 388 & 2,90 \\
Iêmen & 301 & 2,69 & Iêmen & 380 & 2,84 \\
A. Saudita & 269 & 2,40 & Argélia & 312 & 2,33 \\
Total Exp. & 11,173 & 100 & Total Exp. & 13,354 & 100 \\
\hline
\end{tabular}

Fonte: Brasil (2004)

O objetivo dessas medidas, como colocam Burnquist \& Bacchi (2002), está basicamente na busca do isolamento e proteção dos mercados domésticos. Isso ocorre na 
medida em que tais países impedem que suas respectivas ofertas e demandas internas respondam a movimentos de preços no mercado internacional. O resultado dessas políticas tem sido o aumento na produção doméstica, acima dos níveis que prevaleceriam na ausência de intervenção governamental.

Além de mostrar que a Rússia foi o principal destino do açúcar brasileiro em 2001 e em 2002, a Tabela 12 destaca ainda que os outros principais destinos dessa commodity brasileira têm sido países do Oriente Médio e África, bem como o Canadá, Iêmen e Romênia.

\subsubsection{Uma caracterização dos países demandantes do açúcar brasileiro no mercado Internacional}

O objetivo dessa seção é fornecer uma caracterização geral dos principais países demandantes do açúcar brasileiro no período compreendido entre 1995 e 2003. Além de destacar os principais mercados externos para o açúcar brasileiro, buscar-se-á enfatizar a evolução da participação desses países nas exportações brasileiras de açúcar, bem como os tipos de açúcar demandado por cada um deles, bruto ou branco.

A Tabela 13 apresenta dados sobre o volume importado e as participações percentuais dos principais países importadores do açúcar brasileiro do tipo bruto. Através dessa tabela pode-se observar que entre 1995 e 2003 as importações de açúcar do tipo bruto por parte da Rússia aumentaram mais de oito vezes, passando de 519,5 mil toneladas em 1995 para mais de 4,38 milhões de toneladas em 2003. Os países Árabes e africanos ${ }^{4}$ aumentaram o volume importado desse produto em apenas $82 \%$ ao longo do mesmo período. A partir de 1999, esses países têm sido o destino de mais de $70 \%$ das vendas externas de açúcar do tipo bruto brasileiro, sendo a Rússia a principal

\footnotetext{
${ }^{4}$ Os nove países considerados foram os que mais têm participado desse comércio com o Brasil, entre 1995 e 2003. Os países considerados foram: Argélia, Nigéria, Emirados Árabes Unidos, Egito, Marrocos, Irã, Arábia Saudita, Iêmen e Romênia, sendo que os dois últimos estão localizados no sudoeste da Ásia e na Europa central, respectivamente.
} 
demandante. Desde 1999 esse país responde por mais de 50\% das exportações brasileiras desse tipo de açúcar.

Tabela 13. Brasil: exportação de açúcar bruto por país de destino (1000 toneladas) período 1995 a 2003

\begin{tabular}{lcccc}
\hline Países de Destino / Ano & 1995 & 1999 & 2001 & 2003 \\
\hline Rússia (A) & 519,5 & 4.088 & 3.580 & 4.383 \\
Árabes e africanos (B) & 1.063 & 1.615 & 1.920 & 1.935 \\
Total Exportado(C) & 4.800 & 7.827 & 7.090 & 8.354 \\
$(\mathrm{~A}) /(\mathrm{C})$ & $10,82 \%$ & $52,23 \%$ & $50,49 \%$ & $52,46 \%$ \\
$(\mathrm{~B}) /(\mathrm{C})$ & $22,15 \%$ & $20,63 \%$ & $27,08 \%$ & $23,16 \%$ \\
$(\mathrm{~A}+\mathrm{B}) /(\mathrm{C})$ & $32,97 \%$ & $72,86 \%$ & $77,57 \%$ & $75,62 \%$ \\
\hline
\end{tabular}

Fonte: Brasil (2004)

Complementando a análise anterior, o Quadro 1 apresenta os principais países concorrentes do Brasil no mercado desse produto. Em linhas gerais, observa-se que o Brasil é o principal fornecedor de açúcar bruto em todos os países considerados, sendo que Cuba e Austrália se destacam como os principais concorrentes do açúcar bruto brasileiro nesses países. As únicas exceções são a Nigéria, onde o principal concorrente do Brasil é a União Européia, e a Rússia, onde a Tailândia aparece como o terceiro principal fornecedor. 


\begin{tabular}{|l|l|}
\hline País de Destino & \multicolumn{1}{|c|}{ Observações } \\
\hline Rússia & Cuba e Tailândia - Segundo e terceiro fornecedores \\
Irã & Austrália e Cuba - Segundo e terceiro fornecedores \\
A. Saudita & Austrália - Segundo fornecedor \\
Nigéria & União Européia - Segundo fornecedor \\
Romênia & Cuba-Segundo fornecedor \\
Marrocos & Cuba-Segundo fornecedor \\
\hline
\end{tabular}

Quadro 1 - Brasil: principais países concorrentes do Brasil no mercado internacional de açúcar do tipo bruto

Fonte: UNICA (2005)

A Tabela 14 apresenta dados sobre a participação dos principais importadores nas vendas externas brasileiras do açúcar do tipo branco. Chama a atenção a baixa participação da Rússia no total das vendas externas do Brasil desse produto. A participação relativa desse país no comércio total do Brasil de açúcar branco ficou entre pouco mais de 4\% em 1999 e 0,3\% em 2003. Diferentemente do caso do açúcar bruto, em que a Rússia aparece como o principal importador, no caso do açúcar branco o destaque são os países Árabes e Africanos. A participação relativa desses países no total exportado pelo Brasil ficou entre 42,28\% em 1999 e 64,39\% em 2001. 
Tabela 14 - Brasil: exportação de açúcar branco por país de destino (1000 toneladas) 1995 a 2003

\begin{tabular}{lcccc}
\hline Países de Destino / Ano & 1995 & 1999 & 2001 & 2003 \\
\hline RÚSSIA (A) & 14 & 174 & 99,5 & 14 \\
Árabes e africanos (B) & 700 & 1.807 & 2.629 & 2.227 \\
Total Exportado(C) & 1.438 & 4.273 & 4.083 & 4.561 \\
$(\mathrm{~A}) /(\mathrm{C})$ & $0,97 \%$ & $4,07 \%$ & $2,43 \%$ & $0,3 \%$ \\
$(\mathrm{~B}) /(\mathrm{C})$ & $48,68 \%$ & $42,28 \%$ & $64,39 \%$ & $48,83 \%$ \\
$(\mathrm{~A}+\mathrm{B}) /(\mathrm{C})$ & $49,65 \%$ & $46,35 \%$ & $66,82 \%$ & $48,86 \%$ \\
\hline
\end{tabular}

Fonte: Brasil (2004)

Também para o caso do açúcar branco, elaborou-se um quadro resumo com informações sobre os principais países concorrentes do Brasil nesses mercados. Esses dados estão apresentados no Quadro 2, onde se pode notar que o Brasil se destaca como o principal fornecedor de açúcar branco na maior parte dos países analisados. O único mercado em que o Brasil não aparece como o principal fornecedor desse produto é a Argélia, mercado em que a União Européia é o principal fornecedor. É interessante notar também que apenas no caso do Iêmen a União Européia não consta como o segundo principal fornecedor. Nesse caso, Tailândia e Índia, grandes produtores mundiais de açúcar e geograficamente próximos desse país, aparecem como o segundo e terceiro fornecedores do produto. No entanto, nos demais mercados mencionados a União Européia é a principal concorrente do Brasil no fornecimento de açúcar branco. 


\begin{tabular}{|l|l|}
\hline País de Destino & \multicolumn{1}{c|}{ Observações } \\
\hline Marrocos & União Européia - Segundo fornecedor \\
Egito & União Européia - Segundo fornecedor \\
Iêmen & Tailândia e Índia - Segundo e terceiro fornecedores \\
Angola & União Européia - Segundo fornecedor \\
Argélia & União Européia - Principal fornecedor \\
\hline
\end{tabular}

Quadro 2 - Brasil: principais concorrentes do Brasil no mercado internacional de açúcar branco

Fonte: UNICA (2005)

\subsection{A estimação de equações de exportação: uma revisão teórica}

\subsubsection{Considerações gerais}

Diversas são as formulações teóricas que podem ser testadas para a análise empírica dos determinantes do comportamento das exportações de um país. Baseadas, sobretudo, nas teorias do consumidor e do produtor, estas formulações remetem aos fatores condicionantes que podem atuar tanto do lado da demanda quanto do lado da oferta.

O objetivo da estimação de equações de exportação é identificar e avaliar a relevância das principais variáveis que afetam o comércio externo de um país. $\mathrm{O}$ problema central está em especificar essas relações em uma forma adequada para o ajustamento estatístico. Ademais, deve-se escolher de forma apropriada as variáveis dependente e explicativa e a forma funcional adequada a ser adotada. Esses aspectos são discutidos nas próximas quatro subseções. 


\subsubsection{A construção de um modelo econométrico: As formas estrutural e reduzida ${ }^{5}$}

Em termos gerais, um modelo econométrico é um conjunto de equações que procura explicar, em termos quantitativos, alguns fenômenos econômicos. Um modelo econométrico pode ser representado na seguinte forma:

$$
\begin{gathered}
Y_{1}=f_{1}\left(Y_{2}, Y_{3}, \ldots ., Y_{n}, X_{1}, X_{2}, \ldots, X_{m}\right) \\
Y_{2}=f_{2}\left(Y_{1}, Y_{3}, \ldots, Y_{n}, X_{1}, X_{2}, \ldots, X_{m}\right) \\
\quad \ldots \quad \ldots \\
Y_{n}=f_{n}\left(Y_{1}, Y_{2}, \ldots ., Y_{n-1}, X_{1}, X_{2}, \ldots, X_{m}\right)
\end{gathered}
$$

Este modelo inclui " $n$ " equações, cada uma das quais descreve uma variável particular $Y_{K}$ como uma função das $(n-1)$ variáveis remanescentes e $m$ outras variáveis, $X_{J}, \operatorname{com}(j=1, \ldots, m)$. Os $Y_{i}$ são chamados de variáveis endógenas (ou dependentes) enquanto os $X_{i}$ são chamadas de variáveis exógenas (ou explicativas).

As $f_{i}$ usadas em pesquisas econômicas permitirão a "solução" do sistema de equações acima. Dessa forma, é possível expressar as variáveis endógenas como função apenas das variáveis exógenas, como segue no sistema de equações (2). Nesse caso, supõe-se que todas as equações do sistema têm solução simultânea, o que implica a existência de ajustamento instantâneo ao desequilíbrio.

Quando o modelo é expresso como no sistema (1) tem-se a representação de um modelo estrutural. Esse sistema representa a estrutura de um fenômeno econômico e mostra a forma como qualquer variável particular influencia diretamente a variável endógena. O sistema (2), por outro lado, é chamada de modelo na forma reduzida, e pode ser pensado como sendo um sistema em equilíbrio.

\footnotetext{
${ }^{5}$ Subseção baseada em Leamer \& Stern (1970)
} 


$$
\begin{gathered}
Y_{1}=f_{1}\left(X_{1}, X_{2}, \ldots, X_{m}\right) \\
Y_{2}=f_{2}\left(X_{1}, X_{2}, \ldots, X_{m}\right) \\
\ldots \quad \ldots \quad \ldots \quad \ldots \\
Y_{n}=f_{n}\left(X_{1}, X_{2}, \ldots, X_{m}\right)
\end{gathered}
$$

A diferença entre essas duas formas de representar um modelo econométrico pode ser ilustrada considerando-se a primeira equação do modelo estrutural. Uma variação em $X_{1}$ induzirá uma mudança em $Y_{1}$, mas essa mudança em $Y_{1}$ induzirá também mudanças em $Y_{2}, \ldots, Y_{n}$, as quais, por sua vez, alterarão $Y_{1}$ novamente. Eventualmente, assumindo estabilidade, o sistema atingirá um novo equilibrio. A influência de $X_{1}$ sobre $Y_{1}$ em equilíbrio é expresso pela primeira equação no sistema na forma reduzida. Em suma, o modelo estrutural indica o impacto inicial de uma variável sobre a outra, enquanto que a forma reduzida indica o equilíbrio final.

Esses pontos podem ser ilustrados com um modelo simples de demanda e oferta:

$$
\begin{aligned}
& Q=\alpha+\beta P+\gamma D \\
& P=\alpha+b Q+c S
\end{aligned}
$$

A equação (3) é a equação de demanda, indicando que a quantidade demandada $Q$ é função linear do preço $P$ e de algum fator deslocador da demanda $D$. A equação (4) é a equação de oferta, indicando que o preço de oferta $P$ é função linear da quantidade vendida $Q$ e de algum fator deslocador da oferta $\mathrm{S}$. Este é um modelo em sua forma estrutural, tendo como variáveis endógenas $Q$ e $P$ e variáveis exógenas $D$ e $S$.

Como discutido anteriormente, cada variável endógena nesse modelo é função de uma variável exógena e da outra variável endógena do modelo. Dessa forma, uma 
variação na variável $D$, deslocador da demanda, gera uma variação de $\gamma$ unidades na quantidade demandada $Q$. Dessa variação na quantidade demandada decorre uma variação no preço, levando o sistema a um novo equilíbrio.

A forma reduzida correspondente é, por sua vez, representada por:

$$
\begin{aligned}
& Q=(1-\beta b)^{-1}(\alpha+\gamma D+\beta a+\beta c S) \\
& P=(1-\beta b)^{-1}(b \alpha+b \gamma D+a+c S)
\end{aligned}
$$

onde, como discutido, as variáveis endógenas são expressas como função apenas das variáveis exógenas.

De (3) pode-se ver que a variação em $D$ terá um impacto sobre a quantidade demandada igual à $\gamma$ unidades. Este deslocamento na curva de demanda tenderá a induzir um aumento no preço gerando um deslocamento para cima na função oferta. Esse aumento nos preços irá reduzir o impacto da mudança em $D$ sobre a quantidade demandada de mercado. $\mathrm{O}$ equilíbrio resultante pode ser lido diretamente da equação na forma reduzida (5), a qual indica que o impacto inicial de magnitude $\gamma$ será atenuado pelo fator $(1-\beta b)^{-1}$.

O sistema na sua forma reduzida pode servir como um importante instrumento tanto nas análises prospectivas, como nas análises de política comercial. A análise prospectiva requer a seleção adequada de um conjunto particular de variáveis exógenas (ou explicativas) $X_{J}$, as quais serão inseridas dentro das equações, na sua forma reduzida, para o cálculo das previsões acerca dos valores das variáveis endógenas (ou dependentes) $Y_{i}$. A análise de política comercial envolve questões acerca do impacto da variação no valor de um instrumento de política $X_{i}$ sobre a variável $Y_{K}$. O valor da resposta a tais mudanças poderá ser lido diretamente da $K_{t h}$ equação na forma reduzida. 


\subsubsection{Forma funcional}

As formas funcionais mais utilizadas nos estudos empíricos em comércio internacional são a linear e a log-linear, e podem ser representadas, respectivamente, por:

$$
X Q=a+b\left(E P^{x} / P\right)+c Y^{w}+v
$$

$\mathrm{e}$

$$
\log X Q=\log a+b \log \left(E P_{i}^{x} / P\right)+c \log Y^{w}+\log v
$$

Em (7) $X Q$ representa a quantidade exportada, a é o termo constante na regressão, $b$ é o coeficiente que capta o efeito preço, $c$ o coeficiente da variável renda externa e $v$ é um termo de erro refletindo as influências menores, as quais são consideradas não correlacionadas com as variáveis explanatórias. Em (8) a equação é apresentada com as variáveis em logaritmos.

A maioria dos trabalhos sobre equações de exportação utiliza a forma log-linear sem, no entanto, discutir a problemática da escolha de uma ou outra forma funcional. Pode-se inferir, a partir de Leamer \& Stern (1970) e Braga \& Markwald (1983), que a nítida opção na literatura pela forma log-linear relaciona-se ao fato de que nesta forma de especificação as elasticidades são obtidas diretamente dos resultados da regressão e, diferentemente das formas lineares, são constantes e, portanto, independem dos valores assumidos pelas variáveis.

Por último, Braga \& Markwald (1983) afirmam que a estimação utilizando a forma $\log$-linear gera, na maioria das vezes, coeficiente $R^{2}$ e valores da estatística $t$ e Durbin-Watson mais precisos do que aqueles obtidos sob a forma linear. Daí a ampla opção pela utilização da forma log-linear. 


\subsubsection{A escolha da variável dependente}

Duas questões intimamente relacionadas estão presentes no momento da escolha da variável dependente, quais sejam: $a$ ) o critério de agregação e $b$ ) a forma de quantificação. O critério de agregação envolve a definição da cesta de produtos a ser analisada, como, por exemplo, definir quais produtos compõe o grupo dos chamados "produtos básicos" ou o dos "produtos manufaturados" (Braga \& Markwald, 1983).

Em relação à forma de quantificação, Leamer \& Stern (1970) afirmam que os dados mais prontamente disponíveis estão em termos de valor, mais do que em termos quantitativos. Os autores, no entanto, sugerem que a quantidade é a variável dependente apropriada. Braga \& Markwald (1983) afirmam que o uso de um índice de valor (constante ou corrente) além de resultar em proxies pouco satisfatórias dos índices de quantum, apresenta ainda o inconveniente de introduzir a variável preço em ambos os lados da equação. No entanto, segundo os autores, um índice de valor é, com alguma freqüência, utilizado em estudos empíricos devido à impossibilidade de se obter agregação de quantidades.

Cardoso \& Dornbush (1980) propuseram o uso da razão entre a quantidade exportada e a produzida domesticamente como a variável dependente em sua função de oferta de exportação de manufaturados. No entanto, segundo Zini (1988), os coeficientes estimados nesses modelos não são mais elasticidades no sentido padrão, mas sim elasticidades condicionais em relação à razão da quantidade exportada sobre o produto total. Segundo o autor, Pinto (1980) contornou este problema expressando a variável dependente como razão entre o produto exportado e o produto potencial. Ao definir a variável dependente dessa forma, supõe-se que as firmas mantêm uma certa capacidade planejada para suprir os mercados externos.

Castro \& Cavalcanti (1997) procurando calcular equações de exportação totais e desagregadas (manufaturado, semimanufaturados e básicos) para o Brasil utilizaram como variável dependente o valor das exportações em dólares americanos deflacionado pelo Índice de Preços no Atacado (IPA) americano. 


\subsubsection{A escolha das variáveis explicativas}

$\mathrm{Na}$ análise dos determinantes da demanda e da oferta para as exportações brasileiras pode-se elencar uma ampla gama de variáveis explicativas, as quais, podem variar de acordo com o setor em análise, com o nível de agregação da variável dependente, o período, a disponibilidade de dados e, também, com o conhecimento do pesquisador acerca do setor em análise.

Nessa subseção serão apresentadas as variáveis mais freqüentemente usadas na pesquisa empírica em comércio internacional. As variáveis serão apresentadas em seis grupos, seguindo uma subdivisão próxima à proposta por Leamer \& Stern (1970) e Braga \& Markwald (1983), como segue: a) variáveis que captam o efeito preço; b) variáveis deslocadoras da demanda externa por exportação; c) variáveis que captam algum efeito tendencial; d) variáveis que captam os ciclos e) variáveis que captam defasagens ou custos de ajustamento, f) nível de reservas estrangeiras e crédito à exportação.

\section{a) Variável para captar o efeito preço}

O efeito preço é incorporado na especificação de uma equação de demanda externa pelas exportações de um país comparando-se os preços dos produtos exportados por esse país com o de seus competidores nesse mercado. A função dessa variável é dar a idéia do grau de competitividade do país em questão no mercado em análise.

Cavalcanti \& Ribeiro (1998) destacam que, dentre as variáveis explicativas do lado da oferta de exportação, a variável preço aparece como sendo a principal. Os autores conceituam a remuneração real do exportador como um indicador que pode se referir (1) tanto à comparação entre receitas e despesas associadas às vendas externas (visão de lucratividade) como à (2) remuneração das exportações relativamente às vendas no mercado doméstico (visão de mercados competitivos). 
No primeiro caso, além de um índice de preços agregados, que não reflete propriamente a realidade dos custos de cada setor de atividade, os indicadores apropriados dos custos podem ser índices de salário real, preço dos principais insumos utilizados, custos de comercialização e distribuição, impostos, entre outros. No segundo caso, seria razoável a utilização de um índice de preços no atacado (IPA), como proxy dos tradables. Em ambos os casos, a remuneração das exportações deve incluir um índice de incentivos existentes às vendas externas, sejam elas fiscais ou creditícias.

A comparabilidade entre a rentabilidade das vendas nos mercados interno e externo coloca a taxa de câmbio real como uma variável crucial para o cálculo da oferta de exportação. A taxa de rentabilidade real da atividade exportadora seria, então, dada pela multiplicação do índice de preços de exportação pela taxa de câmbio nominal e por algum índice de incentivos às atividades exportadoras, divididas por um índice de preço. Disso decorre que o efeito preço deve ser examinado através de um conjunto de variáveis que afetam a remuneração real do exportador, e aparece em geral, resumido sob a forma de uma variável composta, como segue:

$$
\frac{P_{X} S_{X} E}{P_{D}}
$$

Onde:

$P_{X}$ é o preço das exportações

$S_{X}$ é um índice de incentivos às exportações

$P_{d}$ é um índice dos preços domésticos dos produtos exportados

$E$ é a taxa de câmbio nominal

Zini (1988) discute o papel dos preços domésticos na função de oferta de exportação. Para o autor, dado um nível de preços de exportação, a rentabilidade de produzir bens exportáveis se reduz quando os custos domésticos sobem, e, dessa forma, os preços domésticos servem como uma proxy para esses custos. Um aumento dos 
preços domésticos implicaria uma queda na rentabilidade de vender no mercado externo, e isso geraria uma queda na oferta de exportação.

Diversos autores argumentam que, assumindo homogeneidade no preço tanto para países consumidores como para os países produtores, a variável preço relevante pode ser expressa como a razão de dois preços: $\left(P_{X} / P_{X W}\right)$, no caso da demanda por exportações $\left(X_{D}\right), \mathrm{e}\left(E P_{X} / P_{d}\right)$, no caso da oferta de exportação, $X_{S}$.

Onde:

$P_{X}$ é o preço das exportações (US\$)

$P_{d}$ é um índice dos preços domésticos dos produtos exportados

E é a taxa de câmbio nominal (R\$/US\$)

$P_{X W}$ é o preço mundial das exportações (em US\$)

Nesse caso, $\left(X_{D}\right)$ responde negativamente ao preço relativo $\left(P_{X} / P_{X W}\right)$, e $\left(X_{S}\right)$ depende positivamente do preço relativo $\left(E P_{X} / P_{d}\right)$. Do lado da demanda por exportações, isto implica que os países consumidores se importam apenas com preço relativo, e não com preços em separado, $P_{X}$ e $P_{X W}$. Pelo lado da oferta de exportações, isto significa dizer que os países produtores não discriminam entre os mercados interno e externo. No entanto, as duas hipóteses podem ser questionadas. Enquanto os países consumidores podem ter preferência por produtos com base em sua origem, os países produtores podem discriminar entre os mercados doméstico e externo, principalmente quando se levam em conta fatores tais como a proximidade ao mercado, condições oligopolistas de suprimento e controle de redes de distribuição local (Zini, 1988).

Para Cavalcanti \& Ribeiro (1998), no caso da demanda por exportação, a escolha dos preços dos bens substitutos nos mercados internacionais pode recair sobre índices de 
preços mundiais ou sobre preços relevantes para os parceiros comerciais, em geral, preços de importação ou de algum índice representativo dos tradable.

\section{b) Variáveis deslocadoras da demanda externa por exportações}

Um índice da renda do resto do mundo ou o quantum das exportações ou importações mundiais são as variáveis que mais comumente são incluídas visando captar os efeitos de deslocadores da demanda (Braga \& Markwald, 1983).

Nesse caso, tanto Braga \& Markwald (1983) como Cavalcanti \& Ribeiro (1998) salientam que na busca de uma variável que retrate o nível de renda externa (real) destinada aos tradables deve-se ter a preocupação de selecionar os principais parceiros comerciais do país sob análise, ponderados pela participação de cada um na pauta de exportação desse país. Dessa forma, ter-se-ia um índice de renda externa relevante para o país.

Finalmente, considerar a curva de demanda por exportações não perfeitamente elástica significa admitir que os exportadores não podem vender quantidades cada vez maiores de produtos sem serem, eventualmente, forçados a aceitar preços FOB menores (Braga \& Markwald, 1983).

\section{c) Variáveis que captam um efeito tendencial}

Principalmente quando se trabalha com séries temporais, a inclusão de uma variável para captar um efeito tendencial mostra-se adequada para um melhor ajustamento do modelo. Um índice de capacidade produtiva pode ser, por exemplo, incluído na equação de oferta de exportação de manufaturados, como fator de escala ou de tendência. Segundo Braga \& Markwald (1983), em uma especificação menos rigorosa pode-se usar um índice de produto efetivo. 
Em geral, o valor da elasticidade associado a esta variável é utilizado para inferências sobre a existência de viés pró ou anticomercial do país em análise, conforme sua estimativa seja superior ou inferior à unidade, respectivamente. Quando da ocorrência de valor unitário para essa variável, afirma-se que há um efeito neutro da evolução da capacidade instalada sobre as quantidades exportadas (Braga \& Markwald, 1983).

\section{d) Variáveis que captam efeitos cíclicos}

Tanto no caso de bens homogêneos, como no caso de bens diferenciados, mudanças cíclicas no produto doméstico podem afetar o volume das exportações. A inclusão de alguma variável associada aos ciclos da atividade interna é recomendada como uma forma de captar a idéia de que as exportações representam, em grande medida, uma alternativa para evitar a capacidade ociosa.

Muitos estudos têm mostrado uma correlação negativa entre o crescimento das exportações e a taxa de utilização da capacidade, entre eles Cardoso \& Dornbusch (1980), Braga \& Markwald (1983), Rios (1987), Zini (1988), Amazonas \& Barros (1995), Castro \& Cavalcanti (1997) e Cavalcanti \& Ribeiro (1998).

Amazonas \& Barros (1995) argumentam que o sinal negativo da variável taxa de utilização da capacidade é normalmente atribuído à ocorrência de um sistema de mark $u p$, sob a hipótese de que a maior parte das firmas operam domesticamente em oligopólio, ainda que estejam sujeitas à competição perfeita no mercado internacional. $\mathrm{O}$ sinal negativo dessa variável poderia, também, representar uma estratégia intertemporal das companhias, para as quais seria mais vantajoso priorizar o atendimento aos clientes domésticos com os quais mantém uma relação mais estável. 


\section{e) Variáveis que captam as defasagens ou custos de ajustamento}

A introdução de variáveis defasadas é particularmente importante para se ter uma medida da influência das mudanças passadas nas variáveis independentes sobre o comportamento corrente da variável dependente.

Considera-se que esses efeitos serão tão mais importantes quanto mais curtas forem as unidades de tempo usadas na análise. A idéia por traz desse raciocínio é a de que quando a variável dependente está representada em dados trimestrais, por exemplo, esta pode ser influenciada mais pelos preços do trimestre anterior do que pelos preços do trimestre corrente.

A inclusão da variável dependente defasada está associada à existência de custos de ajustamento, num contexto do chamado modelo de desequilíbrio, em oposição aos modelos de equilíbrio, para os quais o processo de ajustamento entre quantidade e preço a seus valores de equilibrio completa-se dentro da unidade de tempo utilizada na análise. Com base nesses modelos, torna-se possível estimar a defasagem média do ajustamento (mean lag), bem como distinguir entre as elasticidades de curto e longo prazos (Rios, 1987).

Adicionalmente, em comércio internacional pode ocorrer que um embarque em um período seja relativo a uma negociação efetuada com antecedência, que teve como referência para a tomada de decisão o comportamento das variáveis observado em períodos anteriores. Aliás, é essa sistemática que induz à utilização de modelos dinâmicos como os Vetores Auto-Regressivos (VAR), por exemplo, no estudo dos determinantes do comércio exterior.

\section{f) Nível de reservas estrangeiras e crédito à exportação}

As variáveis nível de reserva estrangeira e crédito não foram encontradas em nenhum dos trabalhos empíricos consultados envolvendo o Brasil, apesar de, como 
salientam Leamer \& Stern (1970), serem de extrema relevância principalmente quando se está trabalhando com países em desenvolvimento.

Muitas vezes, no caso da variável nível de reservas estrangeiras, pode ocorrer de a demanda pela exportação de um dado país responder mais à disponibilidade de reservas estrangeiras do país demandante, do que ao seu nível de renda real.

O objetivo da inclusão da variável crédito na equação de oferta de exportação é indicar a influência da disponibilidade (ou não) do crédito e condições as quais o crédito está disponível para o financiamento das exportações.

\subsubsection{Formas de especificação de um modelo de comércio}

Quando da especificação de um modelo de exportações, uma questão inicial diz respeito à hipótese sobre a dimensão que o país ocupa no mercado internacional do produto ou grupo de produtos em análise. De acordo com Zini (1988), Rios (1987), Cavalcanti \& Ribeiro (1998) e Barros et al. (2002), três são as formulações teóricas básicas de especificação de um modelo de exportação.

Baseada na hipótese do país pequeno, uma primeira formulação teórica considera o país exportador como um participante marginal no mercado internacional. Em outras palavras, as exportações desse país seriam incapazes de influenciar o nível de preços internacionais do produto ou grupo de produtos em análise. O resultado decorrente dessa abordagem é que esse país enfrentaria uma curva de demanda por suas exportações infinitamente preço-elásticas. Neste caso, a modelagem se resume na estimação de equações de oferta de exportação, considerando que os preços são determinados exogenamente e que o país em questão pode vender quantidades ilimitadas a esses preços.

Uma segunda forma de especificação de um modelo de comércio internacional considera, portanto, que a elasticidade preço da demanda por exportações é finita e que a função oferta de exportação é perfeitamente elástica. A consideração de uma função de oferta de exportação perfeitamente elástica justifica-se na ocorrência de excesso 
considerável de capacidade instalada na indústria doméstica, ou na presença de tecnologia produtiva sujeita a retornos constantes ou crescentes à escala (Cavalcanti \& Ribeiro, 1998). A hipótese de oferta de exportação infinitamente elástica implica, portanto, uma análise confinada à função demanda por exportação.

Uma terceira alternativa de especificação de um modelo de comércio corresponde à estimação de um sistema de equações simultâneas, onde a elasticidade preço da demanda e de oferta de exportação é obtida empiricamente, em vez de estabelecida de forma apriorística. A suposição da elasticidade preço da demanda finita justifica-se quando país em análise detém parcela significativa do mercado mundial de um determinado produto ou a produção de bens diferenciados

Subjacente a esta forma de especificação de um modelo de comércio está a hipótese de que os preços são totalmente flexíveis e que se ajustam instantaneamente de modo a igualar oferta e demanda no mercado. No entanto, a constatação de que as quantidades efetivamente transacionadas nem sempre correspondem àquelas demandadas ou ofertadas, deu origem aos chamados modelos de desequilíbrio, como desenvolvidos nos trabalhos de Goldstein \& Khan (1978), Braga \& Markwald (1983), Rios (1987), Zini (1988) e outros.

Em geral, considera-se que esse desequilíbrio tem origem ou na morosidade do processo de ajustamento de preços e quantidades a seus valores de equilibrio, impedindo que esse processo se conclua dentro da unidade de tempo de observação.

\subsubsection{As diferentes abordagens nos estudos sobre equações de exportação}

Apresenta-se, a seguir, de forma resumida, uma discussão dos principais estudos sobre os determinantes do desempenho do comércio exterior brasileiro. O objetivo é mostrar os esforços acadêmicos realizados para o aprimoramento da discussão sobre equações de exportação para o Brasil. Antes, porém, vale apresentar o modelo utilizado por Goldstein \& Kahn (1978) para estimação de equações de oferta e demanda para as 
exportações agregadas de 8 países industriais ${ }^{6}$. A metodologia de análise proposta por esses autores foi posteriormente incorporada, em parte ou como um todo, em diversos estudos sobre o comércio exterior brasileiro, entre eles Cardoso \& Dornbush (1980), Musalen (1980), Pinto (1980), Braga \& Markwald (1983), Zini Júnior (1988), entre outros.

Goldstein \& Kahn (1978), utilizando dados trimestrais para os anos entre 1955 e 1970, propuseram duas versões de um modelo básico de exportações: um modelo de equilíbrio e um modelo de desequilíbrio. Uma vez especificado adequadamente o modelo de oferta e demanda de exportação, estes seriam estimados simultaneamente, de forma a não ignorar as relações simultâneas existente entre quantidade exportada e seus preços.

a) Modelo de equilíbrio

Admite-se que não há defasagens no sistema, de forma que o ajustamento entre quantidades exportadas e seus preços aos respectivos valores de equilíbrio é instantâneo.

A demanda mundial pelas exportações de um país individual é especificada na forma log-linear, como segue:

$\log X_{t}^{d}=\alpha_{0}+\alpha_{1} \log (P X / P X W)_{t}+\alpha_{2} \log Y W$

Onde:

$X^{D} \quad$ é a quantidade demandada de exportação

$P X \quad$ é o preço de exportações

$P X W$ é a média ponderada dos preços dos produtos concorrentes de outros países

$Y W$ é a média ponderada das rendas reais dos parceiros comerciais do país exportador

\footnotetext{
${ }^{6}$ Bélgica, França, Alemanha, Itália, Japão, Países Baixos, Reino Unido e Estados Unidos.
} 
Uma vez que (10) é expressa em logaritmos, $\alpha_{1}$ e $\alpha_{2}$ são, respectivamente, elasticidade (da demanda por exportação) preço e renda. Espera-se que $\alpha_{1}$ seja negativo e $\alpha_{2}$ seja positivo.

A oferta de exportação é também especificada como uma função log-linear dos preços relativos das exportações e de um índice de capacidade produtiva do país.

$$
\log X_{t}^{s}=\beta_{0}+\beta_{1} \log (P X / P)_{t}+\beta_{2} Y_{t}^{*}
$$

Onde:

$X^{s}$ é quantidade de exportação ofertada

$P X$ é o preço das exportações

$P$ é o preço doméstico

$Y^{*}$ é a capacidade produtiva doméstica

A eq. (11) traz consigo a hipótese de que se o preço das exportações se elevam em relação ao preço doméstico, a produção para exportação torna-se mais lucrativa e, assim, os exportadores irão ofertar mais. Além disso, espera-se, ceteris paribus, que as exportações se elevem em decorrência de um aumento da capacidade produtiva do país. Dessa forma, considera-se, que $\beta_{1}$ e $\beta_{2}$ são positivos. A eq. (11) pode ser escrita como:

$$
\log P X_{t}=b_{0}+b_{1} \log X_{1}^{S}+b_{2} \log Y_{1}^{*}+b_{3} \log P_{1}
$$

Onde:

$$
b_{0}=-\frac{\beta_{0}}{\beta_{1}} ; b_{1}=\frac{1}{\beta_{1}} ; b_{2}=-\frac{\beta_{2}}{\beta_{1}} ; \text { e } b_{3}=\frac{\beta_{1}}{\beta_{1}}
$$

Uma vez que $\beta_{1}$ e $\beta_{2}>0$, espera-se que $b_{1}, b_{3}>0$ e $b_{2}<0$. As eq. (10) e (11) constituem o modelo de equilíbrio e as estimativas dos parâmetros estruturais podem ser obtidas pelas estimativas dessas duas equações simultaneamente (assumindo 
$X^{S}=X^{D}=X_{t}$ ). Com o objetivo de obter o efeito isolado das variáveis exógenas sobre a quantidade e preço de exportação, pode-se resolver as duas equações para obter as formas reduzidas a seguir, onde $D=1-\alpha_{1} b_{1}$ :

$$
\begin{aligned}
& \log X_{t}=\frac{\alpha_{0}+\alpha_{1} b_{0}}{D}-\frac{\alpha_{1}}{D} \log P X W_{t}+\frac{\alpha_{2}}{D} \log Y W_{t}+\frac{\alpha_{1} b_{2}}{D} Y_{t}^{*}+\frac{\alpha_{1} b_{3}}{D} P_{t} \\
& \log P X_{t}=\frac{b_{0}+\alpha_{1} b_{0}}{D}-\frac{\alpha_{1} b_{1}}{D} \log P X W_{t}+\frac{\alpha_{2} b_{1}}{D} \log Y W_{t}+\frac{b_{2}}{D} Y_{t}^{*}+\frac{b_{3}}{D} P_{t}
\end{aligned}
$$

b) Modelo de desequilíbrio

Nessa versão do modelo de exportação admite-se a possibilidade de que o ajustamento do sistema aos valores de equilíbrio ocorra com algum atraso. A existência de contratos de longo prazo, informação imperfeita e custo de adaptação torna razoável supor que o ajustamento a uma perturbação requer tempo e a inclusão de algum mecanismo dinâmico de resposta (Zini Júnior, 1988). O mecanismo de ajustamento utilizado pelos autores é o seguinte:

$$
\Delta \log X_{t}=\gamma\left[\log X_{t}^{d}-\log X_{t-1}\right]
$$

Onde $\Delta$ é o operador de primeira diferença e $\gamma$ é o coeficiente de ajustamento. Pela substituição de (10) em (15) obtém-se a seguinte equação para estimação das exportações:

$$
\log X_{t}=c_{0}+c_{1} \log (P X / P X W)_{t}+c_{2} \log Y W+c_{3} \log X_{t-1}
$$

Onde: $c_{0}=\gamma \alpha_{0}, c_{1}=\gamma \alpha_{1}, c_{2}=\gamma \alpha_{2}$ e $c_{3}=1-\gamma$. Baseados nos sinais esperados dos parâmetros $\alpha_{1}, \alpha_{2}$ e $\gamma$ têm-se $c_{1}\left\langle 0, c_{2}>0\right.$ e $c_{3}>0$. O modelo de desequilíbrio pode também ser aplicado para as equações na forma reduzida. 
Em relação aos estudos empíricos sobre o comportamento das exportações brasileiras, vê-se que até início dos anos 80 a maior parte se concentrava apenas na estimação de funções de oferta de exportação. Admitia-se explicitamente a hipótese que o Brasil era tomador de preços no mercado internacional e, portanto, a demanda externa pelas exportações brasileiras poderia ser considerada infinitamente elástica. Esta opção de análise está presente em estudos como os de Cardoso \& Dornbush (1980) e Musalen (1981). Em ambos os casos, portanto, foram estimadas apenas equações de oferta de exportações na sua forma estrutural, adotando-se, implicitamente, a hipótese de que a variável preço capta integralmente todas as mudanças ocorridas do lado da demanda.

Por mais plausível que fosse a suposição da participação marginal do Brasil nas exportações mundiais de manufaturados no período, uma opção mais adequada seria a especificação de um modelo que permitisse a obtenção da elasticidade preço da demanda empiricamente, ao invés de estabelecê-la, a priori, como infinita. Por isso, e pelo fato de o Brasil apresentar grandes saldos comerciais a partir do primeiro triênio da década de 1980, muitos estudos sobre as exportações brasileiras de manufaturados passaram a assumir a hipótese de país grande para o Brasil, fazendo estimações por meio de modelos de equações simultâneas.

Dois trabalhos sobre o comércio exterior brasileiro bastante representativos dessa opção de abordagem são os de Braga \& Markwald (1983) e o de Zini Júnior (1988). No primeiro estudo o objetivo era a estimação de funções de exportação e importação para manufaturados brasileiros pelo método dos Mínimos Quadrados em Três Estágios (3SLS), a partir de dados anuais para os anos entre 1959 e 1981. No segundo estudo foram usados dados trimestrais submetidos a ajustes de sazonalidade, referentes ao período entre o primeiro trimestre de 1970 e o terceiro trimestre de 1986. As exportações foram divididas por grupos de origem setorial e o procedimento de mínimos quadrados em dois estágios (2SLS) foi usado para todos os grupos. Formalmente, a estrutura analítica de ambos os trabalhos é bastante semelhante aos modelos de equilíbrio e desequilíbrio de Goldstein \& Kahn (1978). A estrutura da função de oferta de exportação de Zini Júnior (1988) difere da de Goldstein \& Kahn (1978) na medida em inclui, além de um índice de capacidade produtiva doméstica (produto potencial), um 
índice de utilização da capacidade para captar o efeito dos ciclos econômicos domésticos. Por sua vez, Braga \& Markwald (1983) também incluem um índice de utilização da capacidade na sua função oferta de exportação, mas desconsideram o efeito da capacidade produtiva doméstica sobre as exportações brasileira de manufaturados.

Apesar de fornecerem importantes informações acerca dos determinantes do desempenho exportador do País, as tentativas de estimação simultânea de um modelo de oferta e demanda para as exportações de manufaturados discutidas, partem de equações estruturais especificadas ad hoc, sem testar adequadamente a validade de tais especificações (Cavalcanti \& Ribeiro, 1998).

Alguns estudos empíricos sobre o comércio exterior brasileiro em anos mais recentes têm seguido a abordagem de séries temporais, podendo-se citar os de Castro \& Cavalcanti (1997), Cavalcanti \& Ribeiro (1998), Carvalho \& Negri (2000), Miranda (2001), Barros et al. (2002), Alves \& Bacchi (2004), Costa (2004) entre outros.

Castro \& Cavalcanti (1997) conduziram trabalho para estimar equações para exportações totais e desagregadas (manufaturados, semimanufaturados e básicos) brasileiras, a partir de dados anuais em valor (US\$) para o período entre 1955 e 1995 . As variáveis explicativas utilizadas consistiram na taxa de câmbio real, nas importações mundiais (como proxy para o nível de renda mundial) e em um indicador do nível de atividade doméstica. A análise das exportações totais partiu de um VAR com três defasagens das variáveis exportações totais, taxa de câmbio real e importações totais. Para as exportações desagregadas, foram utilizadas as mesmas variáveis na modelagem de vetores auto-regressivos (VAR), além de dummies para anos selecionados. O objetivo era proporcionar subsídios para o processo de formulação, implementação e avaliação de políticas econômicas.

Cavalcanti \& Ribeiro (1998) estimaram equações de exportação para o Brasil a partir de dados mensais para os anos entre 1977 e 1996 utilizando a metodologia VAR. O objetivo era estudar o desempenho e determinantes das exportações brasileiras de manufaturados, semimanufaturados e básicos. As variáveis utilizadas foram um índice de quantum de exportação e de preços de exportação para cada uma das categorias em análise e índices de preços domésticos em dólares, de importações (representativo da 
renda externa) e de preços de importação para os países industrializados, de produto potencial e um de índice de utilização da capacidade produtiva.

Carvalho \& Negri (2000) estimaram equações para os quanta de produtos agropecuários importados e exportados pelo Brasil. No caso das exportações, o período considerado incluía anos de 1977 a 1998. A seguinte equação foi ajustada para as exportações $(X)$ :

$$
X=f\left[\frac{e \cdot P x(1+S)}{P}, Y, Y^{*}\right]
$$

Onde:

$e$ é a taxa de cambio nominal

$P x$ é o preço do produto exportado

$p$ é o preço do produto doméstico

$S$ é a taxa média de subsídio

$Y$ é a renda interna

$Y^{*}$ é a renda externa

A variável que representa o produto potencial (capacidade doméstica de produção - $Y p$ ) e a que representa utilização da capacidade instalada $\left(Y / Y_{p}\right)$ foram consideradas em equações alternativas, como segue:

$$
X=f\left[\frac{e \cdot P x(1+S)}{P}, Y, Y^{*}, Y p\right]
$$

e

$$
X=f\left[\frac{e \cdot P x(1+S)}{P}, Y, Y^{*}, \frac{Y}{Y p}\right]
$$


Dummies e variáveis que representam tendências foram utilizadas na análise e os ajustamentos feitos na forma logaritma. Em relação às exportações, constatou-se que estas são influenciadas basicamente pelo nível de atividade mundial e, em menor grau, pela taxa de câmbio real. No longo prazo, a desvalorização cambial de $1 \%$ ocasionaria um aumento nas exportações do setor em apenas $0,12 \%$, enquanto a elevação no produto mundial em $1 \%$ influenciaria positivamente as exportações setoriais em $0,65 \%$.

Miranda (2001) avaliou, quantitativamente, os impactos de barreiras nãotarifárias (BNTs) sobre os volumes e preços das vendas externas de carne bovina brasileira para os Estados Unidos e União Européia para o período entre janeiro de 1992 e dezembro de 2000. Para tanto, a autora propôs um modelo reduzido para as vendas externas de carne bovina para esses mercados derivado de funções de oferta e demanda internas por esse produto. Portanto, a quantidade ofertada de carne bovina pelo Brasil no mercado internacional foi considerada um excedente do mercado doméstico e descrita como:

$$
X_{S}=H\left(P_{I}, P_{W}, T C, W_{i}, Y_{I}, Z_{D}\right)
$$

Por sua vez, a demanda externa pelo produto brasileiro foi descrita como:

$$
X_{D}=m\left(P_{B} / C, P_{W}, Z_{D}\right)
$$

Onde:

$X_{S}$ é quantidade ofertada de carne bovina pelo Brasil no mercado externo $X_{D}$ é quantidade demandada de carne bovina do Brasil no mercado externo $P_{I}$ é o preço doméstico da carne bovina $P_{W}$ é o preço da carne bovina dos concorrentes no mercado internacional (US\$); $W_{l}$ é o deslocador da oferta de carne doméstica $T C$ é Taxa de câmbio (R \$/US\$) 
$Z_{D}$ é deslocador da demanda externa pela carne bovina brasileira

$P_{B}$ é p preço de exportação da carne bovina brasileira (R $\$$ )

Considera-se $P_{X}=P_{B} / C=$ preço em US $\$$ da carne bovina exportada pelo Brasil.

Equações para os preços das vendas externas também foram estimadas. $\mathrm{Na}$ especificação das formas funcionais, foram consideradas duas situações: $a$ ) demanda pelas exportações de carne bovina brasileira perfeitamente elástica; $b$ ) demanda pelas as exportações brasileiras de carne bovina não perfeitamente elástica. A autora encontrou que as exportações brasileiras de carne in natura para a União Européia são influenciadas não só pelas condições de demanda naquele bloco, mas também pelas condições domésticas no mercado de boi gordo e de carnes. A taxa de câmbio real mostrou-se uma variável relevante para o desempenho do setor. No caso do mercado Norte Americano, que só importa o produto industrializado, verificou-se que as variáveis de oferta e demanda domésticas de carne não tiveram efeitos sobre os preços praticados. Isso, segundo a autora, permitiu caracterizar o Brasil como um tomador de preços nesse mercado, resultado que diferiu do encontrado para o caso das vendas externas de carnes especiais para a União Européia.

Barros et al. (2002) ajustaram um modelo uniequacional para estimação de funções de oferta de exportação para diferentes produtos agropecuários brasileiros ${ }^{7} . \mathrm{Na}$ definição desse modelo, os autores, assim como Miranda (2001), consideraram que o quantum exportado de produtos agrícolas é derivado de funções de oferta e demanda internas. O modelo teórico utilizado pelos autores parte das seguintes definições de demanda e oferta domésticas:

$$
\begin{aligned}
& q^{S}=\Phi+\not p d+\mu f \quad \gamma>0, \mu<0 \\
& q^{D}=\Omega+\eta p d+\theta y \quad \eta<0, \theta>0
\end{aligned}
$$

\footnotetext{
${ }^{7}$ Os produtos agropecuários considerados foram: frango, complexo soja (grão, óleo e farelo), algodão, café, carne bovina (resfriada, congelada e industrializada), e açúcar.
} 
Onde:

$q^{S}$ e $q^{D}$ são as quantidades oferecida e demandada no mercado, respectivamente $p d$ é o preço doméstico

$f$ é um deslocador da oferta

$y$ é a renda per capita

Em equilíbrio tem-se que:

$q^{S}=q^{D}$

Assim:

$\Phi+\not p d+\mu f=\Omega+\eta p d+\theta y$

A partir dessa igualdade determina-se:

$p d^{*}=[(\Omega-\Phi)+\theta y-\mu f] /(\gamma-\eta)$

que representa o logaritmo do preço doméstico de equilíbrio.

Supõe-se que o produto doméstico possa ser exportado ao preço $p x$ (expresso em moeda do país exportador). Pressupõe-se, ainda, que o produto selecionado para exportação reduz a disponibilidade interna (e eleva o preço doméstico), sem influenciar o padrão de qualidade do produto comercializado internamente. A partir da razão entre o preço externo, $p x$, e o preço interno, $p d$, tem-se a margem de exportação $(m=p x / p d)$ que cobre o custo dessa operação. Admite-se que a margem $m$ (representada na forma logaritma) seja relacionada a $p d$ :

$$
m=\alpha p d
$$


Onde $\alpha$ é a elasticidade relacionando $m$ e $p d$.

Uma vez que $p x=p d+m$, tem-se que:

$$
p d=p x-m=p x-\alpha p d
$$

Dessa forma, as equações (22) e (23) podem ser reescritas como:

$$
\begin{aligned}
& q^{S}=\Phi+\not p x-\gamma \alpha p d+\mu f \\
& q^{d}=\Omega+\eta p x-\eta \alpha p d+\theta y
\end{aligned}
$$

Pode-se representar genericamente a oferta de exportação (em logaritmo), na forma de excesso de oferta sobre a demanda doméstica. Nesse caso, ela envolverá as mesmas variáveis que afetam as funções (26) e (27), como segue:

$$
q^{x}=f(p x, p d, f, y)
$$

em que $q^{x}=\ln Q^{x}$ para $Q^{x}=Q^{S}-Q^{d}$; as variáveis em maiúsculas representam as quantidades, e não seus logaritmos. Sabendo-se que $p x=p e T C$, onde pe é o preço de exportação em moeda nacional e $T C$ é a taxa de câmbio efetiva real, pode-se re-escrever a eq. (28) como:

$$
q^{x}=f(p e, T C, p d, f, y)
$$

Os resultados do modelo estimado para o quantum exportado de açúcar mostraram que, dentre as variáveis explicativas, o preço doméstico foi a que apresentou o maior efeito sobre o volume de exportações de açúcar, após o período de um mês. A elasticidade-preço relativa estimada para essa variável indicou que o aumento de $1 \%$ nos 
preços domésticos implica uma redução de 2,9\% nas externas de açúcar, coeteris paribus. $\mathrm{O}$ segundo maior efeito foi relacionado à taxa de câmbio efetiva, de forma que um incremento da ordem de $1 \%$ nessa variável promove o incremento nas exportações de açúcar da ordem de $2,8 \%$, mantendo-se todas as outras variáveis constantes. Além disso, uma elevação de $1 \%$ nos preços internacionais de açúcar provoca um incremento nas vendas externas desse produto em $2,5 \%$.

Costa (2004) buscou identificar o efeito das medidas protecionistas da União Européia e dos Estados Unidos sobre as exportações brasileiras de açúcar, desagregadas pelas principais regiões produtoras: Centro-Sul e Norte-Nordeste. O modelo de oferta de exportação foi definido para o açúcar bruto, considerando-se que o Brasil é tomador de preços no mercado internacional do açúcar. A seguinte função foi ajustada:

$$
\ln x e=f(\ln p e, \ln t c, \ln p d, \ln Y, \ln p r e f, \ln W)
$$

Onde:

$$
\begin{aligned}
& \text { In pe é preço de exportação do açúcar bruto } \\
& \ln t c \text { é a taxa de câmbio } \\
& \ln p d \text { é o preço doméstico do açúcar refinado } \\
& \ln \text { pref é o preço exportação do açúcar refinado } \\
& \ln W \text { é um deslocador da oferta de açúcar } \\
& \ln Y \text { é a renda doméstica }
\end{aligned}
$$

Por outro lado, na estimação da elasticidade-preço de oferta para a União Européia, o modelo de oferta de exportação foi definido para o açúcar refinado. Nesse caso, o quantum exportado pelo bloco foi considerado um excedente do seu consumo doméstico, da mesma forma que os modelos descritos em Miranda (2001), Bacchi et al. (2002) e Barros et al. (2002).

Alves \& Bacchi (2004) estimaram uma equação de oferta de exportação brasileira de açúcar utilizando a metodologia de Auto-Regressão Vetorial, com dados 
mensais para o período entre outubro de 1995 e dezembro de 2002. As variáveis consideradas foram quantidade exportada, preço das exportações, preço doméstico, taxa de cambio real e renda interna. Uma dummy para representar o período de safra e entressafra da cultura da cana-de-açúcar também foi usada com a finalidade de melhorar o ajustamento do modelo. Com o objetivo de avaliar os impactos de variações nas condicionantes das exportações brasileiras de açúcar, os autores propuseram um modelo fundamentando-se em Barros et al. (2002), considerando, portanto, o quantum exportado de açúcar pelo Brasil como um excedente do mercado doméstico. Os resultados mostraram que as variáveis relacionadas ao mercado doméstico, no caso, renda interna e preço doméstico do açúcar, tiveram grande influência sobre o quantum exportado de açúcar. Uma variação de $1 \%$ no preço doméstico de açúcar provoca uma queda de $1,36 \%$ no volume exportado de açúcar após dois meses. Em relação à renda interna, a queda no volume de açúcar exportado pelo Brasil é de 3,67\%, após três meses.

Silveira (2004), partindo da observação da expressiva representatividade do Brasil no comércio mundial de açúcar, buscou avaliar a existência de relação entre os preços do mercado físico do açúcar no Brasil e os preços internacionais desta commodity, representados pelas cotações dos contratos futuros das bolsas de Nova Yorque (NYBOT) e de Londres (LIFFE). Para tanto, o autor analisou as relações entre os logaritmos das médias semanais dos preços domésticos de açúcar, representados pelo preço do Estado de São Paulo, e os preços internacionais de açúcar. Os resultados das funções de correlação cruzada entre as variáveis do modelo apontaram tanto a existência de relação contemporânea significativa, como a causalidade dos preços das bolsas internacionais sobre os preços domésticos. Com esses resultados foram especificados modelos com a finalidade de analisar o processo de transmissão de preços entre os mercados doméstico e internacional. As elasticidades obtidas nas funções de transmissão de preços indicaram que os valores passados das cotações da NYBOT são referência para a formação de preços no mercado doméstico de açúcar, sendo a influência contemporânea baixa. Finalmente, o autor avaliou o impacto que produção brasileira de açúcar, a qual define o potencial de exportação dessa commodity pelo Brasil, tem sobre a formação do preço no mercado internacional desse produto. Os resultados mostraram 
que o direcionamento de mais matéria prima para a produção de açúcar, considerando as baixas as taxas de crescimento do consumo no mercado interno, tem efeito negativo e significativo no nível de preços a vigorar no mercado internacional. 


\section{PROCEDIMENTOS METODOLÓGICOS E O MODELO ECONÔMICO PROPOSTO}

\subsection{A metodologia}

\subsubsection{Aspectos gerais: variáveis estacionárias e não-estacionárias}

Como discutido em Hill et al. (2003), a análise de dados de séries temporais é de vital interesse tanto para macroeconomistas, estudando o comportamento das economias nacional e internacional, como para economistas financeiros e, também, para os pesquisadores que desejam analisar os efeitos relacionados à oferta e demanda de produtos agrícolas. O processo estocástico gerador das séries de tempo pode ser estacionário, se as suas características não se alteram ao longo do tempo, ou nãoestacionários, se ocorrer o inverso. A maior parte das séries de tempo utilizadas em estudos econômicos são não-estacionárias.

Um processo estocástico $y_{t}$ é estacionário se sua média e variância são constantes ao longo do tempo e se a covariância entre os valores da série depende apenas da distancia no tempo que separa os dois valores, e não dos tempos reais em que as variáveis são observadas. Tem-se então que:

$$
\begin{array}{ll}
E\left(y_{t}\right)=\mu & \text { Média constante } \\
\operatorname{Var}\left(y_{t}\right)=\sigma^{2} & \text { Variância constante } \\
\operatorname{Cov}\left(y_{t}, y_{t+s}\right)=\operatorname{Cov}\left(y_{t}, y_{t-s}\right) & \text { Covariância depende de } s, \text { e não de } t
\end{array}
$$


Nos processos estocásticos estacionários os choques são necessariamente temporários, de forma que seus efeitos se dissipam ao longo do tempo e a série volta a sua tendência de longo prazo. Por outro lado, em um processo não-estacionário tem-se a presença de componentes permanentes. Análises econométricas feitas a partir de séries não estacionárias levam a estimadores de mínimos quadrados e estatísticas de teste não são confiáveis. A aparente significância dessas relações pode ser falsa e os resultados espúrios.

Regressões espúrias fornecem resultados aparentemente significantes a partir de dados não relacionados. Hill et al. (2003) afirma que se o valor de $R^{2}$ de um modelo ajustado com séries temporais for maior que a estatística de Durbin-Watson deve-se suspeitar de regressão espúria.

Segundo Enders (1995), quatro casos precisam ser considerados quando se trabalha com séries não-estacionárias. Considere o modelo que segue:

$$
y_{t}=a_{0}+a_{1} z_{1}+e_{t}
$$

Caso 1) Ambos $\left\{y_{l}\right\}$ e $\left\{z_{l}\right\}$ são estacionários. Nesse caso o modelo clássico de regressão é apropriado;

Caso 2) As seqüências $\left\{y_{t}\right\}$ e $\left\{z_{t}\right\}$ são integradas de ordens diferentes. A equação de regressão usando tais variáveis em nível não tem significado;

Caso 3) As sequiências $\left\{y_{1}\right\}$ e $\left\{z_{t}\right\}$ são integradas de mesma ordem e os resíduos contém uma tendência estocástica. Os resultados dessa regressão com as variáveis em nível são sem significado. Recomenda-se, nesse caso, que a equação de regressão seja estimada nas primeiras diferenças. Considera-se primeira diferença de (34) como sendo:

$$
\Delta y_{t}=a_{0}+a_{1} \Delta z_{t}+\Delta e_{1}
$$

Onde: $\Delta y_{t}=y_{y}-y_{t-1}, \Delta z_{t}=z_{t}-z_{t-1}$ e $\Delta e_{t}=e_{t}-e_{t-1}$ 
Uma vez que $\left\{y_{t}\right\},\left\{z_{t}\right\}$ e $\left\{e_{t}\right\}$ contém raiz unitária, a primeira diferênça de cada variável é estacionária;

Caso 4) As seqüências $\left\{y_{t}\right\}$, e $\left\{z_{t}\right\}$ são integradas de mesma ordem e a seqüência de resíduos é estacionária. Nessa circunstância, $\left\{y_{t}\right\} \mathrm{e}\left\{z_{t}\right\}$ são co-integradas.

Existem algumas formas para testar se uma série é ou não estacionária. A seguir serão apresentadas duas formas de fazê-lo, quais sejam, a verificação da estacionariedade através da função de autocorrelação e a verificação da estacionariedade através do teste de raiz unitária.

\subsubsection{Testando estacionariedade: a função de autocorrelação ${ }^{1}$ e $o$ teste de raizes unitárias $^{2}$}

Enders (1996) afirma que a inspeção da função de autocorrelação serve apenas como um indicador inicial da existência de não estacionariedade. Testes formais como dos de Dickey-Fuller (1976, 1979 e 1981), por exemplo, podem ajudar a determinar se a série tem ou não tendência e se a tendência é determinista ou estocástica.

A partir da definição de covariância entre as variáveis da equação (34), $y_{t}$ e $y_{t+s}$, é possível construir uma função de autocorrelação, $\rho_{s}$, da série como:

$$
\rho_{S}=\frac{\operatorname{cov}\left(y_{t}, y_{i+s}\right)}{\operatorname{var}\left(y_{i}\right)}=\frac{\gamma_{s}}{\gamma_{0}}
$$

O valor de $\rho=1$ para $S=0$. Se $S>1$, as correlações são números puros entre -1 e 1. As estimativas das correlações amostrais são:

\footnotetext{
${ }^{1}$ Discussão baseada em Hill et al. (2003)

${ }^{2}$ Discussão baseada em Enders (1995,1996)
} 


$$
\hat{\rho}_{S}=\frac{\operatorname{cov}\left(y_{t, y_{t+s}}\right)}{\operatorname{Var} r\left(y_{t}\right)}=\frac{\hat{\gamma}_{S}}{\hat{\gamma}_{0}}
$$

onde as variâncias e as covariâncias são estimadas a partir de uma amostra de tamanho $T$ de acordo com as seguintes fórmulas:

$$
\begin{aligned}
& \hat{\gamma}_{S}=\frac{\sum\left(y_{t}-\bar{y}\right)\left(y_{t+S}-\bar{y}\right)}{T} \\
& \hat{\gamma}_{0}=\frac{\left.\sum y_{1}-\bar{y}\right)^{2}}{T}
\end{aligned}
$$

A inspeção visual dessas funções pode ser um primeiro indicador da não estacionariedade da série. A ilustração gráfica das correlações amostrais $\hat{\rho}_{S}$ fornece um correlograma a partir do qual pode-se verificar visualmente a estacionariedade das séries. Quando uma série é estacionária, as autocorrelações gradualmente diminuem indicando que os valores mais afastados no passado passam a ser cada vez menos correlacionados com os valores correntes. Por outro lado, para séries não-estacionárias, as autocorrelações não diminuem tão rapidamente.

Pode-se também testar a estacionariedade de uma série temporal de forma direta através do teste de raiz unitária.

Seguindo Hill et al. (2003), considere um modelo AR(1) para a série temporal $y_{1}:$

$$
y_{t}=a_{1} z_{t-1}+e_{t}
$$


Suponha que $e_{t}$ seja uma perturbação aleatória, com média zero e variância constante $\sigma_{e}^{2}$. Nesse caso, se $a_{1}=1$ tem-se que $y_{t}$ é um passeio aleatório (random walk) não estacionário, $y_{t}=y_{t-1}+e_{t}$, que apresenta raiz unitária, uma vez que $a_{1}=1$.

Pode-se provar que o processo passeio aleatório descrito acima é não estacionário através do cálculo de sua variância. Supondo que $y_{0}=0$, então, por substituições repetidas:

$$
\begin{aligned}
& y_{1}=e_{1} \\
& y_{2}=y_{1}+e_{2} \\
& y_{3}=y_{2}+e_{3}=e_{1}+e_{2}+e_{3} \\
& y_{t}=\sum_{j=1}^{t} e_{j}
\end{aligned}
$$

Assim,

$$
\operatorname{var}\left(y_{t}\right)=t \sigma_{e}^{2}
$$

Como a variância de $y_{t}$ é dependente do tempo, ela é dita não-estacionária. Se $\left|a_{1}\right|<1$, tem-se que o processo $\mathrm{AR}(1)$ é estacionário. É possível testar a nãoestacionariedade da série através do teste da hipótese nula de que $a_{1}=1$ contra a hipótese alternativa de que $\left|a_{1}\right|<1$.

Rearranjando a eq. (39) através da subtração de $y_{t-1}$ de ambos os seus lados, obtém-se:

$$
\begin{aligned}
& y_{t}-y_{t-1}=a_{1} y_{t-1}-y_{t-1}+e_{t}: \\
& \Delta y_{t}=\left(a_{1}-1\right) y_{t-1}+e_{t} \\
& =y_{t-1}+e_{t}
\end{aligned}
$$


em que $\Delta y_{t}=y_{t}-y_{t-1}$ e $\gamma=a_{1}-1$.

Disso decorre que:

$$
\begin{aligned}
& H_{0}: a_{1}=1 \leftrightarrow H_{0}: \gamma=0 \\
& H_{1}: a_{1}<1 \leftrightarrow H_{1}: \gamma<0
\end{aligned}
$$

A variável $\Delta y_{t}=y_{t}-y_{t-1}$ é chamada de primeira diferença da série $y_{t}$. Se $y_{t}$ segue um passeio aleatório, então $\gamma=0$

$$
\Delta y_{t}=y_{t}-y_{t-1}=e_{t}
$$

Como argumenta Hill et al. (2003), uma característica interessante da série $\Delta y_{t}=y_{t}-y_{t-1}$ é que ela é estacionária se, como se supôs, o erro $e_{t}$ for puramente aleatório. Séries como $y_{t}$, que podem ser transformadas em estacionárias tomando-se a primeira diferença, são chamadas de integradas de ordem 1, e denotadas por $I(1)$. As variáveis estacionárias são integradas de ordem zero, $I(0)$. Em termos gerais, portanto, se uma série pode ser diferenciada $d$ vezes para se tornar estacionária, ela é chamada integrada de ordem $d$, ou $I(d)$.

O teste de hipóteses como colocado em (43) pode ser efetuado por mínimos quadrados ordinários observando a estatística $t$ para a hipótese $\gamma=0$. Dickey $\&$ Fuller (1976) apresentaram três diferentes equações para se testar a presença de raiz unitária, dependendo do processo gerador da série temporal, incluindo ou não termos deterministas, constante e tendência:

$$
\begin{aligned}
& \Delta y_{1}=\gamma y_{1-1}+e_{t} \\
& \Delta y_{1}=a_{1}+\gamma y_{t-1}+e_{t}
\end{aligned}
$$




$$
\Delta y_{t}=a_{1}+a_{2} t+\gamma y_{t-1}+e_{t}
$$

A primeira equação é chamada de passeio aleatório puro, a segunda tem a presença de um intercepto (drift) e a terceira apresenta, além de um intercepto, uma tendência linear. Não se rejeitando a hipótese nula, conclui-se que a série $y_{t}$ segue um passeio aleatório. A estatística padrão $t$ de student e $F$ não são aplicáveis para se testar estacionariedade. No caso do passeio aleatório puro (45) deve-se utilizar a estatística denominada $\tau$, no modelo com intercepto (46) deve-se utilizar a estatística $\tau_{\mu}$ e no modelo com tendência linear (47), a estatística $\tau_{\tau}$, cujas distribuições são apresentadas em Fuller (1976).

Esses valores críticos não mudam se (45), (46) e (47) forem expandidas resultando em (48), (49) e (50), respectivamente:

$$
\begin{aligned}
& \Delta y_{t}=\gamma y_{t-1}+\sum_{i=2}^{p} \beta_{i} \Delta y_{t-i+1}+e_{t} \\
& \Delta y_{t}=a_{0}+\gamma y_{t-1}+\sum_{i=2}^{p} \beta_{i} \Delta y_{t-i+1}+e_{t} \\
& \Delta y_{t}=a_{0}+\gamma y_{t-1}+a_{2} t+\sum_{i=2}^{p} \beta_{i} \Delta y_{t-i+1}+e_{t}
\end{aligned}
$$

nas quais $p$ é a ordem do processo autoregressivo que descreve o comportamento da série temporal.

As mesmas estatísticas $\tau, \tau_{\mu}$ e $\tau_{\tau}$, são utilizadas para testar a hipótese $\gamma=0$. Nesses casos tem-se uma extensão do teste de Dickey-Fuller, chamado de teste DickeyFuller aumentado (ADF).

Fuller (1981) apresentou ainda três estatísticas $F$ adicionais, chamadas $\phi_{1}, \phi_{2} \mathrm{e}$ $\phi_{3}$, para testar conjuntamente hipóteses sobre os coeficientes da regressão. Por exemplo, para se testar a hipótese nula $\gamma=0 \mathrm{em}(46)$ ou (49) utiliza-se a estatística $\phi_{1}$. Incluindo- 
se tendência temporal na regressão, como em (47) ou (50), a hipótese conjunta $a_{0}=\gamma=a_{2}=0$ é testada utilizando-se a estatística $\phi_{2}$ e a hipótese conjunta $\gamma=a_{2}=0$ é testada usando a estatística $\phi_{3}$.

Nos testes de Dickey-Fuller assume-se que os erros são estatisticamente independentes e têm variância constante. Uma generalização do procedimento de Dickey-Fuller foi desenvolvida por Phillips \& Perron (1989) e permite que os resíduos da equação utilizada para o teste de raiz unitária sejam heterogêneos ou fracamente dependentes.

Por fim, na análise da existência de raiz unitária, especial atenção deve ser dada ao fato de ser possível existir mudança estrutural na série de dados. A presença de quebra estrutural na série pode levar as estatísticas de Dickey-Fuller e Phillips-Perron a um viés em direção a não rejeição da hipótese de raiz unitária. Uma alternativa para se testar raiz unitária na presença de quebra estrutural envolve a divisão da amostra em duas partes e o uso dos testes de Dickey-Fuller para se testar cada parte. O problema com esse procedimento é que os graus de liberdade para cada uma das regressões resultantes são reduzidos. Um procedimento formal para testar raiz unitária na presença de quebra estrutural utilizando a amostra toda foi desenvolvido por Perron (1989).

Alguns problemas com o poder dos testes de raiz unitária são citados na literatura pertinente. Enders (1995) afirma que simulações de Monte Carlo têm mostrado que o poder dos vários testes de Dickey-Fuller e de Phillips-Perron é muito baixo. Por exemplo, os testes de raiz unitária não têm o poder de distinguir entre um processo com raiz unitária e uma processo com raiz quase-unitária. Em geral, os testes tendem a indicar presença de raiz unitária. Ademais, tais testes têm também pouco poder para distinguir entre um processo com tendência estocástica e um processo com tendência determinista. Em amostras finitas, um processo com tendência estacionária pode ser arbitrariamente bem aproximado por um processo com presença de raiz unitária e vice versa.

Uma dificuldade adicional surge quando da determinação de quais regressores deterministas deverão ser incluídos no modelo. A menos que o pesquisador conheça o 
real processo gerador dos dados, fica pendente a questão acerca de qual forma é a mais apropriada para ser estimada: (48), (49) ou (50).

Enders (1995) sugere um procedimento para testar raiz unitária nos casos em que a forma real do processo gerador dos dados é desconhecido:

Passo 1) Começa-se com um processo menos restritivo (incluindo intercepto e tendência temporal) e usa-se a estatística $\tau_{\tau}$ para testar a hipótese nula $\gamma=0$. Como discutido acima, os testes de raiz unitária têm baixo poder para rejeitar a hipótese nula. Dessa forma, se se conclui por rejeitar a hipótese nula da raiz unitária $\left(H_{0}\right)$, não há necessidade de prosseguir. Conclui-se que a seqüência $\left\{y_{1}\right\}$ não contém raiz unitária, sendo, portanto, estacionária;

Passo 2) Se $H_{0}$ não é rejeitada, é necessário determinar se regressores desnecessários foram incluídos na regressão. Usando a estatística $\tau_{\beta_{\tau}}$, testa-se a significância do coeficiente do termo de tendência $\left(a_{2}\right)$ sob a hipótese nula da raiz unitária. Para confirmação desse resultado testa-se $\gamma=a_{2}=0$ usando a estatística $\phi_{3}$. Se a tendência não é significativa, passa-se ao passo 3 . Caso contrário, se a tendência for significativa, testa-se novamente a presença de raiz unitária $(\gamma=0)$ usando a distribuição normal padronizada. Se $H_{0}$ é rejeitada, conclui-se que o processo não contém raiz unitária e é estacionário em torno de uma tendência determinista. Caso contrário, conclui-se que a seqüência $\left\{y_{t}\right\}$ contém raiz unitária, ou seja, é nãoestacionária. Nesse caso, o termo de tendência estaria, na verdade, associado a uma tendência quadrática da série em nível;

Passo 3) Estima-se a equação sem o termo de tendência. Testa-se a presença de raiz unitária usando a estatística $\tau_{\mu}$. Se $H_{0}$ é rejeitada, conclui-se que o modelo não contém raiz unitária. Se $H_{0}$ não é rejeitada, testa-se a significância da constante $a_{0}$ usando a estatística $\tau_{\alpha \mu}$, dado $\gamma=0$. A confirmação desse resultado pode ser obtida testando-se a hipótese $a_{0}=\gamma=0$, usando a estatística $\phi_{1}$. Se o intercepto não é estatisticamente significativo, estima-se a equação (48) e procede-se ao passo 4 . Se o 
intercepto é significativo, testa-se a presença de raiz unitária usando a distribuição normal padronizada. Se $H_{0}$ é rejeitada, conclui-se que a seqüência $\left\{y_{t}\right\}$ não contém raiz unitária e a série é estacionária em torno de uma constante. Caso contrário, concluise que a seqüência $\left\{y_{t}\right\}$ contém raiz unitária e uma tendência determinista (drift) no nível.

Passo 4) Estima-se a equação sem o termo de tendência ou o intercepto, usandose a estatística $\tau$ para testar a presença de raiz unitária. Se a hipótese nula da raiz unitária é rejeitada, conclui-se que a seqüência $\left\{y_{t}\right\}$ não contém raiz unitária. Caso contrário, conclui-se que a seqüência $\left\{y_{t}\right\}$ contém raiz unitária.

O procedimento acima é utilizado para testar a presença de uma raiz unitária, caso mais comum em séries econômicas, especialmente quando se trabalha com valores reais.

\subsubsection{Análise econométrica utilizando Vetores Auto-Regressivos (VAR) ${ }^{3}$}

Até a década de 1970 , a abordagem tradicional dos econometristas quando trabalhavam com modelos de séries temporais multiequacionais, era a estimação de modelos na forma estrutural, através de duas medidas básicas: a) classificação a priori das variáveis em "endógenas" e "exógenas" e b) imposição de restrições zero nos parâmetros estruturais.

Sims (1980) propôs uma abordagem alternativa baseada na estimação de modelos na forma reduzida, onde todas as variáveis são tratadas como endógenas, consideradas simetricamente definidas (deixa de existir, portanto, a questão da dependência e independência das variáveis). Nesse modelo, todas as variáveis passam a depender das próprias defasagens e das defasagens de todas as demais variáveis do sistema, até uma ordem máxima $p$. Testes de Akaike (AIC) e Schwarz (SC) para um

\footnotetext{
${ }^{3}$ Seção baseada em Enders $(1995,1996)$
} 
contexto multiequacional são amplamente utilizados para a definição do número de defasagens $p$ nos modelos VAR.

Considerando-se, como exemplo, o seguinte modelo bivariado:

$$
\begin{aligned}
& y_{t}=b_{10}+b_{12} z_{t}+\gamma_{11} y_{t-1}+\gamma_{12} z_{t-1}+\varepsilon_{y t} \\
& z_{t}=b_{20}+b_{21} y_{t}+\gamma_{21} y_{t-1}+\gamma_{22} z_{t-1}+\varepsilon_{z t}
\end{aligned}
$$

Ambas as equações constituem-se em um VAR bivariado de primeira ordem, uma vez que a maior defasagem é unitária. Assume-se que: a) as variáveis $y_{t}$ e $z_{t}$ são estacionárias; $b$ ) que $\varepsilon_{y t}$ e $\varepsilon_{z t}$ são distúrbios ruído branco com desvio padrão $\sigma_{y}$ e $\sigma_{z}$, respectivamente; e $c)$ que $\left\{\varepsilon_{y t}\right\}$ e $\left\{\varepsilon_{z t}\right\}$ são choques não correlacionados. As equações (51) e (52) não são uma forma reduzida, pois existe um efeito contemporâneo de $z_{t}$ sobre $y_{t}$ e de $y_{t}$ sobre $z_{t}$.

As eq. (51) e (52) podem ser escritas como:

$$
\begin{aligned}
& y_{t}+b_{12} z_{t}=b_{10}+\gamma_{11} y_{t-1}+\gamma_{12} z_{t-1}+\varepsilon_{y t} \\
& z_{t}+b_{21} y_{t}=b_{20}+\gamma_{21} y_{t-1}+\gamma_{22} z_{t-1}+\varepsilon_{z t}
\end{aligned}
$$

Utilizando-se notação matricial, tornam-se:

$$
\left.\left[\begin{array}{cc}
1 & b_{12} \\
b_{21} & 1
\end{array}\right] \begin{array}{l}
y_{t} \\
z_{t}
\end{array}\right]=\left[\begin{array}{l}
b_{10} \\
b_{20}
\end{array}\right]+\left[\begin{array}{ll}
\gamma_{11} & \gamma_{12} \\
\gamma_{21} & \gamma_{22}
\end{array}\right]\left[\begin{array}{c}
y_{t-1} \\
z_{t-1}
\end{array}\right]+\left[\begin{array}{c}
\varepsilon_{y t} \\
\varepsilon_{z t}
\end{array}\right]
$$

ou

$$
B x_{t}=\Gamma_{0}+\Gamma_{1} x_{t-1}+\varepsilon_{t}
$$


Onde:

$$
\begin{array}{lll}
B=\left[\begin{array}{cc}
1 & b_{12} \\
b_{21} & 1
\end{array}\right] & x_{t}=\left[\begin{array}{l}
y_{t} \\
z_{t}
\end{array}\right] & \Gamma_{0}=\left[\begin{array}{l}
b_{10} \\
b_{20}
\end{array}\right] \\
\Gamma_{1}=\left[\begin{array}{ll}
\gamma_{11} & \gamma_{12} \\
\gamma_{21} & \gamma_{22}
\end{array}\right] & \varepsilon_{t}=\left[\begin{array}{l}
\varepsilon_{y t} \\
\varepsilon_{z t}
\end{array}\right] &
\end{array}
$$

A eq. (55) representa um VAR na forma primitiva. Pré-multiplicando (55) por $\mathbf{B}^{-1}$, tem-se um VAR na sua forma padrão:

$$
\mathbf{x}_{\mathrm{t}}=\mathbf{A}_{0}+\mathbf{A}_{1} \mathbf{x}_{t-1}+\mathbf{e}_{\mathbf{t}}
$$

Onde:

$$
\begin{aligned}
& \mathbf{A}_{0}=\mathbf{B}^{-1} \Gamma_{0} \\
& \mathbf{A}_{1}=\mathbf{B}^{-1} \Gamma_{1} \\
& \mathbf{e}_{\mathbf{t}}=\mathbf{B}^{-1} \varepsilon_{\mathbf{t}}
\end{aligned}
$$

Define-se $a_{i 0}$ como o elemento $i$ do vetor $\mathbf{A}_{0}, a_{i j}$ como o elemento da linha $i$ e coluna $j$ da matriz $\mathbf{A}_{1}$, e $e_{i t}$ como o elemento $i$ do vetor $\mathbf{e}_{\mathbf{t}}$. A partir dessa nova notação, é possível re-escrever (56) em forma equivalente:

$$
\begin{aligned}
& y_{t}=a_{10}+a_{11} y_{1-1}+a_{12} z_{t-1}+e_{1 t} \\
& z_{1}=a_{20}+a_{21} y_{t-1}+a_{22} z_{t-1}+e_{2 t}
\end{aligned}
$$

Sendo $e_{t}=B^{-1} \varepsilon_{i}$, tem-se: 


$$
\begin{aligned}
& e_{1 t}=\left(\varepsilon_{y t}-b_{12} \varepsilon_{z t}\right) /\left(1-b_{12} b_{21}\right) \\
& e_{2 t}=\left(\varepsilon_{z t}-b_{21} \varepsilon_{y t}\right) /\left(1-b_{12} b_{21}\right)
\end{aligned}
$$

Desde que $\varepsilon_{y t}$ e $\varepsilon_{z t}$ sejam processos ruído branco, segue que ambos $e_{1}$ e $e_{2}$ têm média zero, variância constante e são serialmente não correlacionados.

A matriz de variância e covariância dos erros $e_{1}$ e $e_{2 t}$ é definida como:

$$
\Sigma=\left[\begin{array}{cc}
\operatorname{var}\left(e_{1 t}\right) & \operatorname{cov}\left(e_{1 t}, e_{2 t}\right) \\
\operatorname{cov}\left(e_{1 t}, e_{2 t}\right) & \operatorname{var}\left(e_{2 t}\right)
\end{array}\right]
$$

Sendo todos os elementos de $\sum$ independentes do tempo, é possível usar uma formato mais compacto para a matriz de variância e covariância dos erros:

$$
\Sigma=\left[\begin{array}{ll}
\sigma_{1}^{2} & \sigma_{12} \\
\sigma_{21} & \sigma_{2}^{2}
\end{array}\right]
$$

Onde:

$$
\begin{aligned}
& \operatorname{var}\left(e_{12}\right)=\sigma_{i}^{2} \\
& \sigma_{12}=\sigma_{21}=\operatorname{cov}\left(e_{1 t}, e_{2 t}\right)
\end{aligned}
$$

\subsubsection{Estimação e identificação}

Sims (1980) propôs uma estratégia de estimação de forma a contornar as restrições de identificação inerentes aos modelos estruturais. Considere a seguinte generalização multivariada da eq. (56): 


$$
\mathbf{x}_{t}=\mathbf{A}_{0}+\mathbf{A}_{1} \mathbf{x}_{t-1}+\mathbf{A}_{2} \mathbf{x}_{t-2}+\ldots+\mathbf{A}_{\mathbf{p}} \mathbf{x}_{t-p}+\mathbf{e}_{\mathrm{t}}
$$

Onde:

$\mathbf{x}_{\mathbf{t}}=$ um vetor $(n x l)$ contendo cada uma das $n$ variáveis incluídas no modelo VAR

$\mathbf{A}_{0}=$ um vetor $(n x l)$ de termos de intercepto

$\mathbf{A}_{\mathbf{i}}=$ uma matriz $(n \times n)$ de coeficientes

$\mathbf{e}_{\mathbf{i}}=$ um vetor $(n x 1)$ de termos de erros

As variáveis a serem incluídas no VAR são selecionadas de acordo com o modelo econômico relevante. Dado que a matriz $\mathbf{A}_{0}$ contém $n$ termos de interceptos e a matriz $\mathbf{A}_{\mathrm{i}}$ contém $n^{2}$ coeficientes, $n+p n^{2}$ termos precisam ser estimados.

Nota-se que do lado direito de (57) e (58) contém apenas variáveis prédeterminadas e que, como já salientado, os termos de erros são serialmente não correlacionados e com variância constante. Dessa forma, cada equação no sistema pode ser estimada por Mínimos Quadrados Ordinários (MQO). Ainda que os erros sejam correlacionados através das equações, a estimativa usando regressões aparentemente não correlacionadas (SUR) não seria necessária, uma vez que as variáveis do lado direito em ambas as regressões são idênticas.

Para ilustrar os procedimentos de identificação, considera-se o VAR estrutural bivariado de primeira ordem representado pelas eq. (51) e (52). Dada a retroalimentação (feedback) inerente a esse sistema, as equações não podem ser estimadas diretamente através da equação primitiva. A razão para isso é que $z$, é correlacionado com o termo de erro $\varepsilon_{y t}$ e $y_{t}$ com o termo de erro $\varepsilon_{z t}$. No entanto, MQO pode ser utilizado para estimar o VAR na sua forma padrão, ou seja, como nas eq. (57) e (58). Por meio de MQO é possivel obter as estimativas dos dois elementos de $A_{0}$ e dos quatro elementos de $A_{i}$. Além disso, por meio dos resíduos das duas regressões, é possível calcular a 
estimativa das variâncias de $e_{1 t}$ e $e_{2 t}$ e a covariância entre $e_{1 t}$ e $e_{2 t}$. O problema que surge é o da impossibilidade de recuperar os parâmetros estruturais a partir dos parâmetros na forma reduzida, a não ser que sejam impostas de forma apropriada restrições ao sistema na sua forma estrutural.

A razão para o problema da identificação aparece quando se compara o número de parâmetros do sistema na sua forma estrutural com o número de parâmetros de um modelo VAR na forma reduzida. Estimando (56) e (57), obtém-se estimativa de seis coeficientes $\left(a_{10}, a_{20}, a_{11}, a_{12}, a_{21}\right.$ e $\left.a_{22}\right)$ e os valores calculados da $\operatorname{Var}\left(e_{1 t}\right), \operatorname{Var}\left(e_{2 t}\right)$ e $\operatorname{Cov}\left(e_{1 t}, e_{2 t}\right)$. No entanto, o sistema na sua forma estrutural (51) e (52) contém dez parâmetros. Além dos dois interceptos $b_{10}$ e $b_{20}$, tem-se ainda quatro coeficientes autoregressivos, $\gamma_{11}, \gamma_{12}, \gamma_{21}$ e $\gamma_{22}$, os coeficientes da relação contemporânea e dois desvios padrões, $\sigma_{y}$ e $\sigma_{z}$. Ao todo, o sistema na forma estrutural contém dez parâmetros enquanto o sistema VAR na sua forma reduzida contém apenas nove parâmetros. Nesse caso específico, se exatamente um parâmetro no sistema estrutural for restrito, o sistema é exatamente identificado, e se mais de um parâmetro for restrito, o sistema é superidentificado.

Um modo de identificar o modelo é utilizar o sistema recursivo proposto por Sims (1980). Suponha que seja imposto ao modelo estrutural uma restrição de forma que $b_{21}=0$. Reescrevendo (51) e (52) com essa restrição:

$$
\begin{aligned}
& y_{t}=b_{10}-b_{12}+\gamma_{11} y_{t-1}+\gamma_{12} z_{t-1}+\varepsilon_{y t} \\
& z_{t}=b_{20}+\gamma_{21} y_{t-1}+\gamma_{22} z_{t-1}+\varepsilon_{z t}
\end{aligned}
$$

Impor a restrição $b_{2 \imath}=0$ significa que $\mathbf{B}^{-1}$ é dado por: 


$$
\mathbf{B}^{-1}=\left[\begin{array}{cc}
1 & -b_{12} \\
0 & 1
\end{array}\right]
$$

Pré-multiplicando o sistema na forma estrutural pela matriz $\mathbf{B}^{-1}$ tem-se:

$$
\left[\begin{array}{c}
y_{t} \\
z_{t}
\end{array}\right]=\left[\begin{array}{c}
b_{10}-b_{12} b_{20} \\
b_{20}
\end{array}\right]+\left[\begin{array}{cc}
\gamma_{11}-b_{12} \gamma_{21} & \gamma_{12}-b_{12} \gamma_{22} \\
\gamma_{21} & \gamma_{22}
\end{array}\right]\left[\begin{array}{c}
y_{t-1} \\
z_{t-1}
\end{array}\right]+\left[\begin{array}{c}
\varepsilon_{y t}-b_{12} \varepsilon_{z t} \\
\varepsilon_{z t}
\end{array}\right]
$$

Estimar esse sistema usando MQO fornece os seguintes parâmetros teóricos estimados:

$$
\begin{aligned}
& y_{t}=a_{10}+a_{11} y_{t-1}+a_{12} z_{t-1}+e_{1 t} \\
& z_{t}=a_{20}+a_{21} y_{t-1}+a_{22} z_{t-1}+e_{2 t}
\end{aligned}
$$

Onde:

$$
\begin{aligned}
& a_{10}=b_{10}-b_{12} b_{20} \\
& a_{11}=\gamma_{11}-b_{12} \gamma_{21} \\
& a_{12}=\gamma_{12}-b_{12} \gamma_{22} \\
& a_{20}=b_{20} \\
& a_{21}=\gamma_{21} \\
& a_{22}=\gamma_{22} \\
& \operatorname{Var}\left(e_{1}\right)=\sigma_{y_{2}}^{2}+b_{12}{ }^{2} \sigma_{z}^{2} \\
& \operatorname{Var}\left(e_{2}\right)=\sigma_{z}^{2} \\
& \operatorname{Cov}\left(e_{1}, e_{2}\right)=-b_{12} \sigma_{z}^{2}
\end{aligned}
$$

Dessa forma, obtém-se nove parâmetros estimados $a_{10}, a_{11}, a_{12}, a_{21}, a_{22}$, $\operatorname{Var}\left(e_{1 t}\right), \operatorname{Var}\left(2_{2 t}\right)$ e $\operatorname{Cov}\left(e_{1 t}, e_{2 t}\right)$, os quais podem ser substituídos nas nove equações 
acima para simultaneamente resolver para $b_{10}, b_{12}, \gamma_{11}, \gamma_{12}, b_{20}, \gamma_{21}, \gamma_{22}, \sigma_{y}^{2}$ e $\sigma_{z}^{2}$ parâmetros da forma estrutural. Nota-se também que as estimativas das seqüências de $\left\{\varepsilon_{y t}\right\}$ e $\left\{\varepsilon_{z t}\right\}$ podem ser recuperadas.

$$
\left[\begin{array}{c}
e_{1 t} \\
e_{2 i}
\end{array}\right]=\left[\begin{array}{c}
\varepsilon_{y t}-b_{12} \varepsilon_{2 t} \\
\varepsilon_{2 i}
\end{array}\right]
$$

A hipótese $b_{21}=0$ significa que $y_{t}$ não tem efeito contemporâneo sobre $z_{t}$. A decomposição dos resíduos dessa forma é chamada de decomposição de Cholesky. Uma forma alternativa para a decomposição de Cholesky seria considerar $b_{12}=0$.

$\mathrm{Na}$ estimação de um VAR também se discute se as variáveis precisam ser diferenciadas para se especificar um modelo apenas com variáveis estacionárias. Os simpatizantes da abordagem de Box-Jenkins são favoráveis à transformação das variáveis por meio da diferenciação. Sims (1980) não recomenda a diferenciação das variáveis, mesmo quando da presença de raiz unitária. $\mathrm{O}$ autor argumenta que o objetivo da análise VAR é determinar as inter-relações entre variáveis, e não a estimativas de parâmetros. Uma vez que o objetivo não é fazer testes de hipóteses, não há problema em estimar a regressão com as variáveis em nível. $\mathrm{O}$ autor afirma que ao proceder à transformação das variáveis não-estacionárias em estacionárias por meio da diferenciação, possíveis relações de longo prazo entre essas variáveis estarão sendo ignoradas. Por último, o autor argumenta que mesmo havendo interesse em testar hipóteses, sob certas condições, é possível usar as estatísticas padrão da regressão das variáveis em nível, em particular se as variáveis forem co-integradas.

\subsubsection{A função de resposta a impulso}

Por meio da função de resposta a impulso busca-se responder como uma determinada variável $y$ responde a um choque ("impulso") em outra variável $z$. De outra 
forma, busca-se investigar o efeito de um choque em $\mathrm{z}$ no período $t$ sobre a evolução de $y$ em $t, t+1, t+2$, etc. As respostas devem ser buscadas não no modelo em sua forma reduzida, mas no modelo estrutural.

Um vetor auto-regressivo pode ser escrito como um vetor de média móvel.

$$
\mathbf{x}_{\mathbf{t}}=\boldsymbol{\mu}+\sum_{\mathbf{i}=\mathbf{0}}^{\infty} \mathbf{A}_{1}^{\mathrm{i}} \mathbf{e}_{\mathbf{t}+\mathbf{i}}
$$

Escrevendo (57) e (58) na forma matricial:

$$
\left[\begin{array}{l}
y_{t} \\
z_{t}
\end{array}\right]=\left[\begin{array}{l}
a_{10} \\
a_{20}
\end{array}\right]+\left[\begin{array}{ll}
a_{11} & a_{12} \\
a_{21} & a_{22}
\end{array}\right]\left[\begin{array}{l}
y_{t-1} \\
z_{t-1}
\end{array}\right]+\left[\begin{array}{l}
e_{1 t} \\
\varepsilon_{2 t}
\end{array}\right]
$$

ou, utilizando (71) obtém-se:

$$
\left[\begin{array}{l}
y_{t} \\
z_{t}
\end{array}\right]=\left[\begin{array}{l}
\bar{y} \\
\bar{z}
\end{array}\right]+\sum_{i=0}^{\infty}\left[\begin{array}{ll}
a_{11} & a_{12} \\
a_{21} & a_{22}
\end{array}\right]^{i}\left[\begin{array}{l}
e_{1 t-1} \\
\varepsilon_{2 t-1}
\end{array}\right]
$$

A eq. (73) expressa $y_{t}$ e $z_{l}$ em termos das sequiências $\left\{e_{1 t}\right\}$ e $\left\{e_{2 t}\right\}$. Entretanto, pode-se re-escrever (73) em termos de $\left\{\varepsilon_{z t}\right\}$ e $\left\{\varepsilon_{y t}\right\}$. Das equações (59) e (60) tem-se que o vetor de erros pode ser escrito como:

$$
\left[\begin{array}{l}
e_{1 t} \\
e_{2 t}
\end{array}\right]=\left[\left(1 / 1-b_{12} b_{21}\right)\left[\begin{array}{cc}
1 & -b_{12} \\
-b_{21} & 1
\end{array}\right]\left[\begin{array}{c}
\varepsilon_{y t} \\
\varepsilon_{z t}
\end{array}\right]\right.
$$

De forma que (73) e (74) podem ser combinados para formar:

$$
\left[\begin{array}{l}
y_{t} \\
z_{t}
\end{array}\right]=\left[\begin{array}{l}
\bar{y} \\
\bar{z}
\end{array}\right]+\left[\left(1 / 1-b_{12} b_{21}\right)\right] \sum_{i=0}^{\infty}\left[\begin{array}{ll}
a_{11} & a_{12} \\
a_{21} & a_{22}
\end{array}\right]^{i}\left[\begin{array}{l}
e_{1 t-1} \\
\varepsilon_{2 t-1}
\end{array}\right]
$$


Para simplificar, pode-se definir uma matriz $\varphi_{\mathrm{i}}$ dos elementos $\phi_{j k(}(i)$ :

$$
\phi_{i}=\left[\left(A_{1}^{i} / 1-b_{12} b_{21}\right)\left[\begin{array}{cc}
1 & -b_{12} \\
-b_{21} & 1
\end{array}\right]\right.
$$

Assim, a representação em médias móveis (74) e (75) pode ser escrita em termos de $\left\{\varepsilon_{z t}\right\}$ e $\left\{\varepsilon_{y t}\right\}$ :

$$
\left[\begin{array}{l}
y_{t} \\
z_{t}
\end{array}\right]=\left[\begin{array}{l}
\bar{y} \\
\bar{z}
\end{array}\right]+\sum_{i=0}^{\infty}\left[\begin{array}{ll}
\phi_{11}(i) & \phi_{12}(i) \\
\phi_{21}(i) & \phi_{22}(i)
\end{array}\right]\left[\begin{array}{l}
\varepsilon_{y t-i} \\
\varepsilon_{z t-i}
\end{array}\right]
$$

Ou, de forma mais compacta:

$$
x_{t}=\mu+\sum_{i=0}^{\infty} \phi_{i} \varepsilon_{t-i}
$$

A representação de média móvel é especialmente usada para examinar as interações entre $y_{t}$ e $z_{t}$. Os coeficientes $\phi_{i}$ podem ser usados para gerar os efeitos de choques em $\varepsilon_{y t}$ e $\varepsilon_{z t}$. Nessa notação, fica claro que os elementos $\phi_{j k}(0)$ são multiplicadores de impacto, de forma que, por exemplo, o coeficiente $\phi_{12}(0)$ é o impacto instantâneo da mudança em uma unidade de $\left\{\varepsilon_{z t}\right\}$ sobre $y_{t}$. Do mesmo modo, $\phi_{11}(1)$ e $\phi_{12}(1)$ são, respectivamente, a resposta em um período da mudança em uma unidade de $\left\{\varepsilon_{y t-1}\right\}$ e $\left\{\varepsilon_{z t-1}\right\}$ sobre $y_{y t}$.

Após $n$ períodos, o efeito acumulado dos choques $\varepsilon_{z t}$ sobre a seqüência $\left\{y_{t}\right\}$ é: 


$$
\sum_{i=0}^{n} \phi_{12}(i)
$$

Assumindo que $\left\{y_{t}\right\}$ e $\left\{z_{t}\right\}$ são estacionários, necessariamente $\sum_{i=0}^{\infty} \phi_{j k}^{2}(i)$ é finito.

A esses quatro conjuntos de coeficientes $\phi_{11}(i), \phi_{12}(i), \phi_{21}(i)$ e $\phi_{22}(i)$ dá-se o nome de função resposta a impulso. Expressar graficamente os coeficientes de $\phi_{j k}(i)$ versus $i$ é um modo prático de verificar visualmente o comportamento das séries $\left\{y_{l}\right\}$ e $\left\{z_{l}\right\}$ em resposta a vários choques.

Seria interessante que se fosse possivel conhecer todos os parâmetros do sistema de equações na sua forma estrutural. No entanto, é preciso impor restrições adicionais de modo a poder identificar o sistema. Como já mencionado, uma possível forma de identificação para um sistema bivariado é a decomposição de Choleski, de maneira que:

$$
\begin{aligned}
& e_{1 t}=\varepsilon_{y t}-b_{12} \varepsilon_{z t} \\
& e_{2 t}=\varepsilon_{z l}
\end{aligned}
$$

Assim, se (81) for usado, todos os erros observados na seqüência $\left\{e_{21}\right\}$ são atribuídos aos choques $\left\{\varepsilon_{z l}\right\}$. Dada uma seqüência calculada $\left\{\varepsilon_{z l}\right\}$, o conhecimento dos valores da seqüência $\left\{e_{1 t}\right\}$ e o coeficiente de correlação entre $e_{1 t}$ e $e_{2 t}$, torna-se possível o cálculo da seqüência $\left\{\varepsilon_{y t}\right\}$. Ainda que a decomposição de Choleski restrinja o sistema de forma que um choque $\varepsilon_{y}$ não tenha efeito direto sobre $z_{t}$, há um efeito indireto da variável defasada de $y_{1}$ que afeta o valor contemporâneo de $z_{t}$. O ponto chave é que a decomposição força uma assimetria potencialmente importante sobre o 
sistema uma vez que um choque $\varepsilon_{z t}$ tem efeito contemporâneo sobre ambos $y_{1}$ e $z_{l}$. Por essa razão considera-se que (80) e (81) impõe uma ordenação das variáveis. Um choque $\varepsilon_{z l}$ afeta diretamente $e_{1 t}$ e $e_{2 t}$, mas um choque $\varepsilon_{y t}$ não afeta $e_{2 t}$. Dessa forma, $z_{t}$ é prior a $y_{t}$.

Alternativamente é possível impor também $b_{12}=0$ e decompor os erros usando:

$$
\begin{aligned}
& e_{1 t}=\varepsilon_{y t} \\
& e_{2 t}=-b_{21} \varepsilon_{y t}+\varepsilon_{z t}
\end{aligned}
$$

Resta ainda decidir qual das decomposições alternativas é mais apropriada. Em alguns casos existem algumas suposições teóricas para definir que uma variável não tem efeito contemporâneo sobre outra. Ademais, a idéia de impor restrições à estrutura VAR parece ir contra a abordagem de Sims que argumentava contra a imposições de restrições de identificação. O caso é que identificação significa impor algum tipo de estrutura ao modelo VAR e a decomposição de Choleski apresenta um conjunto mínimo de hipóteses que pode ser usado para identificar o modelo estrutural.

É importante notar que a importância de ordenamento das variáveis depende da magnitude do coeficiente de correlação, $\rho_{21}$, entre $e_{1 t}$ e $e_{2 t}$. Denota-se esse coeficiente de correlação por $\rho_{21}=\sigma_{21} / \sigma_{1} \sigma_{2}$ e supõe-se que o modelo estimado gera um valor de $\sum$ tal que $\rho_{21}$ seja igual a zero. Nesse caso, o ordenamento das variáveis não é importante. Formalmente, (78) e (79) se tornam $e_{1 t}=\varepsilon_{y t}$ e $e_{2 t}=\varepsilon_{z t}$ quando $\rho_{21}=0$, pois nesse caso $b_{21}=0$. Assim, se não há correlação entre os resíduos das equações, $y_{t}$ e $z_{t}$ são equivalentes aos choques $\varepsilon_{y t}$ e $\varepsilon_{z t}$, respectivamente. Usualmente o pesquisador quer testar a significância de $\rho_{21}$ e, como uma regra geral, se $\left|\rho_{21}\right|>0,2$ o procedimento recomendado é obter a função resposta a impulso usando uma ordenação particular. Deve-se comparar o resultado da função de resposta a 
impulso obtida ao se inverter a ordenação. Se as implicações forem muito diferentes, é necessário investigar melhor $\mathrm{o}$ relacionamento contemporâneo entre as variáveis utilizadas.

\subsubsection{Decomposição da variância do erro de previsão}

Utilizando-se a metodologia VAR é possível também proceder à decomposição da variância do erro de previsão $k$ períodos à frente. Suponha que sejam conhecidos os coeficientes de $A_{0}$ e de $\boldsymbol{A}_{1}$ e que se queira prever os vários valores de $x_{t+i}$ condicionais ao valor de $x_{t}$ um período à frente. Tem-se, então, $\mathbf{x}_{\mathbf{t}+1}=\mathbf{A}_{\mathbf{0}}+\mathbf{A}_{\mathbf{1}} \mathbf{x}_{\mathrm{t}}+\mathbf{e}_{\mathbf{t}+\mathbf{1}}$. A expectativa condicional de $x_{t+i}$ é:

$$
\mathbf{E} \mathbf{x}_{\mathbf{t}+1}=\mathbf{A}_{0}+\mathbf{A}_{1} \mathbf{x}_{t}
$$

Note que o erro de previsão, um passo a frente, é $x_{t+1}-E_{t} x_{t+1}=e_{t+1}$. Do mesmo modo, a previsão $x_{t+2}$ dois passos adiante é:

$$
\begin{aligned}
& \mathbf{x}_{t+2}=\mathbf{A}_{0}+\mathbf{A}_{1} \mathbf{x}_{\mathrm{t}+1}+\mathbf{e}_{\mathrm{t}+2} \\
& =\mathbf{A}_{\mathbf{0}}+\mathbf{A}_{1}\left(\mathbf{A}_{\mathbf{0}}+\mathbf{A}_{1} \mathbf{x}_{\mathbf{t}+1}+\mathbf{e}_{\mathrm{t}+2}\right)+\mathbf{e}_{\mathrm{t}+2}
\end{aligned}
$$

Se as expectativas condicionais forem tomadas, o erro de previsão de $x_{t+2}$ dois passos à frente é:

$$
\mathbf{E} \mathbf{x}_{t+2}=\left[\mathbf{I}+\mathbf{A}_{1}\right] \mathbf{A}_{\mathbf{0}}+\mathbf{A}_{1}^{2} \mathbf{x}_{t}
$$


O erro de previsão dois passos adiante, ou seja, a diferença entre a realização de $x_{t+2}$ e a previsão, é $\mathbf{e}_{\mathbf{t}+2}+\mathbf{A}_{1} \mathbf{e}_{\mathrm{t}+1}$. Generalizando, o erro de previsão $n$ passos adiante é:

$$
\mathbf{E} \mathbf{x}_{t+n}=\left(I+A_{1}+A_{1}^{2}+\ldots+A_{1}^{n-1}\right) A_{0}+A_{1}^{n-1} x_{t}
$$

e o erro de previsão associado é:

$$
\mathbf{e}_{t+n}+A_{1} \mathbf{e}_{t+n-1}+A_{1}^{2} \mathbf{e}_{t+n-2}+\ldots+A_{1}^{n-1} \mathbf{e}_{t+1}
$$

É possível escrever esses erros de previsão em termos dos choques $\varepsilon_{y t}$ e $\varepsilon_{z t}$. A decomposição da variância dos erros de previsão indica a parcela do movimento em uma seqüência que é dada pelos seus próprios choques versus a parcela do movimento dado pelos choques das outras variáveis. Se os choques $\varepsilon_{z t}$ não explicam nenhuma parcela da variância do erro de previsão de $\left\{y_{1}\right\}$ ao longo de todo o horizonte de previsão, concluise que a seqüência $\left\{y_{i}\right\}$ é exógena. Em tal circunstância, a seqüência $\left\{y_{t}\right\}$ se desenvolveria independentemente dos choques $\varepsilon_{z t}$ e da seqüência $\left\{z_{t}\right\}$. Em outro extremo, os choques $\varepsilon_{z t}$ poderiam explicar toda a variância do erro de previsão da seqüência $\left\{y_{1}\right\}$ ao longo de todo o horizonte de previsão de forma que $\left\{y_{t}\right\}$ seria totalmente endógeno. É comum no curto prazo que uma variável explique quase toda a sua variância do erro de previsão e, num horizonte de previsão maior, essa proporção se reduza.

É preciso observar que a decomposição da variância contém o mesmo problema inerente às funções resposta a impulso, associado à necessidade de identificação. 


\subsubsection{VAR estrutural}

Como já discutido anteriormente, a vantagem da abordagem de Sims (1980) usando VAR é que todas as variáveis são tratadas simetricamente. Além de útil como um instrumento para examinar as relações entre um conjunto de variáveis, as estimativas utilizando um modelo VAR podem também servir como instrumento de previsões.

Ainda que o modelo seja subidentificado, uma especificação apropriada do modelo fornecerá previsões não-viesadas e com variância mínima. A abordagem convencional do modelo VAR tem sido criticada pela falta de conteúdo econômico. O único papel do pesquisador é sugerir as variáveis apropriadas a serem incluídas no VAR, e o ordenamento das variáveis é feita ad hoc.

O objetivo do modelo VAR estrutural é usar a teoria econômica, ao invés da decomposição de Choleski, para identificá-lo. Isso porque a decomposição de Choleski faz fortes suposições sobre os erros estruturais. A menos que haja fundamentos teóricos para supor, por exemplo, que inovações em $y_{t}$ não terão efeito contemporâneo em $z_{t}$, os choques serão inapropriadamente identificados. Como resultado, a função de resposta a impulso e a decomposição da variância dos erros de previsão, resultado de uma identificação inapropriada, poderão ser bastante enganosas.

Discutiu-se anteriormente que se o coeficiente de correlação, $\rho_{21}$, entre $e_{1 t}$ e $e_{2 t}$ for baixo, a ordenação das variáveis não é importante. Entretanto, em um modelo VAR com muitas variáveis é improvável que todas as correlações sejam baixas. Ao selecionar as variáveis a serem incluídas na regressão, muito provavelmente serão escolhidas variáveis que apresentam fortes co-movimentos.

Sims (1980) e Bernanke (1986) propuseram uma forma alternativa de modelagem usando a análise econômica. O seguinte modelo é proposto: 


$$
\left[\begin{array}{ccccc}
1 & b_{12} & b_{13} & \ldots & b_{1 n} \\
b_{21} & 1 & b_{23} & \ldots & b_{2 n} \\
\cdot & \cdot & \cdot & \cdot & \cdot \\
b_{n 1} & b_{n 2} & b_{n 3} & \ldots & 1
\end{array}\right]\left[\begin{array}{c}
x_{11} \\
x_{2 t} \\
\ldots \\
x_{n t}
\end{array}\right]=\left[\begin{array}{c}
b_{10} \\
b_{20} \\
\ldots \\
b_{n 0}
\end{array}\right]=\left[\begin{array}{ccccc}
\gamma_{11} & \gamma_{12} & \gamma_{13} & \ldots & \gamma_{1 n} \\
\gamma_{21} & \gamma_{22} & \gamma & \ldots & \gamma_{2 n} \\
\cdot & \cdot & \cdot & \ldots & \cdot \\
\gamma_{n 1} & \gamma_{n 2} & \gamma_{n 3} & \ldots & m n
\end{array}\right]\left[\begin{array}{c}
x_{1 t-1} \\
x_{2 t-1} \\
\ldots \\
x_{n t-1}
\end{array}\right]+\left[\begin{array}{c}
\varepsilon_{11} \\
\varepsilon_{2 t} \\
\ldots \\
\varepsilon_{n t}
\end{array}\right]
$$

Em um formato compacto, tem-se:

$$
B x_{t}=\Gamma_{0}+\Gamma_{1} x_{t-1}+\varepsilon_{t}
$$

que pré-multiplicando por $\mathbf{B}^{-1}$ resulta em:

$$
\mathbf{x}_{\mathrm{t}}=\mathbf{B}^{-1} \boldsymbol{\Gamma}_{\mathbf{0}}+\mathbf{B}^{-1} \boldsymbol{\Gamma}_{1} \mathbf{x}_{t-1}+\mathbf{B}^{-1} \varepsilon_{\mathrm{t}}
$$

Nessa equação, $\mathbf{A}_{0}=\mathbf{B}^{-1} \boldsymbol{\Gamma}_{0}, \mathbf{A}_{1}=\mathbf{B}^{-1} \boldsymbol{\Gamma}_{1}$ e $\mathbf{e}_{\mathbf{t}}=\mathbf{B}^{-1} \boldsymbol{\varepsilon}_{\mathbf{t}}$. Usando MQO é possível obter a matriz de variância/covariância,

$$
\sum=\left[\begin{array}{cccc}
\sigma_{1}^{2} & \sigma_{12} & \ldots & \sigma_{1 n} \\
\sigma_{21} & \sigma_{2}^{2} & \ldots & \sigma_{2 n} \\
\cdot & \cdot & \cdot & \cdot \\
\sigma_{n 1} & \sigma_{n 2} & \ldots & \sigma_{n}^{2}
\end{array}\right]
$$

onde cada elemento é construído como a soma $\sigma_{i j}=(1 / T) \sum_{t=1}^{T} e_{i t} e_{j t}$.

Uma vez que $\sum$ é simétrica, ela contém somente $\left(n^{2}+n\right) / 2$ elementos diferentes. Dado que os elementos da diagonal principal de $\mathbf{B}$ são todos um, $\mathbf{B}$ contém $n^{2}-n$ incógnitas. Além disso, há os $n$ valores não conhecidos $\operatorname{Var}\left(\varepsilon_{i t}\right)$ para um total de $n^{2}$ incógnitas do modelo estrutural - isto é, os $n^{2}-n$ valores de $\mathbf{B}$ mais os $n$ valores da $\operatorname{Var}\left(\varepsilon_{i t}\right)$. Então, para identificar $n^{2}$ incógnitas a partir dos $\left(n^{2}+n\right) / 2$ elementos independentes conhecidos de $\sum$ é necessário impor $n^{2}-\left[\left(n^{2}+n\right) / 2\right]=\left(n^{2}+n\right) / 2$ restrições adicionais ao sistema. 
No sistema acima, a decomposição de Choleski requereria que todos os elementos acima da diagonal principal fossem iguais a zero:

$$
\begin{array}{r}
b_{12}=b_{13}=b_{14}=\ldots=b_{1 n}=0 \\
b_{23}=b_{24}=\ldots=b_{2 n}=0 \\
b_{34}=\ldots=b 3 n=0 \\
\ldots \\
b_{n-1 n}=0
\end{array}
$$

Assim, haveria um total de $\left(n^{2}+n\right) / 2$ restrições, de forma que o sistema seria exatamente identificado. Pode-se verificar que a decomposição de Choleski sempre resulta em um sistema exatamente identificado. É claro que a ordenação exigida por tal decomposição pode não ser consistente com a teoria econômica. Para exemplificar, considere um caso específico de decomposição de Choleski utilizando um VAR com três variáveis:

$$
\begin{aligned}
& e_{1 t}=\varepsilon_{1 t} \\
& e_{2 t}=c_{21} \varepsilon_{1 t}+\varepsilon_{2 t} \\
& e_{3 t}=c_{31} \varepsilon_{1 t}+c_{32} \varepsilon_{2 t}+\varepsilon_{3 t}
\end{aligned}
$$

Da discussão anterior, demonstra-se que $\varepsilon_{1}, \varepsilon_{2 t}$ e $\varepsilon_{3 t}$ podem ser identificados a partir das estimativas de $e_{t t}, e_{2 t}, e_{3 t}$ e da matriz de variância/covariância. Um modo alternativo de modelar a relação entre os erros de previsão e as inovações estruturais é:

$$
\begin{aligned}
& e_{1 t}=\varepsilon_{1 t}+c_{13} \varepsilon_{3 t} \\
& e_{2 t}=c_{21} \varepsilon_{1 t}+\varepsilon_{2 t} \\
& e_{3 t}=c_{32} \varepsilon_{2 t}+\varepsilon_{3 t}
\end{aligned}
$$

Pode-se notar a ausência de estrutura triangular. A condição necessária para a exata identificação de $\mathbf{B}$ é satisfeita uma vez que tem-se três restrições $[(9-3) / 2=3]$. 
Assim, a proposta de Sims (1980) e Bernanke (1986) permite que as relações contemporâneas sejam estabelecidas com base na teoria econômica. Modelos superidentificados podem também ser estimados.

Um ponto que merece ser chamado a atenção diz respeito ao uso da metodologia VAR-estrutural no ajustamento dos modelos de exportação. Essa modelagem permite, asseguradas as restrições de identificação, que mais de uma variável seja tomada como endógena, pois na matriz de relações contemporâneas é possível considerar efeito mútuo entre duas variáveis. Em suma, a metodologia Var-estrutural pode ser usada para representar sistemas de equações simultâneas definidos quando existe uma interdependência contemporânea entre preços e exportação.

\subsubsection{Análise de co-integração}

O conceito de co-integração relaciona processos não-estacionários com a noção de equilíbrio de longo prazo. Como já discutido, os modelos de regressão utilizando séries de dados não estacionárias podem gerar resultados espúrios. Espera-se que, se $y_{t}$ e $x_{t}$ são variáveis não estacionárias I(1), sua diferença ou uma combinação linear delas como, por exemplo, $e_{t}=y_{1}-\beta_{1}-\beta_{2} x_{1}$, seja igualmente I(1). No entanto, nos casos em que $e_{t}=y_{t}-\beta_{1}-\beta_{2} x_{t}$ é um processo $\mathrm{I}(0)$, as variáveis $y_{t}$ e $x_{t}$ são chamadas cointegradas (Hill et al., 2003). De outra forma, tem-se um vetor de co-integração $(1-\beta)^{\prime}$ se $e_{t}$ é estacionário, cuja ordem de integração é $I(d-b)$, onde $b>0$.

Essa relação de equilíbrio de longo prazo entre variáveis não-estacionárias implica que essas variáveis compartilham tendências estocásticas semelhantes, uma vez que $e$, (desvio do equilíbrio) é estacionário. Isso significa que tais variáveis não se movem independentemente umas das outras. Em decorrência disso, apenas diferenciar todas as variáveis não-estacionárias usadas na análise de regressão seria, nesse contexto, incorreto, gerando uma má especificação do modelo (Enders, 1996). Engle \& Granger 
(1987), propuseram a inclusão de um componente que recupera este desvio da trajetória de longo prazo das variáveis nos modelos em que elas são usadas nas diferenças. A esse componente, que nada mais é do que o resíduo da regressão da equação de co-integração defasado, deram o nome de termo de correção de erro.

No entanto, quando se utilizam mais de duas variáveis no modelo a utilização do método de Engle e Granger pode gerar problemas. Isto ocorreria devido a possibilidade de existência de múltiplos vetores de co-integração, caso em que o resultado produzido por este procedimento seria uma combinação linear dos diferentes vetores de cointegração, e de existência de endogeneidade dos regressores. Para contornar esse problema, o procedimento de Johansen (1988) tem sido utilizado para testar cointegração entre as variáveis.

Considerando um modelo com $n$-variáveis representado por:

$$
\Delta \mathrm{x}_{\mathrm{X}}=\Gamma_{0}-\pi \mathrm{x}_{-1}+\Gamma_{1} \Delta \mathrm{x}_{-2}+\ldots+\Gamma_{2} \Delta \mathrm{x}_{-2}+\ldots+\Gamma_{\mathrm{p}} \Delta \mathrm{x}_{-\mathrm{p}}+\varepsilon_{\mathrm{t}}
$$

onde $\Gamma_{0}$ é um vetor $\left(\begin{array}{lll}n & x & l\end{array}\right)$ de termos de intercepto com os elementos $\Gamma_{\mathbf{i} 0}, \boldsymbol{\Gamma}_{i}$ é uma matriz $(n \times n)$ de coeficientes com os elementos $\boldsymbol{\Gamma}_{\mathbf{j k}}(\mathbf{i}), \boldsymbol{\pi}$ é a matriz com os elementos $\pi_{j k}$ tal que um ou mais dos $\pi_{j k} \neq 0$ e $\varepsilon_{\mathrm{t}}$ é um vetor $(n \times l)$ com os elementos $\varepsilon_{j l}$. Se todas as variáveis em $x_{t}$ forem $\mathrm{I}(1)$ e se houver uma representação de correção de erros dessas variáveis como na equação (96), haverá uma combinação linear das variáveis I(1) que é estacionária. Resolvendo a equação (96) para $\pi x_{t-1}$, obtém-se:

$$
\pi \mathbf{X}_{-1}=\Delta \mathbf{x}-\pi_{0}-\sum \pi_{i} \Delta \mathbf{X}_{-i}-\varepsilon_{r}
$$

Sendo cada expressão do lado direito estacionária, $\pi x_{t-1}$ será necessariamente estacionária. Cada linha de $\pi$ gera um vetor de co-integração de $x_{t}$. Assim, um modelo de correção de erro para variáveis I(1) implica em co-integração. 
Johansen (1988) propôs usar o rank de $\pi$ para determinar se as variáveis em $\left\{x_{t}\right\}$ são ou não co-integradas. Para tanto, considera-se um modelo VAR multivariado de primeira ordem com $n$ variáveis:

$$
\mathbf{x}_{\mathbf{t}}=\mathbf{A}_{1} \mathbf{x}_{\mathrm{t}-1}+\varepsilon_{\mathrm{t}}
$$

Subtraindo $\mathbf{x}_{t-1}$ de cada lado da equação obtém-se:

$$
\begin{aligned}
& x_{t}-x_{t-1}=A_{1} x_{t-1}-x_{t-1}+\varepsilon_{t} \\
& \Delta x_{t}=\left(A_{1}-I\right) x_{t-1}+\varepsilon_{t} \\
& \Delta x_{t}=\pi x_{t-1}+\varepsilon_{t}
\end{aligned}
$$

onde $\mathbf{x}_{\mathbf{t}}$ e $\varepsilon_{l}$ são vetores $(n \times 1), \mathbf{A}_{\mathbf{I}}$ são matrizes de parâmetros $(n \times n)$, I é uma matriz identidade $(n \times n)$ e $\pi$ é definido como sendo $\left(\mathbf{A}_{1}-\mathbf{I}\right)$. O rank de $\pi$ é igual ao número de vetores de co-integração. Essa equação pode ser modificada para incluir intercepto,

$$
\Delta \mathbf{x}_{t}=A_{0}+\pi x_{t-1}+\varepsilon_{t}
$$

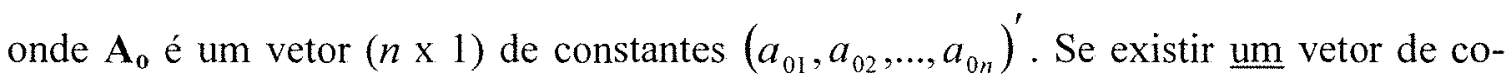
integração, tem-se:

$$
\pi_{11} x_{1 t-1}+\pi_{12} x_{2 t-1}+\ldots+\pi_{1 n} x_{n t-1}=0
$$

Adicionalmente, podem-se incluir termos sazonais: 


$$
\Delta x_{t}=A_{0}+\pi x_{t-1}+\psi D_{t}+\varepsilon_{t}
$$

$\Psi$ é uma matriz $(n \times(f-1))$ e $\mathbf{D}_{\mathbf{t}}$ é uma matriz $((f-1) \times 1)$.

O efeito de incluir as constantes é permitir a presença de uma tendência linear no processo gerador das séries temporais. No caso de binárias sazonais, o rank de $\pi$ pode ser visto como o número de relações de co-integração de uma série desazonalizada.

Um intercepto pode ser incluído no vetor de co-integração. Considerando-se um sistema de $n+l$ variáveis, deixando todos os valores de $\left(x_{n+1,1}=1, x_{n+1,2}=1, \ldots\right)$ tem-se que:

$$
\Delta \mathbf{x}_{t}=\pi^{*} \mathbf{x}^{*}-1+\varepsilon_{t}
$$

Onde:

$$
x_{t-1}^{*}=\left(x_{1 t-1}, x_{2 t-1}, \ldots, x_{n t-1,1}\right)
$$

e,

$$
\pi^{*}=\left[\begin{array}{ccccc}
\pi_{11} & \pi_{12} & \ldots & \pi_{1 n} & \pi_{10} \\
\pi_{21} & \pi_{22} & \ldots & \pi_{2 n} & \pi_{20} \\
\cdot & \cdot & \cdot & \cdot \\
\pi_{m 1} & \pi_{n 1} & \pi_{m m} & \pi_{n 0}
\end{array}\right]
$$

Aqui os vetores de co-integração têm a forma:

$$
\begin{aligned}
& \pi_{11} x_{1 t-1}+\pi_{12} x_{2 t-1}+\ldots+\pi_{1 n} x_{n t-1}+\pi_{10}=0 \\
& \pi_{21} x_{1 t-1}+\pi_{22} x_{2 t-1}+\ldots+\pi_{2 n} x_{n t-1}+\pi_{20}=0
\end{aligned}
$$


Generalizando (98) e incluindo um termo representando a constante e um representando variáveis não estocásticas tem-se:

$$
\mathbf{x}_{\mathbf{t}}=\mathrm{A}_{1} \mathbf{x}_{\mathbf{t}-\mathrm{1}}+\ldots+\mathrm{A}_{\mathrm{k}} \mathbf{x}_{\mathrm{t}-\mathrm{k}}+\mathrm{A}_{\mathbf{0}}+\boldsymbol{\psi} \mathrm{D}_{\mathrm{t}}+\varepsilon_{\mathrm{t}} \quad t=1, \ldots, \mathrm{T}
$$

na qual $\mathbf{x}_{t}$ é um vetor $\left(\begin{array}{lll}p & \mathrm{x} & 1\end{array}\right)$ de variáveis estocásticas e $\mathbf{D}_{t}$ é um vetor de variáveis não estocásticas (binárias).

Assume-se que todas as variáveis são I(1):

$$
\Delta \mathbf{x}_{\mathrm{t}}=\Gamma_{1} \Delta \mathbf{x}_{\mathrm{t}-1}+\ldots+\Gamma_{\mathrm{k}-1} \Delta \mathbf{x}_{\mathrm{t}-\mathrm{k}+1}+\Pi \mathbf{x}_{\mathrm{t}-1}+\mathrm{A}_{0}+\psi \mathrm{D}_{\mathrm{t}}+\varepsilon_{\mathrm{t}}
$$

O número de vetores de co-integração é obtido identificando-se a significância das raízes características de $\boldsymbol{\Pi}$. Sabe-se que o rank da matriz é igual ao número de raízes característica diferentes de zero. Suponha-se que tenha sido obtida a matriz $\boldsymbol{\Pi}$ e suas raízes características foram ordenadas, de tal forma que $\lambda_{1}>\lambda_{2}>\ldots>\lambda_{n}$.

O teste para o número de raízes características que são estatisticamente diferentes de zero pode ser conduzido da seguinte forma:

$$
\begin{aligned}
& \lambda_{\text {traso }}(r)=-T \sum_{i=r+1}^{n} \ln \left(1+\hat{\lambda}_{i}\right) \\
& \left.\lambda_{\max }=(r, r+1)\right)=-T \ln \left(1-\hat{\lambda}_{r+1}\right)
\end{aligned}
$$

onde $\hat{\lambda}_{i}$ são os valores estimados das raizes características obtidas das estimativas da matriz II ; e $T$ é o número de observações usadas no ajustamento.

Se existem $r$ vetores de co-integração, apenas $r$ combinações lineares das variáveis são estacionárias, sendo as demais combinações lineares não-estacionárias. 
Se as variáveis não são co-integradas, o rank de $\Pi$ é zero. Desde que $\ln (1)=0$ cada uma das expressões $\ln \left(1-\lambda_{i}\right)$ será igual a zero se as variáveis não forem cointegradas. Se o rank da matriz $\Pi$ é um, a primeira expressão $\ln \left(1-\lambda_{i}\right)$ é negativa e as demais $\ln \left(1-\lambda_{2}\right)=\ln \left(1-\lambda_{3}\right)=\ldots=\ln \left(1-\lambda_{n}\right)=0$.

\subsection{O modelo econômico proposto}

Aproximadamente $70 \%$ do açúcar exportado pelo Brasil é do tipo bruto, produzido especificamente para o mercado externo. O restante, denominado açúcar branco (inclui o açúcar cristal e o refinado), tem como destino tanto o mercado interno como o externo. Observando-se o perfil de demanda dos dois principais importadores de açúcar brasileiro - Rússia e países árabes e africanos em conjunto, observa-se, como já comentado no Capítulo 2, que estes diferem bastante em relação ao tipo de açúcar demandado, bruto ou branco. No ano de 2003, por exemplo, 99,68\% do açúcar comprado pela Rússia do Brasil eram do tipo bruto e apenas $0,32 \%$ do tipo branco. Por outro lado, os percentuais de açúcar do tipo branco e do tipo bruto demandados pelo mercado Árabe e africano em seu conjunto no mesmo período foram praticamente equivalentes, 50,03\% e 49,97\%, respectivamente (Brasil, 2004).

Dadas as diferenças existentes no mercado de açúcar bruto e branco, optou-se por especificar modelos econômicos diferenciados por tipo de açúcar demandado. $\mathrm{O}$ principal destino do açúcar bruto é a Rússia, enquanto que o do açúcar branco é o conjunto de países árabes e africanos.

\subsubsection{Modelo proposto para o açúcar branco}

Como mencionado, a produção brasileira de açúcar do tipo branco pode ter como destino tanto o mercado doméstico, como o mercado externo. Então, para o caso do açúcar branco, considerou-se um modelo no qual se pressupõe que a quantidade de 
açúcar branco que o Brasil oferta no mercado externo é um excedente do mercado doméstico, uma definição próxima à proposta por Miranda (2001) e Barros (2002). Dessa forma, o modelo especificado permite avaliar a influência das condições do mercado interno sobre a quantidade de açúcar branco ofertado pelo País no mercado internacional.

O modelo proposto para as exportações de açúcar branco é descrito a seguir:

No mercado doméstico tem-se:

$$
\begin{aligned}
& S=f(p d, p b) \\
& D=g(p d, y b)
\end{aligned}
$$

Onde:

$S$ é a quantidade ofertada de açúcar branco no mercado doméstico

$D$ é a quantidade demandada de açúcar branco no mercado doméstico

$p d$ é o preço doméstico do açúcar branco brasileiro $(\mathrm{R} \$)$

$y b$ é a renda do Brasil

$p b$ é o preço de exportação do açúcar branco brasileiro (R\$)

Considerando-se que preço recebido pelo exportador é $p b=p x c$, onde $p x$ é o preço de exportação em moeda estrangeira e $c$ é a taxa de câmbio nominal, a função (109) pode ser re-escrita como:

$$
S=f(p d, p x, c)
$$

No mercado externo tem-se: 


$$
\begin{aligned}
& X_{S}=S-D=f(p d, p x, c)-g(p d, y b)=h(p d, p x, c, y b) \\
& X_{D}=m(p x, p w, y w)
\end{aligned}
$$

Onde:

$X_{S}$ é a quantidade ofertada de açúcar branco pelo Brasil no mercado externo $X_{D}$ é a quantidade demandada de açúcar branco do Brasil no mercado externo $c$ é a taxa de câmbio (R\$/US\$) $y w$ é o deslocador da demanda externa pelo açúcar brasileiro $p w$ é o preço do açúcar dos concorrentes do Brasil no mercado internacional

No mercado externo em equilíbrio, as vendas externas de açúcar obedecem à igualdade:

$$
X^{*}=X_{S}=X_{D}
$$

Em que $X^{*}$ representa a quantidade de equilíbrio negociada no mercado externo, ou, simplesmente, as vendas externas do Brasil.

Substituindo-se as expressões (112) e (113) na igualdade (114) obtém-se:

$$
X^{*}=h(p d, p x, c, y b)=m(p x, p w, y w)
$$

De forma que o preço de equilíbrio para as vendas externas $X^{*}$ é uma função dada por:

$$
p x=p(p d, y b, c, p w, y w)
$$

e a função de vendas externas para o açúcar branco é dada por: 


$$
X^{*}=\gamma(p d, y b, c, p w, y w)
$$

A renda dos países Árabes e africanos é utilizada como deslocadora da demanda externa pelo açúcar branco brasileiro, uma vez que esses países são os principais importadores dessa commodity brasileira.

A seguir será apresentado o modelo especificado para as exportações de açúcar branco, buscando identificar os sinais esperados para os coeficientes da equação.

Iniciando com um modelo em sua forma mais geral, assume-se que o equilíbrio das vendas externas do açúcar branco brasileiro $\left(X^{*}\right)$ é dado por:

$$
X^{*}=X_{S_{t}}=X_{D_{t}}
$$

onde $X_{S}$ são as vendas externas de açúcar do Brasil e $X_{D}$ é a demanda pelo açúcar brasileiro.

As funções (110) e (111) podem ser expressas por:

$$
\begin{aligned}
& \log S_{t}=a_{0}+a_{1} \log p d_{t}+a_{2} \log p x_{t}+a_{3} \log c_{t}+u_{1 t} \\
& \log D_{t}=b_{0}+b_{1} \log p d_{t}+b_{2} \log y b_{t}+u_{2 t}
\end{aligned}
$$

Como discutido anteriormente, a transformação logarítmica da série permite obter resultados diretamente na forma de elasticidades e soluciona o problema da variância crescente ao longo da série.

A função de oferta de exportação do açúcar branco brasileiro, representada em (112), pode ser estimada pela equação:

$$
\log X_{S t}=a_{0}+a_{1} \log p d+a_{2} \log p b_{t}+u_{1 t}-\left[b_{0}+b_{1} \log p d_{t}+b_{2} \log y b_{t}+u_{2 t}\right]
$$


$=\left(a_{0}-b_{0}\right)+\left(a_{1}-b_{1}\right) \log p d_{t}+a_{2} \log p x_{t}+a_{3} \log c_{t}-b_{2} \log y b_{t}+\left(u_{1 t}-u_{2 t}\right)$

A eq. (121) representa a oferta externa de açúcar branco do Brasil e expressa as condições do mercado interno.

A função (113), que representa a demanda externa pelo açúcar do Brasil em situação de demanda não perfeitamente elástica, pode ser expressa por:

$\log X_{D t}=g_{0}+g_{1} \log p x_{t}+g_{2} \log p w_{t}+g_{3} \log y w_{t}+\tau_{t}$

Substituindo-se as eq. (121) e (122) na igualdade (118), tem-se:

$$
\begin{aligned}
& \left(a_{0}-b_{0}\right)+\left(a_{1}-b_{1}\right) \log p d_{t}+a_{2} \log p x_{t}+a_{3} \log c-b_{2} \log y b_{t}+\left(u_{1 t}-u_{2 t}\right) \\
& =g_{0}+g_{1} \log p x_{t}+g_{2} \log p w_{t}+g_{3} \log y w_{t}+\tau_{1 t}
\end{aligned}
$$

Ao isolar $p x$, no lado esquerdo da equação e re-arranjar os termos chega-se a equação que representa o preço de equilíbrio das vendas externas do açúcar brasileiro:

$$
\log p x_{t}=h_{0}+h_{1} \log p w_{t}+h_{2} \log y w_{t}-h_{3} \log p d_{t}-h_{4} \log c_{t}+h_{5} \log y b_{t}-\rho_{t}
$$

Onde:

$$
\begin{aligned}
& h_{0}=\left(g_{0}-a_{0}+b_{0}\right) /\left(a_{2}-g_{1}\right) \\
& h_{1}=g_{2} /\left(a_{2}-g_{1}\right) \\
& h_{2}=g_{3} /\left(a_{2}-g_{1}\right) \\
& h_{3}=\left(a_{1}-b_{1}\right) /\left(a_{2}-g_{1}\right) \\
& h_{4}=a_{3} /\left(a_{2}-g_{1}\right) \\
& h_{5}=b_{2} /\left(a_{2}-g_{1}\right) \\
& \rho_{t}=\left(\tau_{1}+u_{1}-u_{2}\right) /\left(a_{2}-g_{1}\right)
\end{aligned}
$$


Substituindo-se (123) em (122), chega-se à equação que foi estimada para as vendas externas de açúcar branco pelo Brasil,

$$
\log x_{t}=m_{0}+m_{1} \log p w_{t}+m_{2} \log y w_{t}-m_{3} \log p d_{t}-m_{4} \log c_{t}+m_{5} \log y b_{t}+v_{1 t}
$$

Onde:

$$
\begin{aligned}
& m_{0}=g_{0}+h_{0} g_{\mathrm{I}} \\
& m_{1}=g_{1} h_{1}+g_{2} \\
& m_{2}=g_{1} h_{2}+g_{3} \\
& m_{3}=g_{1} h_{3} \\
& m_{4}=g_{1} h_{4} \\
& m_{5}=g_{1} h_{5} \\
& v_{t}=g_{1} \rho_{1}+\tau_{11}
\end{aligned}
$$

Espera-se que haja uma relação positiva entre a quantidade exportada de açúcar branco e as variáveis: renda dos países Árabes e Africanos em seu conjunto, com a taxa de câmbio e com o preço do açúcar branco dos países concorrentes, e uma relação negativa com o preço doméstico do açúcar branco e com a renda do Brasil. O preço doméstico é uma variável que representa excesso ou escassez de produto no mercado doméstico. Quando há excesso, o preço doméstico cai e as exportações aumentam, ocorrendo o inverso no caso de preços altos.

$$
S x=f(y w, \overline{y b}, \bar{p} w, \bar{c}, \overline{p d})
$$

Finalmente, especificar um modelo VAR utilizando um número elevado de variáveis explicativas, notadamente quando se tem disponível um número reduzido de observações, como é o caso desse estudo, pode comprometer a qualidade dos resultados obtidos. Por essa razão, optou-se por não incluir no modelo final a variável que 
representa o preço do açúcar branco dos concorrentes do Brasil no mercado internacional $\left(p w_{t}\right)$.

\subsubsection{Modelo proposto para exportações de açúcar bruto}

Uma vez que, como mencionado, o açúcar bruto brasileiro é destinado exclusivamente ao mercado externo, propõe-se, nesse caso, um modelo baseado na definição das curvas de oferta e demanda de exportação.

A equação de oferta de exportação para o açúcar brasileiro pode ser representada por:

$$
\log x_{t}=\alpha_{0}+\alpha_{1} \log p x_{t}+\alpha_{2} \log c_{t}+\alpha_{3} \log p d_{t}+\mu_{1 t}
$$

Onde:

$x_{t}$ é a quantidade ofertada de açúcar bruto pelo Brasil

$p x_{t}$ é o preço de exportação de açúcar bruto do Brasil (US\$)

$c_{t}$ é a taxa de câmbio

$p d$, é o preço doméstico do açúcar branco $(\mathrm{R} \$)$

$\mu_{1 t}$ é o erro aleatório

Sendo: $\alpha_{1}>0, \alpha_{2}>0$ e $\alpha_{3}<0$.

Considera-se que os preços internos do açúcar branco determinam, em algum grau, a quantidade exportada de açúcar bruto, existindo flexibilidade por parte das usinas em produzir um ou outro tipo de açúcar. De outro lado, pressupõe-se que a alocação da cana-de-açúcar para a produção de açúcar e álcool é feita de forma relativamente independente dos preços desses produtos, existindo outros fatores que interferem na definição do percentual que será destinado a um e a outro produto, conforme discute Alves (2002). Dessa forma, o preço do álcool não foi incluído na eq. (126), da mesma forma que ele não foi considerado na definição da eq. (109). 
A equação de demanda pelas exportações brasileiras de açúcar bruto, por sua vez, é dada por:

$$
\log x_{t}=\beta_{0}+\beta_{1} \log p x_{t}+\beta_{2} \log y w_{t}+\beta_{3} \log p w_{t}+\mu_{2}
$$

Onde:

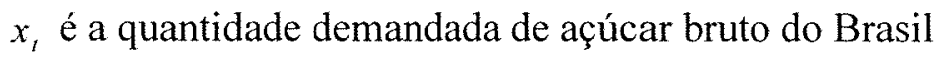

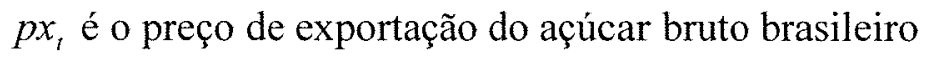
$y w$, é o deslocador da demanda externa pelo açúcar bruto do Brasil ( renda externa)

$p w_{t}$ é o preço do açúcar bruto dos concorrentes do Brasil no mercado internacional $\mu_{2,}$ é o erro aleatório

Sendo: $\beta_{1}<0, \beta_{2}>0$ e $\beta_{3}>0$. Resolvendo a equação (127) para o preço de exportação $(p x)$ tem-se:

$$
\log p x_{t}=\frac{x_{t}}{\beta_{1}}-\frac{\beta_{0}}{\beta_{1}}-\frac{\beta_{2}}{\beta_{1}} \log y w_{t}-\frac{\beta_{3}}{\beta_{1}} \log p w_{t}-\frac{\mu_{1}}{\beta_{1}}
$$

Substituindo-se (128) em (127) encontra-se a forma reduzida para a quantidade exportada de açúcar bruto:

$$
\log x_{t}=a_{0}-a_{1} \log y w_{t}-a_{2} \log p w_{1}+a_{3} \log c_{t}+a_{4} \log p d_{t}-\varepsilon_{1}
$$


Onde:

$$
\begin{array}{lll}
a_{0}=\frac{\alpha_{0}-\alpha_{1} \frac{\beta_{0}}{\beta_{1}}}{1-\frac{\alpha_{1}}{\beta_{1}} ;} & a_{1}=\frac{\alpha_{1} \frac{\beta_{2}}{\beta_{1}}}{1-\frac{\alpha_{1}}{\beta_{1}}} ; & a_{2}=\frac{\alpha_{1} \frac{\beta_{3}}{\beta_{1}}}{1-\frac{\alpha_{1}}{\beta_{1}}} \\
a_{3}=\frac{\alpha_{2}}{1-\frac{\alpha_{1}}{\beta_{1}} ;} & a_{4}=\frac{\alpha_{3}}{1-\frac{\alpha_{1}}{\beta_{1}}} ; & \varepsilon=\frac{\frac{\alpha_{1} \mu_{2}}{\beta_{1}}+\mu_{1}}{1-\frac{\alpha_{1}}{\beta_{1}}}
\end{array}
$$

Dessa forma, a quantidade exportada pelo Brasil de açúcar bruto depende do nível de renda externa, do preço do açúcar bruto dos países concorrentes no mercado internacional, da taxa de câmbio e de um deslocador da oferta doméstica de açúcar bruto, no caso, o preço doméstico do açúcar branco. Uma variável representativa da renda da Rússia foi utilizada como deslocadora da demanda externa pelo açúcar bruto brasileiro, uma vez que esse país é o principal importador desse tipo de açúcar do Brasil.

Espera-se que haja uma relação positiva entre a quantidade exportada de açúcar bruto e as variáveis: renda da Rússia, preço do açúcar bruto dos países concorrentes, e taxa de câmbio, e uma relação negativa com o preço doméstico do açúcar branco.

$$
S x=D x=f(\stackrel{+}{+}, \stackrel{+}{+}, \stackrel{+}{c}, \vec{p} d)
$$

Vale chamar a atenção, novamente nesse caso, para o problema de graus de liberdade para o ajustamento do modelo VAR. Dado o reduzido número de observações optou-se por excluir do modelo final a variável que representa o preço do açúcar bruto dos concorrentes do Brasil no mercado internacional, $p w_{t}$.

Embora no presente trabalho a opção tenha sido ajustar uma equação reduzida para quantidade, seria possível considerar também uma situação na qual o preço do produto exportado em moeda estrangeira fosse incluído no modelo de exportação, como 
feito por Carvalho \& Negri (2000). No entanto, por problemas associados ao número reduzido de observações na amostra, optou-se por não incluí-la na modelagem. Ademais, espera-se que o efeito da variação do preço externo sobre as exportações de açúcar seja bastante semelhantes ao efeito de uma variação cambial, uma vez que as duas variáveis interferem diretamente no preço efetivo recebido pelo exportador. No estudo de Barros et al. (2002) foram obtidas elasticidades de exportação praticamente iguais para o preço externo e câmbio. Essa sistemática seria factível uma vez que a modelagem VAR permite, como já mencionado, que respeitadas as condições de identificação da matriz de relações contemporâneas, sejam considerados os efeitos mútuos contemporâneos entre as variáveis do modelo. Assim, mesmo pressupondo endogeneidade do preço, a metodologia VAR permite a inclusão dessa variável no modelo.

A opção feita por se trabalhar com modelos VAR e não uniequacionais ou sistemas de equações simultâneas justifica-se em função de a primeira abordagem permitir a identificação, de uma forma mais direta, da duração do efeito de um choque nas variáveis do sistema, o que a torna bastante atraente para o ajustamento de modelos que tratam de comércio internacional.

\subsubsection{Fonte dos dados}

Nos Quadros 4 e 5 são apresentadas as fontes dos dados utilizados para compor as variáveis descritas nos modelos econômicos propostos para o açúcar bruto e branco, respectivamente. $\mathrm{O}$ presente estudo utilizou-se de dados trimestrais para o período compreendido entre o quarto trimestre de 1995 e o quarto trimestre de 2003.

Todas as análises de séries temporais foram realizadas utilizando-se o programa Regression Analysis Time Series (RATS), versão 4.0. 


\begin{tabular}{|ll|}
\hline Variáveis & Definição das variáveis e fontes dos dado \\
\hline Equação de exportação ajustada para o açúcar brutôt \\
$x \quad$ Volume exportado de açúcar bruto. O índice de quantum exportado de \\
açúcar bruto pelo Brasil foi calculado a partir de dados obtidos via \\
Sistema AliceWeb do Ministério do Desenvolvimento, Indústria e \\
Comércio Exterior (Brasil, 2004); \\
Renda da Rússia. Utilizou-se como proxy para essa variável um indice de \\
importações totais. Para compor esse índice, fez-se o cálculo da \\
participação percentual anual da Rússia nas importações totais do mundo \\
no período em análise, dados em valores absolutos divulgado pela FAO \\
(2004). Então, procedeu-se à multiplicação desse percentual pelos valores \\
em US\$ das importações totais mundiais trimestrais, dados do Fundo \\
Monetário Internacional Monetário Internacional (FMI) e divulgados \\
pelo Instituto de Pesquisa Econômica Aplicada (IPEA) (2004b); \\
Taxa de câmbio. Dado obtido junto ao IPEA (2004a). Calculou-se a \\
média simples trimestral para os valores mensais da "Taxa de câmbio \\
nominal - R\$ / US\$ -valor de compra"; \\
Preço doméstico. Foram utilizados os valores mensais do preço do açúcar \\
cristal recebido pelo produtor no Estado de São Paulo, dados obtidos \\
junto ao Centro de Estudos Avançados em Economia Aplicada \\
(CEPEA/ESALQ). Esses dados foram deflacionados pelo Índice Geral de \\
Preços (IGP-DI) da Fundação Getúlio Vargas (FGV) e, por meio de \\
média simples, trimestralizados (IPEA, 2004d). \\
pd
\end{tabular}

Quadro 3 - Definição das variáveis utilizadas no modelo ajustado para o açúcar bruto e fontes de dados 


\begin{tabular}{|ll|}
\hline Variáveis & Definição das variáveis e fontes dos dado \\
\hline Equação de exportação ajustada para o açúcar branco \\
Volume exportado de açúcar branco. O índice de quantum exportado de \\
açúcar branco pelo Brasil foi calculado a partir de dados obtidos via \\
Sistema AliceWeb do Ministério do Desenvolvimento, Indústria e \\
Comércio Exterior (Brasil, 2004). \\
Renda dos países Árabes e Africanos. Utilizou-se como proxy para essa \\
variável um índice de importações totais. Para compor esse índice, fez-se o \\
cálculo da participação percentual anual desses países nas importações \\
totais do mundo no período em análise, dados em valores absolutos \\
divulgado pela FAO (2004). Então, procedeu-se à multiplicação desse \\
percentual pelos valores em US\$ das importações totais mundiais \\
trimestrais, dados do Fundo Monetário Internacional Monetário \\
Internacional (FMI) e divulgados pelo IPEA (2004b). \\
Taxa de câmbio. Dado obtido junto ao IPEA (2004a). Calculou-se a média \\
simples trimestral para os valores mensais da "Taxa de câmbio nominal - \\
R\$ / US\$ -valor de compra" \\
Preço doméstico. Foram utilizados os valores mensais do preço do açúcar \\
cristal recebido pelo produtor no estado de São Paulo, dados obtidos junto \\
ao Centro de Estudos Avançados em Economia Aplicada \\
(CEPEA/ESALQ). Esses dados foram deflacionados pelo Índice Geral de \\
Preços (IGP-DI) da Fundação Getúlio Vargas e, por meio de média \\
simples, trimestralizados (IPEA, 2004d). \\
Renda do Brasil. Foi utilizado um índice do Produto Interno Bruto (PIB) a \\
preços de mercado. Dado (trimestral) fornecido pelo IPEA (IPEAc, 2004). \\
Os valores foram deflacionados pelo IGP-DI. \\
$p d \quad$
\end{tabular}

Quadro 4 - Definição das variáveis utilizadas no modelo ajustado para o açúcar branco e fontes de dados 


\section{RESULTADOS E DISCUSSÕES}

O presente capítulo, que se destina a apresentar os principais resultados obtidos na pesquisa, está dividido em dois subcapítulos. No primeiro subcapítulo são apresentados os resultados dos testes de raiz unitária (para uma raiz) e, ou, ordem de integração das séries de dados e de co-integração. No segundo subcapítulo, que está dividido em duas seções, são realizadas as análises dos modelos de auto-regressão vetorial para o quantum de exportação de açúcar bruto e branco. Na primeira seção desse subcapítulo são analisados os resultados do modelo VAR ajustado para o quantum exportado de açúcar bruto pelo Brasil, e na segunda seção são discutidos os resultados do modelo VAR ajustados para o quantum de açúcar branco exportado pelo Brasil. $\mathrm{Na}$ Tabela 15 é apresentada a nomenclatura utilizada para as variáveis incluídas nos modelos ajustados para o açúcar branco e bruto.

Os testes de Akaike (AIC) e Schwarz (SC) foram os utilizados para a determinação do número de defasagens (ordem do processo auto-regressivo) a ser inclúdo no modelo estimado para testar a presença de raiz unitária. Quando os resultados desses testes divergiam, buscou-se especificar o modelo seguindo o critério da parcimônia, desde que respeitado o pressuposto de ausência de auto-correlação de resíduos, indicada pelo teste $Q$ de Ljung Box. 
Tabela 15. Descrição das variáveis utilizadas na pesquisa

\begin{tabular}{ll}
\hline Variável & \multicolumn{1}{c}{ Definição } \\
\hline $\ln Y r$ & Logaritmo neperiano da renda da Rússia \\
$\ln \mathrm{Ya}$ & Logaritmo neperiano renda dos países árabes e africanos \\
LnYb & Logaritmo neperiano da renda do Brasil \\
$\ln \mathrm{Pd}$ & Logaritmo neperiano preço doméstico do açúcar \\
$\ln \mathrm{Xbrut}$ & Logaritmo neperiano das exportações brasileiras de açúcar bruto \\
$\ln \mathrm{Xbco}$ & Logaritmo neperiano das exportações brasileiras de açúcar branco \\
$\ln \mathrm{C}$ & Logaritmo neperiano da taxa de câmbio nominal \\
\hline
\end{tabular}

\subsection{Testes de raiz unitária}

De acordo com os resultados apresentados na Tabela 16 , tem-se que a variável $\operatorname{lnC}$ é descrita por um processo auto-regressivo de ordem um [(AR1)], enquanto as variáveis $\operatorname{lnYa}$ e $\ln \mathrm{Pd}$ são descritas por um processo auto-regressivo de ordem dois [(AR2)]. A variável lnXbrut é descrita por um processo auto-regressivo de ordem três [(AR3)] e a variável InYr por um processo auto-regressivo de ordem quatro [(AR4)]. Finalmente, as séries $\ln \mathrm{Yb}$ e $\ln \mathrm{Xbco}$ são descritas por um processo auto-regressivo $[(\mathrm{AR} 5)]$ e $[(\mathrm{AR} 6)]$, respectivamente.

Procedeu-se aos testes de raiz unitária (para uma raiz) utilizando-se o procedimento proposto em Enders (1995), descrito no subcapítulo 3.1.1. A recomendação geral é que os modelos sejam considerados inicialmente na sua forma mais geral, incluindo constante e tendência, e que estes termos sejam eliminados progressivamente quando forem não significativos.

Os resultados dos testes de Dickey-Fuller aumentado (ADF) estão também apresentados na Tabela 16 e indicam que as series $\ln Y a, \ln P d$ e $\ln X b c o$ são estacionárias em nível. Por outro lado, os resultados do Modelo 1 para as demais séries apontaram a existência de raiz unitária. Repetindo-se o ajustamento para verificar se essas séries são estacionárias quando analisadas nas primeiras diferenças (Modelo 2), verificou-se que 
todos os coeficientes são significativos, rejeitando-se a hipótese nula de raiz unitária. Dessa forma, considera-se que as variáveis $\ln \mathrm{Yr}, \ln \mathrm{Yb}, \ln \mathrm{Xbrut}$, e $\ln \mathrm{C}$ são integradas de ordem um $[I(1)]$ e na especificação do modelo VAR devem ser consideradas nas diferenças de primeira ordem.

Tabela 16. Resultados dos testes de raiz unitária de Dickey-Fuller Aumentado (ADF)

\begin{tabular}{lccccccc}
\hline Variáveis & $\begin{array}{c}\text { Valor } \\
\text { de } \rho-1\end{array}$ & \multicolumn{7}{c}{ Modelo 1 } & & Modelo 2 \\
& & $\tau_{\tau}$ & $\tau_{\beta \tau}$ & $\tau_{\mu}$ & $\tau_{\alpha \mu}$ & $\tau$ & $\tau$ \\
\hline $\ln Y r$ & 3 & $-0,70$ & 1,48 & $-1,26$ & 1,25 & $-0,23$ & $-5,11^{*}$ \\
$\ln Y a$ & 1 & $-4,42^{*}$ & 3,45 & - & - & - & - \\
$\ln \mathrm{Yb}$ & 4 & $-2,13$ & $-2,11$ & $-0,88$ & 0,87 & $-0,95$ & $-2,69^{*}$ \\
$\ln \mathrm{Pd}$ & 1 & $-3,16$ & 0,99 & $-3,01^{* *}$ & 2,99 & - & - \\
$\ln \mathrm{Xbrut}$ & 2 & $-3,26$ & 2,42 & $-1,99$ & 2,05 & 0,04 & $-6,08^{*}$ \\
$\ln \mathrm{Xbco}$ & 5 & $-3,79 * *$ & 2,12 & - & - & - & - \\
$\ln \mathrm{C}$ & 0 & $-1,82$ & 1,23 & $-1,46$ & 1,48 & 0,43 & $-4,93^{*}$ \\
\hline
\end{tabular}

Fonte: dados da pesquisa

*Significativo ao nível de $1 \%$

** Significativo ao nível de $5 \%$

Modelo $1=\Delta x_{t}=\alpha+\beta t+\gamma x_{t-1}+\sum_{i=1}^{p-1} \lambda \Delta x_{t-1}+\varepsilon_{t}$, nas versões com constante e tendência, sem tendência e sem constante e tendência;

Modelo $2=\Delta \Delta x_{t}=\gamma \Delta x_{t-1}+\sum_{i=1}^{p-2} \lambda_{i} \Delta \Delta x_{t-1}+\varepsilon_{t}$

Nota: não houve presença de auto-correlação serial, conforme teste $Q$ de Ljung Box. 
Considerou-se que esses resultados representam sinalizações pouco precisas em função do pequeno número de observações das séries, uma vez que os testes de raiz unitária requerem grandes amostras. Os resultados obtidos para a função de autocorrelação também não foram decisivas em indicar estacionariedade das séries.

\subsection{Resultado dos modelos de auto-regressão vetorial para o quantum de exportação de açúcar bruto e branco}

Diante da falta de uma definição clara a respeito da estacionariedade das séries, optou-se por testar três especificações diferentes para cada um dos modelos propostos: $i$ ) considerando-se que todas as variáveis do modelo são estacionárias em nível; ii) testando-se uma especificação na qual as variáveis são tomadas em nível ou nas diferenças, conforme o resultado do teste de raiz unitária apresentado na Tabela 16. Nesse caso, seguindo Lima (1997), quando duas ou mais variáveis presentes no modelo são integradas de ordem $1[I(1)]$ procede-se aos testes de co-integração. Quando os resultados dos testes de Máximo Auto-valor e, ou, teste do Traço apontam para a existência de vetor(es) de co-integração, um VAR com correção de erro deve ser ajustado; por último, iii) os mesmos modelos são ajustados considerando-se todas as variáveis em primeiras diferenças. Também nesse caso, um VAR com correção de erro é ajustado na medida em que os resultados dos testes de co-integração indicam existência de relações de longo prazo entre as variáveis dos modelos.

Em linhas gerais, considerou-se que resultados dos ajustamentos para os casos $(i)$ e (ii) acima não se mostraram consistentes, uma vez que o efeito dos choques não desapareceram no tempo, como esperado. Então, optou-se por apresentar os resultados apenas do caso (iii), em que todas as séries são tomadas em diferenças e o modelo incluiu um termo de correção de erro. 


\subsubsection{Equação de exportação para o quantum de açúcar bruto}

Dois testes foram usados para se determinar o número de relações de cointegração existentes entre as variáveis em estudo, quais sejam, os testes do Traço e do Máximo autovalor ( ${ }^{\lambda}$ máx ). De acordo com os resultados da Tabela 17, ambos os testes apontam para a rejeição da hipótese nula de não co-integração. Apenas no caso em que se testou a hipótese alternativa $(r=1)$ contra a hipótese nula $(r \leq 0)$ observou-se que o valor calculado é maior que o valor crítico. Sendo assim, um único vetor de cointegração foi considerado no ajustamento do VEC - modelo de correção de erro.

Tabela 17. Resultados dos testes de co-integração de Johansen entre as séries lnXbrut, $\ln \mathrm{Pd}, \ln \mathrm{C}$ e $\ln \mathrm{Yr}$

\begin{tabular}{cccc}
\hline Hipótese Nula & $\begin{array}{c}\text { Hipótese } \\
\text { Alternativa }\end{array}$ & $\lambda_{\text {máx }}$ & Traço \\
\hline$r \leq 3$ & $r=4$ & 3,83 & 3,83 \\
$r \leq 2$ & $r=3$ & 7,52 & 11,35 \\
$r \leq 1$ & $r=2$ & 12,41 & 23,75 \\
$r \leq 0$ & $r=1$ & $41,48^{*}$ & $65,34^{*}$ \\
\hline
\end{tabular}

Fonte: dados da pesquisa

* Significativo a 5\% de significância [valores críticos em Osterwald-Lenun (1992)]. Modelo com drift, ajustado com duas defasagens.

As estimativas da matriz de coeficientes de relações contemporâneas estão apresentados na Tabela 18. Os sinais dos coeficientes estão de acordo com o esperado (estes devem ser analisados ao contrário dos apresentados), sendo não significativa a relação entre a quantidade de açúcar bruto exportada (lnXbrut) e o preço doméstico (lnPd). Os demais resultados mostraram-se estatisticamente significativos. Verifica-se que um aumento em $1 \%$ na renda da Rússia causa um aumento contemporâneo de 
aproximadamente $0,90 \%$ nas exportações brasileiras do açúcar bruto. Da mesma forma, um aumento em $1 \%$ na taxa de câmbio implica um aumento de pouco mais de $2 \%$ na quantidade exportada desse produto pelo Brasil.

Tabela 18. Estimativa da matriz de coeficientes de relações contemporâneas ${ }^{1}$

\begin{tabular}{|c|c|c|c|}
\hline \multicolumn{2}{|c|}{ Relações } & \multirow[t]{2}{*}{ Coeficientes } & \multirow[t]{2}{*}{ Desvio padrão } \\
\hline Linha & Coluna & & \\
\hline $\operatorname{lnXbrut}$ & $\ln Y r$ & $-0,8976$ & 0,4867 \\
\hline InXbrut & $\ln P d$ & 0,0674 & 0,3396 \\
\hline InXbrut & $\ln C$ & $-2,0179$ & 0,7087 \\
\hline
\end{tabular}

Fonte: dados da pesquisa

$\mathrm{Na}$ Tabela 19 apresentam-se os resultados da decomposição da variância do erro de previsão, os quais, como já discutido anteriormente, permitem avaliar o poder explanatório de cada variável do modelo sobre as demais. Optou-se por destacar apenas os resultados para a variável que representa as exportações brasileiras de açúcar bruto e considerar, como período de análise, apenas oito trimestres após o choque, uma vez que os valores se estabilizam a partir de então.

Observa-se que a maior parte das variações na quantidade exportada de açúcar bruto é explicada pela própria variável, cuja média chegou a quase $71 \%$ no período. É interessante notar também que o poder explanatório da variável preço doméstico sobre quantum exportado de açúcar bruto é baixo contemporaneamente, mas aumenta ao longo do tempo, passando a explicar, a partir do segundo trimestre, de 11,56 a $12,37 \%$ do total das variações na quantidade exportada de açúcar bruto. $O$ inverso ocorreu com as variáveis renda da Rússia e taxa de câmbio, as quais foram mais importantes que o preço doméstico no primeiro trimestre, mas logo a partir do segundo trimestre têm seu poder

\footnotetext{
${ }^{1}$ Dado que as séries foram tomadas em primeiras diferenças, os coeficientes encontrados referem-se a relações entre taxas de crescimento, genericamente denominadas elasticidades.
} 
explanatório reduzido. Ao longo do período analisado, as variáveis renda da Rússia e taxa de câmbio explicam, em média, 6,3\% e 12,5\% das variações nas exportações de açúcar bruto, respectivamente.

Tabela 19. Decomposição histórica da variância do erro de previsão para a quantidade exportada de açúcar bruto

\begin{tabular}{cccccc}
\hline Trimestre & $\begin{array}{c}\text { Desvio- } \\
\text { padrão }\end{array}$ & \multicolumn{4}{c}{ Decomposição da variância devida a choques (\%) } \\
& $\ln$ (n)co & $\operatorname{lnYr}$ & $\ln P d$ & $\ln$ \\
\hline 1 & 0,326 & 72,495 & 8,026 & 0,093 & 19,386 \\
2 & 0,403 & 68,504 & 6,457 & 12,368 & 12,671 \\
3 & 0,419 & 70,282 & 6,098 & 11,857 & 11,763 \\
4 & 0,426 & 70,959 & 6,034 & 11,563 & 11,444 \\
5 & 0,430 & 71,113 & 6,019 & 11,599 & 11,269 \\
6 & 0,431 & 71,209 & 5,989 & 11,598 & 11,204 \\
7 & 0,432 & 71,255 & 5,979 & 11,588 & 11,178 \\
8 & 0,432 & 71,272 & 5,975 & 11,586 & 11,167 \\
\hline
\end{tabular}

Fonte: dados da pesquisa

Nas figuras de 3 a 5 são analisados os impactos que um choque em cada variável do sistema causa sobre si mesma e nas demais variáveis do modelo nos períodos seguintes ao que ocorreu o choque.

Os resultados indicam que o efeito de uma variação na renda da Rússia sobre o quantum exportado de açúcar bruto é positivo e expressivo no primeiro trimestre. Uma variação de $1 \%$ na renda da Rússia provoca, logo no primeiro trimestre, um aumento de aproximadamente $0,9 \%$ na quantidade exportada de açúcar bruto. Esse também é o caso da variável taxa de câmbio, a qual apresenta um efeito mais expressivo no primeiro período, provocando um aumento na quantidade exportada de açúcar de pouco mais de $2 \%$. Em relação ao preço doméstico, tem-se que o maior efeito de um choque nessa 
variável sobre a quantidade exportada ocorre no segundo trimestre, variação negativa de $0,95 \%$. Em todos os casos, os efeitos dos choques deixam de ser expressivos após o quarto período.

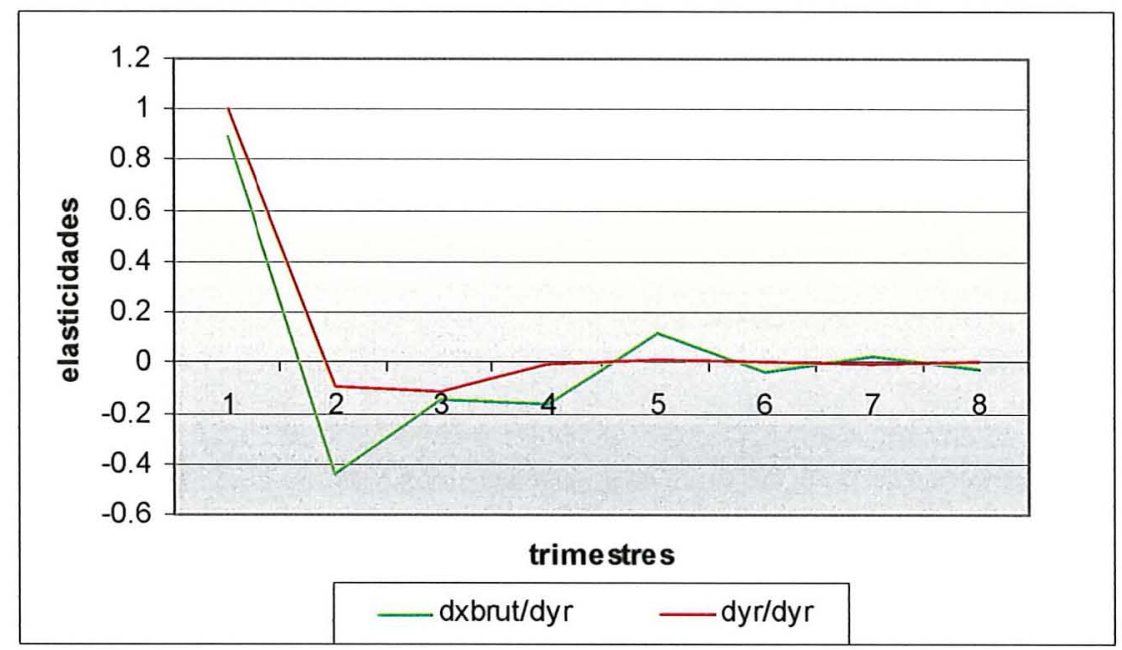

Figura 4 - Função de resposta das exportações de açúcar bruto (lnXbrut.) a um impulso na renda da Rússia $(\ln Y r)$

Fonte: dados da pesquisa

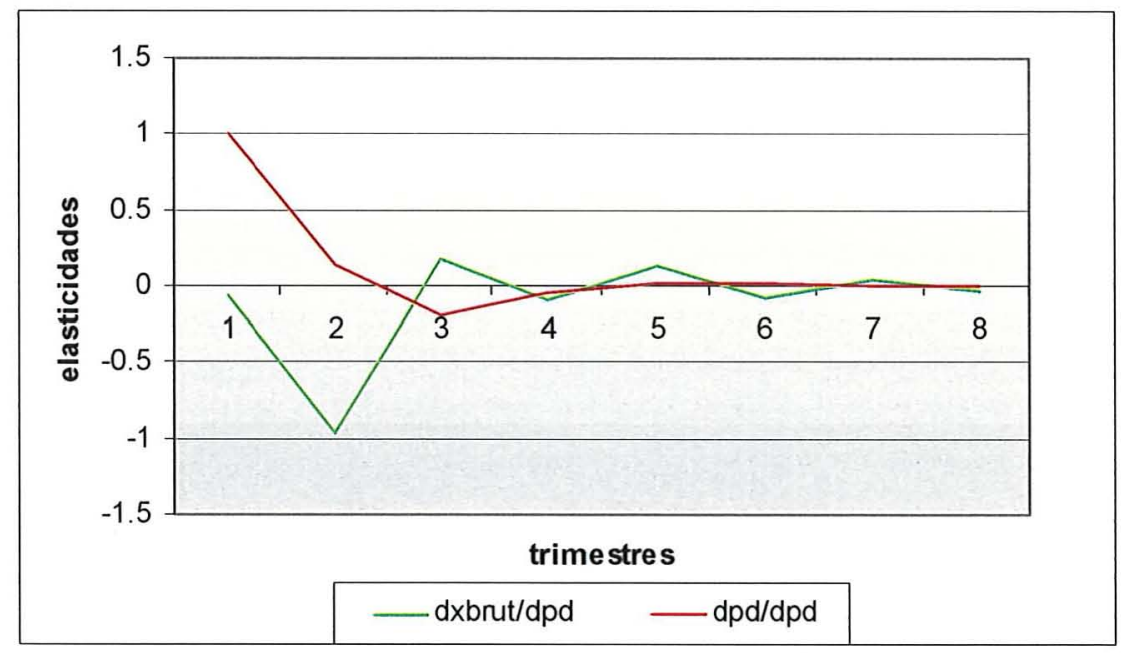

Figura 5 - Função de resposta das exportações de açúcar bruto (lnXbrut.) a um impulso no preço doméstico do açúcar (lnPd)

Fonte: dados da pesquisa 


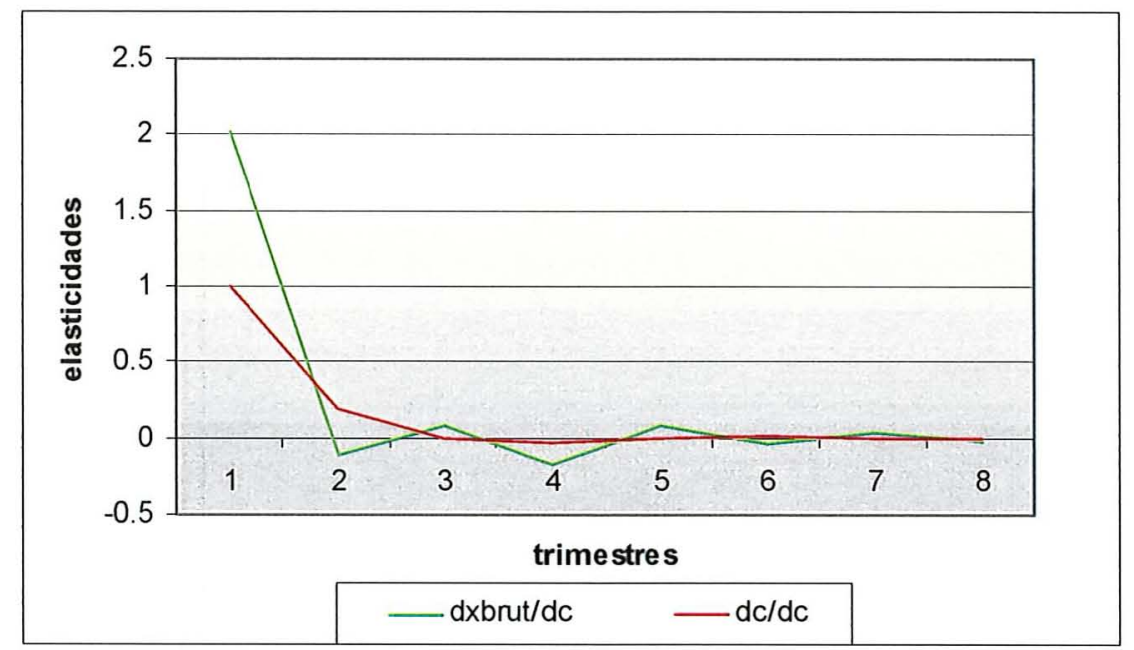

Figura 6 - Função de resposta das exportações de açúcar bruto (lnXbrut.) a um impulso na taxa de câmbio $(\operatorname{lnC})$

Fonte: dados da pesquisa

\subsubsection{Equação de exportação para o quantum de açúcar branco}

Nessa seção são discutidos os resultados do modelo ajustado para a análise das exportações de açúcar branco, em que todas as variáveis do modelo foram consideradas como sendo integradas de ordem 1 [I(1)] pelos motivos expostos anteriormente quando se discutiu os resultados do modelo ajustado para o açúcar bruto. Os testes do Traço e do Máximo autovalor ( ${ }^{\lambda}$ máx ) foram novamente usados para se determinar o número de relações de co-integração existentes entre as variáveis em estudo. Os resultados desses testes encontram-se na Tabela 20. Observa-se que ambos os testes apontam para a rejeição da hipótese nula de não co-integração. Apenas no caso em que se testou a hipótese alternativa $(r=1)$ contra a hipótese nula $(r \leq 0)$ observou-se que o valor calculado é maior que o valor crítico. Dessa forma, um único vetor de co-integração foi considerado no ajustamento do modelo VEC. 
Tabela 20. Resultados dos testes de co-integração de Johansen entre as séries lnXbco, $\ln \mathrm{Pd}, \ln \mathrm{C}, \ln \mathrm{Ya}$ e $\ln \mathrm{Yb}$

\begin{tabular}{cccc}
\hline Hipótese Nula & $\begin{array}{c}\text { Hipótese } \\
\text { Alternativa }\end{array}$ & $\lambda_{\text {máx }}$ & Traço \\
\hline$r \leq 4$ & $r=5$ & 3,27 & 3,27 \\
$r \leq 3$ & $r=4$ & 4,89 & 8,16 \\
$r \leq 2$ & $r=3$ & 12,91 & 21,07 \\
$r \leq 1$ & $r=2$ & 21,93 & 42,99 \\
$r \leq 0$ & $r=1$ & $37,27^{*}$ & $80,26^{*}$ \\
\hline
\end{tabular}

Fonte: dados da pesquisa

* Significativo a 5\% de significância [valores críticos em Osterwald-Lenun (1992)]. Modelo com drift, ajustado com duas defasagens

A Tabela 21 traz os resultados das estimativas da matriz de coeficientes de relações contemporâneas. Os sinais dos coeficientes estão de acordo com o esperado, exceto para o caso da variável renda do Brasil, $\ln Y b$. O coeficiente dessa variável é também o único significativo. A série do Produto Interno Bruto (PIB), utilizada como proxy para representar a renda do Brasil deve estar captando mais o crescimento da economia brasileira, que esteve nos últimos anos baseado fortemente em exportações, do que o aumento do consumo interno em função da renda. É preciso salientar que, devido à inexistência de dados trimestrais para PIB per capita, buscou-se também ajustar este modelo utilizando outras variáveis representativas dos rendimentos dos consumidores. Nesse caso, os resultados obtidos foram semelhantes aos fornecidos anteriormente utilizando-se o PIB. Por último, a Tabela 21 mostra também que o coeficiente da variável câmbio, apesar de ser não significativo, tem o valor do teste $t$ maior que a unidade. Se isso indicar que o coeficiente foi ajustado com alguma precisão pode-se inferir que um aumento em $1 \%$ na taxa de câmbio implica no aumento de $1,2 \%$ na quantidade exportada de açúcar branco. 
É importante mencionar que o teste $t$ no caso dos modelos VAR não têm um rigor expressivo na indicação da significância estatística do coeficiente.

Tabela 21. Estimativa da matriz de coeficientes de relações contemporâneas

\begin{tabular}{lccc}
\hline & Relações & Coeficientes & Desvio padrão \\
Linha & Coluna & & \\
\hline $\operatorname{lnXbco}$ & $\operatorname{lnYa}$ & $-0,2336$ & 1,6764 \\
$\operatorname{lnXbco}$ & $\ln \mathrm{d}$ & 0,1188 & 0,4363 \\
$\operatorname{lnXbco}$ & $\operatorname{lnYb}$ & $-7,5744$ & 2,0439 \\
$\operatorname{lnXbco}$ & $\operatorname{lnC}$ & $-1,2023$ & 1,1493 \\
\hline
\end{tabular}

Fonte: dados da pesquisa

Os resultados da decomposição da variância do erro de previsão para o presente modelo se encontram na Tabela 24 . Observa-se que quase metade das variações na quantidade exportada de açúcar branco, média de $48,3 \%$ no período, é explicada pela própria variável. Vale notar ainda, que as variáveis de mercado interno, renda do Brasil e preço doméstico, explicam em média $29,95 \%$ e $11,38 \%$ das variações na quantidade exportada de açúcar branco, respectivamente. Por outro lado, as variáveis de mercado externo, taxa de cambio e renda dos países Árabes e Africanos têm baixo poder explanatório médio, $6,22 \%$ e 4,15\%, respectivamente. Esse resultado corrobora a hipótese de que as exportações de açúcar branco dependem em grande parte das condições domésticas.

Finalmente, as figuras de 6 a 9 trazem os efeitos de choques nas variáveis que compõem o modelo de vendas externas de açúcar branco. Na Figura 6, observa-se que uma variação de $1 \%$ na variável lnYa provoca, só após quatro trimestres, uma variação positiva na quantidade exportada (da ordem de $0,82 \%$ ). No segundo e terceiro trimestres esse efeito é negativo, fato não esperado e que pode ter ocorrido em função da proxy utilizada, que se constitui numa agregação de dados de diversos países. A Figura 7 
mostra que o efeito de uma variação na variável preço doméstico tem efeito expressivo no quantum exportado de açúcar branco já no segundo trimestre, uma variação negativa de 1,27\%, perdendo importância a partir do terceiro trimestre. Na Figura 8 tem-se que um choque na renda do Brasil implica um efeito positivo e expressivo apenas contemporaneamente. Uma variação em $1 \%$ na renda do Brasil provoca contemporaneamente um aumento de $7,57 \%$ na quantidade exportada. Finalmente, na Figura 9, observa-se que o maior efeito de um choque na taxa de cambio sobre o quantum exportado de açúcar branco ocorre no terceiro trimestre, uma variação de aproximadamente $1,5 \%$.

Tabela 22. Decomposição histórica da variância do erro de previsão para a quantidade total exportada de açúcar branco

\begin{tabular}{ccccccc}
\hline Trimestre & Desvio & \multicolumn{5}{c}{ Decomposição da variância devida a choques (\%) } \\
& Padrão & $\operatorname{lnXbco}$ & $\operatorname{lnYr}$ & $\ln P d$ & $\ln \mathrm{Yb}$ & $1 \mathrm{C}$ \\
\hline 1 & 0,43 & 56,77 & 0,07 & 0,16 & 39,17 & 3,83 \\
2 & 0,49 & 51,26 & 0,59 & 14,12 & 31,11 & 2,92 \\
3 & 0,52 & 47,02 & 4,98 & 12,86 & 28,21 & 6,93 \\
4 & 0,52 & 46,55 & 5,56 & 12,73 & 28,19 & 6,97 \\
5 & 0,52 & 46,24 & 5,52 & 12,78 & 28,25 & 7,20 \\
6 & 0,52 & 46,16 & 5,52 & 12,79 & 28,24 & 7,29 \\
7 & 0,52 & 46,16 & 5,53 & 12,79 & 28,23 & 7,29 \\
8 & 0,52 & 46,16 & 5,53 & 12,79 & 28,23 & 7,29 \\
\hline
\end{tabular}

Fonte: dados da pesquisa 


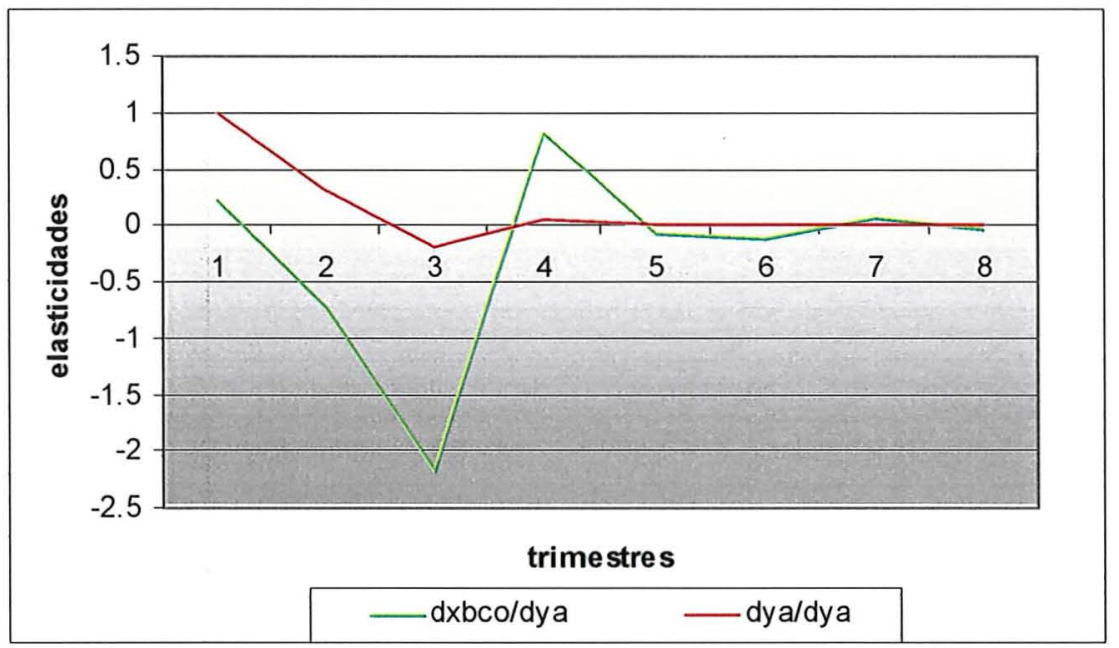

Figura 7 - Função de resposta das exportações de açúcar branco (lnXbco) a um impulso na renda dos países árabes e Africanos (lnYa) Fonte: dados da pesquisa

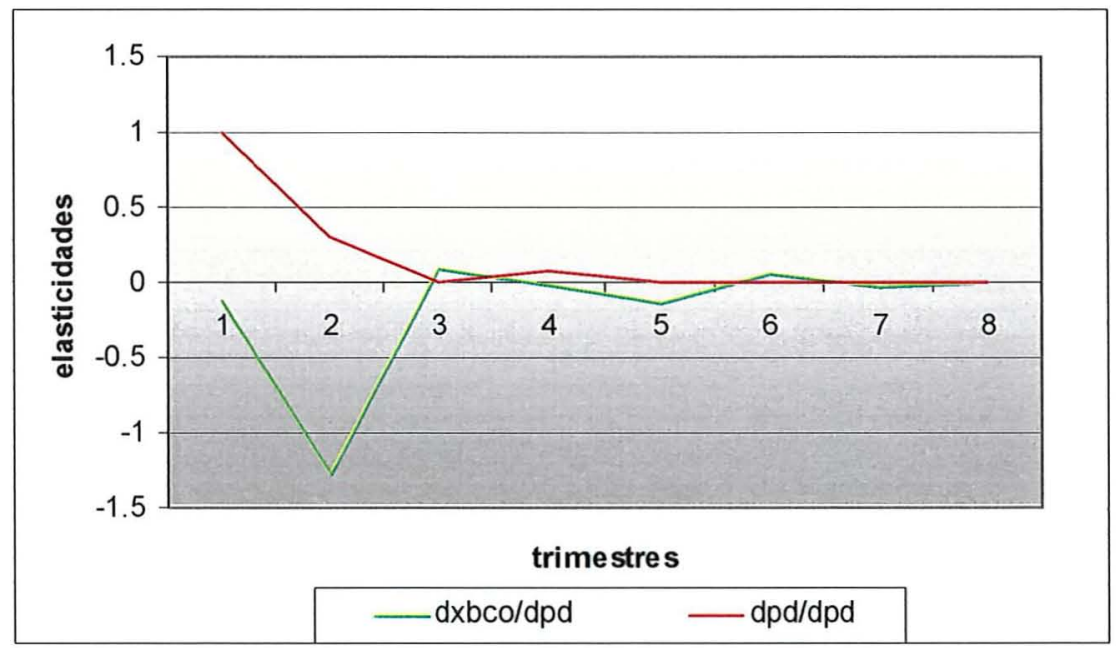

Figura 8 - Função de resposta das exportações de açúcar branco (lnXbco) a um impulso no preço doméstico do açúcar (lnPd)

Fonte: dados da pesquisa 


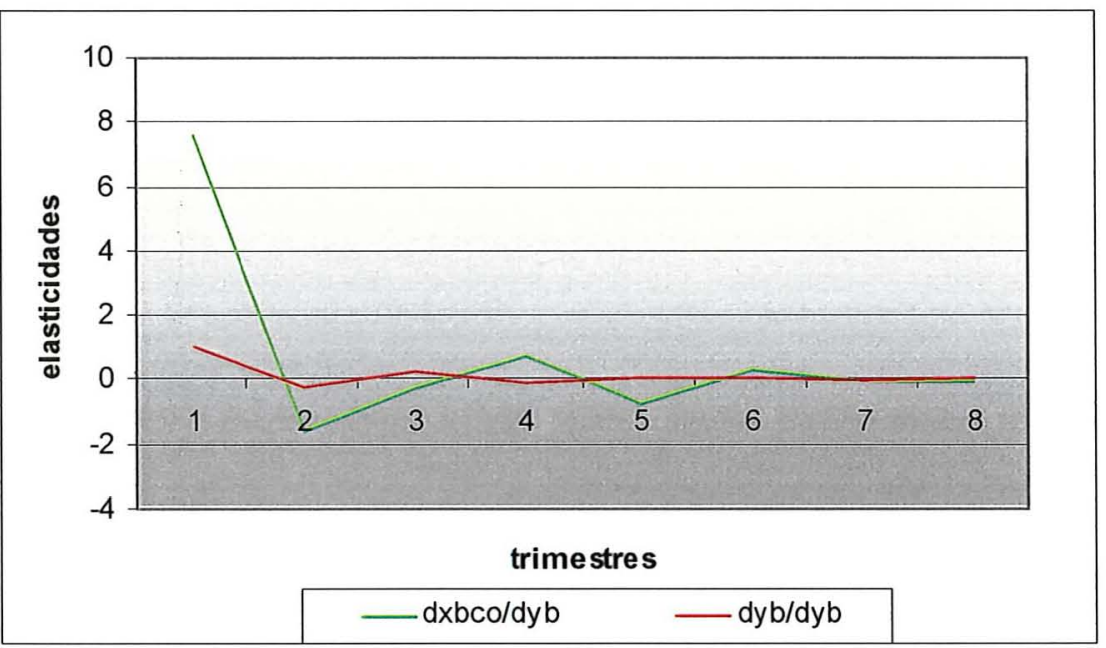

Figura 9 - Função de resposta das exportações de açúcar branco (lnXbco) a um impulso na renda do Brasil $(\ln Y b)$

Fonte: dados da pesquisa

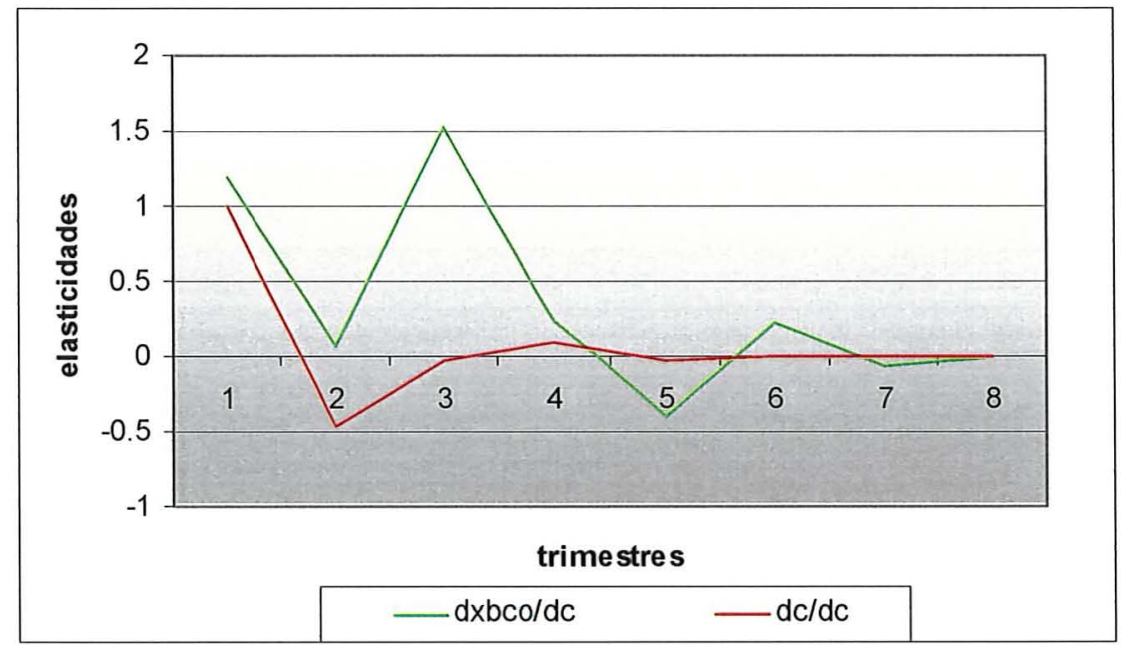

Figura 10 - Função de resposta das exportações de açúcar branco (lnXbco) a um impulso na taxa de câmbio $(\operatorname{lnC})$

Fonte: dados da pesquisa 


\section{CONCLUSÕES}

O objetivo deste estudo consistiu na estimação de equações de exportação que expliquem o comércio internacional do açúcar brasileiro, com a finalidade de identificar as determinantes do desempenho exportador dessa commodity. As estimativas foram feitas a partir de dados trimestrais para o período compreendido entre o quarto trimestre de 1995 e o quarto trimestre de 2003. Diferentemente da maior parte dos estudos realizados anteriormente sobre esse setor, propôs-se a definição e o ajustamento de equações de exportação diferenciadas por tipo de açúcar: bruto e branco. Foram consideradas na análise a renda dos principais mercados importadores do açúcar brasileiro, a saber: a Rússia, para o caso do açúcar bruto, e um grupo de nove países Árabes e Africanos tomados em seu conjunto, para o caso do açúcar branco. A metodologia utilizada foi a de Auto-regressão Vetorial com correção de erro (VEC).

A elevada competitividade do açúcar brasileiro no mercado internacional ficou evidente a partir de meados dos anos 90. Esse fato se deve aos expressivos incrementos de produtividade apresentados pelo setor na última década, notadamente pelos produtores da região Centro-Sul. Isso ocorreu em função dos avanços tecnológicos experimentados pelo setor desde o início dos anos 90, decorrente do processo de desregulamentação por que ele passou no mesmo período. Desde então, as exportações brasileiras tanto de açúcar bruto como do açúcar branco têm aumentado sua importância relativa na geração de divisas para o País ao longo do período analisado.

O presente trabalho proporcionou estimativas de elasticidades das exportações com respeito às variáveis: taxa de câmbio, preço doméstico do açúcar, renda dos países importadores e renda do Brasil. Esses resultados possibilitam a interpretação do desempenho das exportações brasileiras de açúcar bruto e branco ao longo do período 
analisado e podem auxiliar os agentes ligados ao setor sucroalcooleiro na tomada de decisões sobre produção e comercialização.

Uma vez que a produção doméstica de açúcar bruto se destina exclusivamente ao mercado externo e a Rússia é o principal destino para esse produto ajustou-se um modelo reduzido baseado na definição das curvas de oferta e demanda de exportação, incluindo a renda da Rússia como a variável deslocadora da demanda externa por esse produto. Da mesma forma, dado que os países Árabes e africanos são os principais demandantes do açúcar branco incluiu-se a renda desses países na função de demanda por exportações. No caso do açúcar branco, o modelo de exportação foi definido de forma a considerar as condições internas, uma vez que esse produto é também consumido no mercado doméstico.

Diante da falta de uma definição clara a respeito da estacionariedade ou não das séries, optou-se por testar três especificações diferentes para cada um dos modelos propostos e escolher para a análise aquela que mostrasse convergência dos efeitos de choques na função de impulso resposta, o que é esperado que ocorra em caso de séries estacionárias: i) tomando todas as variáveis do modelo como estacionárias em nível; ii) tomando as variáveis em nível ou em diferenças, conforme indicava o resultado do teste de raiz unitária; e iii) tomando todas as variáveis em primeiras diferenças. Tanto no caso "ii" como no caso "iii", um modelo VAR com correção de erro foi ajustado na medida em que os resultados dos testes de co-integração indicaram existência de relação de longo prazo entre as variáveis dos modelos.

Concluiu-se que o modelo mais consistente para explicar o quantum exportado de açúcar do tipo bruto e do tipo branco foi o "iii", em que todas as séries foram tomadas em diferenças e o modelo incluiu um termo de correção de erro. Os ajustamentos para os casos " $i$ " e "il" não se mostraram consistentes, uma vez que o efeito dos choques não desaparece no tempo.

Em termos gerais, os resultados da pesquisa mostraram que existem diferentes condicionantes do desempenho exportador do açúcar bruto e branco. De um lado, as exportações de açúcar bruto dependem essencialmente das condições de mercado externo; de outro, as exportações de açúcar branco respondem mais fortemente aos 
fatores de mercado interno. Isso se deve ao fato de o açúcar bruto ser produzido exclusivamente para o mercado externo, enquanto o açúcar branco é também comercializado no mercado doméstico.

As estimativas da matriz de coeficientes de relações contemporâneas no modelo estimado para o açúcar bruto apresentaram sinais consistentes, sendo estatisticamente não significativa a relação entre a quantidade de açúcar bruto exportada e o preço doméstico. Os demais resultados mostraram-se estatisticamente significativos. Verificou-se que um aumento em $1 \%$ na renda da Rússia causa um aumento contemporâneo de aproximadamente $0,90 \%$ nas exportações brasileiras do açúcar bruto. Da mesma forma, um aumento em $1 \%$ na taxa de câmbio implica um aumento de pouco mais de $2 \%$ na quantidade exportada desse produto pelo Brasil.

Os resultados da decomposição da variância do erro de previsão para o quantum de açúcar bruto exportado pelo Brasil evidenciaram um aspecto importante da relação entre o preço doméstico do açúcar e as exportações de açúcar bruto. Observou-se que o poder explanatório da variável preço doméstico sobre quantum exportado de açúcar bruto, apesar de baixo contemporaneamente, aumenta ao longo do período analisado. Esse resultado se deve à flexibilidade do produtor entre produzir açúcar bruto para exportação e o açúcar branco para o mercado doméstico. Isso significa que um aumento no preço doméstico de açúcar, decorrente de uma quebra de safra, por exemplo, aparece como uma determinante importante na decisão futura sobre o mix de produção do setor. Por outro lado, as variáveis renda da Rússia e taxa de câmbio apresentam-se como mais importantes no primeiro trimestre, tendo o seu poder explanatório diminuído logo a partir do segundo trimestre.

A avaliação dos impactos de choques de uma variável sobre as demais evidenciou a importância da taxa de câmbio nominal sobre o quantum exportado de açúcar bruto. Uma variação de $1 \%$ na taxa de câmbio provoca um aumento na quantidade exportada de açúcar bruto em um pouco mais de $2 \%$ no primeiro trimestre. Da mesma forma, uma variação na renda da Rússia sobre o quantum exportado de açúcar bruto é positivo e expressivo no primeiro trimestre. Uma variação de $1 \%$ na renda da Rússia provoca, logo no primeiro período, um aumento de aproximadamente $0,9 \%$ na 
quantidade exportada de açúcar bruto. No caso da variável preço doméstico, o maior efeito de um choque nessa variável sobre a quantidade exportada de açúcar bruto ocorre no segundo trimestre, uma variação negativa de $0,95 \%$. Em todos os casos, os efeitos dos choques deixam de ser expressivos após o quarto trimestre.

Em relação ao modelo ajustado para as exportações brasileiras de açúcar branco, os sinais da matriz de relações contemporâneas estão de acordo com o esperado exceto para o caso da variável renda do Brasil. No entanto, a escolha da série do Produto Interno Bruto (PIB) como proxy para representar essa variável deve provavelmente estar captando mais o crescimento da economia brasileira, que esteve nos últimos anos baseado fortemente em exportações, do que o aumento do poder aquisitivo da população brasileira. Buscou-se também ajustar este modelo utilizando outras variáveis representativas dos rendimentos dos consumidores, no entanto, os resultados obtidos foram semelhantes aos fornecidos utilizando-se o PIB. Vale ressaltar, ainda, que o coeficiente da variável câmbio, apesar de ter sido não significativo, apresentou o valor do teste $t$ maior que a unidade, o que permitiu concluir pela existência de alguma relação entre ela e o quantum exportado de açúcar branco. Um aumento em $1 \%$ na taxa de câmbio implica no aumento de 1,2\% na quantidade exportada de açúcar branco.

De acordo com os resultados da decomposição da variância do erro de previsão para este modelo, observou-se que aproximadamente metade das variações na quantidade exportada de açúcar branco, média de 48,3\% no período, é explicada pela própria variável. As variáveis de mercado interno, renda do Brasil e preço doméstico, explicam em média $29,95 \%$ e $11,38 \%$ das variações na quantidade exportada de açúcar branco, respectivamente. Por outro lado, as variáveis de mercado externo, taxa de câmbio e renda dos países Árabes e Africanos, têm baixo poder explanatório, 6,22\% e $4,15 \%$, respectivamente. Este resultado reforça o pressuposto de que as exportações de açúcar branco dependem de forma expressiva das condições domésticas, uma vez que esse produto é consumido no mercado interno.

Os resultados dos efeitos de choques de uma variável sobre as demais indicam que uma variação de $1 \%$ na variável renda dos Árabes e Africanos, só após quatro trimestres, provoca uma variação positiva na quantidade exportada de açúcar branco (da 
ordem de $0,82 \%$ ), fato não esperado. Em relação à variável preço doméstico, tem-se a indicação que um choque nessa variável tem um efeito expressivo sobre o quantum exportado de açúcar branco já no segundo trimestre, uma variação negativa de 1,27\%, perdendo importância a partir do terceiro trimestre. Um choque na variável renda do Brasil implica um efeito positivo e expressivo apenas contemporaneamente. Finalmente, observou-se que o maior efeito de um choque na taxa de câmbio sobre o quantum exportado de açúcar branco ocorre no terceiro trimestre, uma variação aproximada de $1,5 \%$.

O presente trabalho teve como limitação o fato de ter contado com um reduzido número de observações para o ajustamento dos modelos propostos, em função da indisponibilidade de dados para variável preço doméstico em período anterior ao definido. Esse fato tornou impossível a inclusão de variáveis que, em tese, seriam importantes para explicar o quantum exportado de açúcar, como o preço do açúcar dos concorrentes do Brasil no mercado internacional desse produto, por exemplo. A despeito disso, no entanto, considera-se que o objetivo principal do presente trabalho, identificar os impactos de importantes condicionantes do desempenho exportador do açúcar brasileiro, foi alcançado.

Sugere-se, para pesquisas futuras, o uso dessa mesma metodologia para analisar as condicionantes do preço recebido pelo exportador de açúcar, as quais têm influência na rentabilidade dos agentes do setor. 


\section{REFERÊNCIAS BIBLIOGRÁFICAS}

ABBOTT, G.C. Suggar. New York: Routledge, 1990. 396p.

ALVES, L.R.A. Transmissão de preços entre produtos do setor sucroalcooleiro do Estado de São Paulo. Piracicaba, 2002. 106p. Dissertação (MS) - Escola Superior de Agricultura "Luiz de Queiroz", Universidade de São Paulo.

ALVES, L.R.A.; BACCHI, M.R.P. Oferta de exportação de açúcar do Brasil. Revista de Economia e Sociologia Rural, v.42, n.1, p.9-33, jan./mar. 2004.

AMAZONAS, A.; BARROS, A.R. Manufactured exports from Brazil: determinants and consequences. Revista Brasileira de Economia, v.50, n.1, p.73-100, jan./mar. 1995.

BACCHI, M.R.P.; ALVES, L.R.A.; SILVEIRA, A.M. Exportações brasileiras de açúcar: um modelo de auto-regressão vetorial (compact disc). In: CONGRESSO BRASILEIRO DE ECONOMIA E SOCIOLOGIA RURAL, 40., Passo Fundo, 2002. Anais. Brasília: SOBER, 2002.

BARROS, G.S. de C.; BACCHI, M.R.P.; BURNQUIST, H.L. Estimação de equações de oferta de exportação de produtos agropecuários para o Brasil (1992/2000). Rio de Janeiro: IPEA, 2002. 51p. (Texto para discussão, 865)

BERNANKE, B.S. Alternative explanations of the money-income correlation. Carnegie Rochester Conference Séries on Public Policy, v.25, p.49-100, 1986.

BRAGA, H.C.; MARKWALD, R.A. Funções de oferta e de demanda das exportações de manufaturados no Brasil: estimação de um modelo simultâneo. Pesquisa e Planejamento Econômico, v.13, n.3, p.707-744, dez. 1983.

BRASIL. Ministério do Desenvolvimento, Indústria e Comércio (MDIC). Alice Web. http://aliceweb.desenvolvimento.gov.br/ (15 abr. 2004 - 11 dez. 2004) 
BURNQUIST, H.L. Panorama da safra sucroalcooleira na região centro-sul. Preços Agrícolas, v.14, n.158, p.7-10, dez.1999.

BURNQUIST, H.L. (Coord.); BACCHI, M.R.P.; FIGUEIREDO, N.M.S.; VIEIRA, W. da C. Liberalização comercial: um fator de desenvolvimento do setor agrícola brasileiro. Estudos de Política Agrícola, Brasília: IPEA, 1994, 216p.

BURNQUIST, H.L.; BACCHI, M.R.P. Análise das barreiras protecionistas no mercado de açúcar. In: MORAES, M.A.F.D.; SHIKIDA, P.F.A. (Org). Agroindústria canavieira no Brasil: evolução, desenvolvimento e desafios. São Paulo: Atlas, 2002. Cap.6, p.139-156.

BURNQUIST, H.L.; MIRANDA, S.H.G. Desempenho recente das exportações brasileiras de açúcar: uma abordagem de "market-share" constante. Revista de Economia e Sociologia Rural, v.37, n.3, p.69-90, jul./set. 1999.

CARDOSO, E.; DORNBUSCH, R. Uma equação para as exportações brasileiras de manufaturados. Revista Brasileira de Economia, v.34, n.3, p.429-437, jul./set. 1980.

CARON, D. Heterogeneidade e diferenciação dos fornecedores de cana-de-açúcar de São Paulo. São Paulo, 1986. 182p. Tese (Doutorado) - Faculdade de Filosofia, Letras e Ciências Humanas, Universidade de São Paulo.

CARUSO, R.C. Análise da oferta e demanda de açúcar no Estado de São Paulo. Piracicaba, 2002. 79p. Dissertação (MS) - Escola Superior de Agricultura "Luiz de Queiroz", Universidade de São Paulo.

CARVALHO, A.; NEGRI, J.A. Estimação de equações de importação e exportação de produtos agropecuários para o Brasil (1977/1998). Brasília: IPEA, 2000. 30p. (Texto para Discussão, 698)

CARVALHO, F.C.; BRANDT, S.A. Avaliação da política de estabilização de preços no mercado de exportação de açúcar do Brasil. Revista de Economia Rural, v.25, n.3, p.357-365, jul./set. 1987.

CASTRO, A.S.; CAVALCANTI, M.A.F.H. Estimação de equações de exportação e importação para o Brasil: 1955/95. Brasília: IPEA, 1997. 59p. (Texto para Discussão, 469) 
CAVALCANTI, M.A.; RIBEIRO, M.A.F.H. As exportações no período 1977/96: desempenho e determinantes. Brasília: IPEA, 1998. 46p. (Texto para Discussão, 545)

CENTRO DE ESTUDOS AVANÇADOS EM ECONOMIA APLICADA (CEPEA). Indicadores de preços: açúcar. http://www.cepea.esalq.usp.br (25 out. 2004)

CONFEDERAÇÃO NACIONAL DA AGRICULTURA E PECUÁRIA DO BRASIL (CNA). Publicações. http://www.cna.org.br/Cana-de-acucar/TextoPrincipal.htm (21 maio 2004)

COSTA, C.C. Medidas protecionistas utilizadas pelos Estados Unidos e União Européia para o açúcar: impacto sobre a economia das regiões exportadoras do Brasil. Piracicaba, 2004. 291 p. Tese (Doutorado) - Escola Superior de Agricultura "Luiz de Queiroz", Universidade de São Paulo.

DICKEY, D.A.; FULLER, W.A. Distribution of the estimator for auto-regressive time séries with a unit root. Jornal of the American Statistical Association, v.74, n.366, p.427-431, June 1979.

DICKEY, D.A.; FULLER, W.A. Likelihood ratio statistics for autoregressive time séries with a unit root. Econometrica, v.49, n.4, p.1057-1072, July 1981.

ENDERS, W. Applied econometric time series. New York: John Wiley \& Sons, 1995. $433 p$.

ENDERS, W. RATS Handbook for econometric time series. New York: John Wiley \& Sons, 1996. 204p.

ENGLE, R.F.; GRANGER, C.W.J. Co-integration and error correction: representation, estimation, and testing. Econometrica, v.55, n.2, p.251-276, Mar. 1987.

FAO. FAOSTAT. http://faostat.fao.org/faostat (12 Aug. 2004)

FULLER, W.A. Introduction to statistical time series. New York: John Wiley \& Sons, 1976. 424p.

GARDNER, B.L. The economy of agricultural policies. New York: Macmillan Publishing Company, 1987.387p. 
GOLDSTEIN, M.; KHAN, M.S. The supply and demand for exports: a simultaneous approach. The Review of Economics and Statistics, v.60, n.2, p.275-286, Apr. 1978.

GONÇALVES, R.R. A política industrial em uma perspectiva de longo prazo. Rio de Janeiro: IPEA, 1998. 29p. (Texto para Discussão, 590)

HAMILTON, J.D. Time series analysis. New Jersey: Princenton University Press, 1994. 799p.

HARVEY, A. The econometric analysis of time series. Cambridge: MIT Press, 1990. $387 \mathrm{p}$.

HELFAND, S.M.; REZENDE, G.C. A agricultura brasileira nos anos 1990: o impacto das reformas de políticas. In: GASQUES, J.G.; CONCEIÇÃO, J.C.P.R. (Org.). Transformações da agricultura e políticas. Rio de Janeiro: IPEA, 2001. Cap.6, p.247-301.

HILL, R.C.; GRIFFITHS, W.E.; JUDGE, G. Econometria. São Paulo: Saraiva, 2003. $480 \mathrm{p}$.

INSTITUTO BRASILEIRO DE GEOGRAFIA E ESTATÍSTICA (IBGE). Banco de dados. //www.sidra.ibge.gov.br (25 mar. 2004)

INSTITUTO DE PESQUISA ECONÔMICA AVANÇADA (IPEA). Ipeadata: tema: câmbio. http://www.ipeadata.gov.br (18 jul. 2004a)

INSTITUTO DE PESQUISA ECONÔMICA AVANÇADA (IPEA). Ipeadata: tema: economia internacional. http://www.ipeadata.gov.br (18 jul. 2004b)

INSTITUTO DE PESQUISA ECONÔMICA AVANÇADA (IPEA). Ipeadata: tema: contas nacionais. http://www.ipeadata.gov.br (23 jul. 2004c)

INSTITUTO DE PESQUISA ECONÔMICA AVANÇADA (IPEA). Ipeadata: tema: preços. http://www.ipeadata.gov.br (23 jul. 2004d)

JOHANSEN, S. Statistical analysis of cointegration vectors. Journal of Economic Dynamics and Control, v.12, n.2/3, p.231-254, 1988.

JOHANSEN, S.; JUSELIUS, K. Maximum likelihood estimation and inference on cointegration: with aplications to the demand for money. Oxford Bulletin of Economics and Statistics, v.52, n.2, p.169-219, 1990. 
JORNAL DA CANA. História. http://www.jornalcana.com.br/ Conteudo/HistoriadoSetor.asp (16 mar. 2004)

KUME, H.; PIANI, G. ICMS sobre as exportações brasileiras: uma estimativa da perda fiscal e do impacto sobre as vendas externas. Rio de Janeiro: IPEA, 1997. 22p. (Texto para Discussão, 465)

LEAMER, E.E.; STERN, R.M. Quantitative international economics. Chicago: Aldine Publ., 1970. 209p.

LIMA, E.C.R. A interdependência entre os mercados de frango e bovinos: uma aplicação da metodologia VAR-Estrutural. Rio de Janeiro: IPEA, 1997. 22p. (Texto para discussão, 501)

MARJOTTA-MAISTRO, M.C. Análise do consumo industrial de açúcar no Estado de São Paulo. Piracicaba, 1998. 100p. Dissertação (MS) - Escola Superior de Agricultura "Luiz de Queiroz", Universidade de São Paulo.

MARJOTTA-MAISTRO, M.C. Ajustes nos mercados de álcool e gasolina no processo de desregulamentação. Piracicaba, 2002. 180p. Tese (Doutorado) - Escola Superior de Agricultura "Luiz de Queiroz", Universidade de São Paulo.

MIRANDA, S.H.G. de. Quantificação dos efeitos das barreiras não-tarifárias sobre as exportações brasileiras de carne bovina. Piracicaba, 2001. 233p. Tese (Doutorado) - Escola Superior de Agricultura "Luiz de Queiroz", Universidade de São Paulo.

MORAES, M.A.F.D. de. A desregulamentação do setor sucroalcooleiro do Brasil. Americana: Caminho Editorial, 2000. 238p.

MOREIRA, M.M. Abertura comercial e indústria: atualizando os resultados. Revista da Sobeet, v.2, n.2, p.1-6, 1997.

MUSALEM, A.R. Política de subsídios e exportações de manufaturados no Brasil. Revista Brasileira de Economia, v.35, n.1, p.17-41, jan./mar. 1981.

NEVES, M.F.; WAAK, R.S.; MAMONE, A. O sistema agroindustrial da cana de açúcar: caracterização das transações entre usinas e empresas de alimentos. In: CONGRESSO BRASILEIRO DE ECONOMIA E SOCIOLOGIA RURAL, 36. , Poços de Caldas, 1998. Resumos. Brasília: SOBER, 1998. 
OSTERWALD-LENUM, M.A. A note with quantiles of the asynptotic distribution of the maximum likelihood cointegration rank test statistics. Oxford Bulletin of Economics and Statistics, v.53, n.3, p.461-472, 1992.

PERRON, P. The great crash, the oil price shock, and the unit root hypothesis.

Econometrica, v.57, n.1, p.1361-1401, Jan. 1989.

PHILLIPS, P.C.B.; PERRON, P. Testing for a unit root in time series regression.

Biometrica, v.72, n.2, p.335-346, 1988.

PINTO, M.B.P. O crescimento das exportações brasileiras de manufaturados, 19541974. Estudos Econômicos, v.10, n.3, p.100-141, set./dez. 1980.

RAMOS, P. Agroindústria canavieira e propriedade fundiária no Brasil. São Paulo: HUCITEC, 1999. 243p.

REIS, J.N.P.; CRESPO, J.E.Q. Um modelo econométrico para as exportações de açúcar do Brasil. Agricultura em São Paulo, v.45, n.1, p.17-32, 1998.

RESENDE, M.F.C.; ANDERSON, P. Mudanças estruturais na indústria brasileira de bens de capital. Rio de Janeiro: IPEA, 1999. 54p. (Texto para Discussão, 658)

RIOS, S.M.P. Exportações brasileiras de produtos manufaturados: uma avaliação econométrica para o período 1964/84. Pesquisa e Planejamento Econômico, v.17, n.2, p.299-332, ago. 1987.

SHIKIDA, P.F.A. A evolução diferenciada da agroindústria canavieira no Brasil de 1975 a 1995. Piracicaba, 1997. 191p. Tese (Doutorado) - Escola Superior de Agricultura "Luiz de Queiroz", Universidade de São Paulo.

SILVEIRA, A.M. A relação entre os preços de açúcar nos mercados doméstico e internacional. Piracicaba, 2004. 74p. Dissertação (MS) - Escola Superior de Agricultura "Luiz de Queiroz", Universidade de São Paulo.

SIMS, C.A. Macroeconomics and reality. Econometrica, v.48, n.1, p.1-48, Jan.1980.

SENHADJI, A.S.; MONTENEGRO, C.E. Time series analysis of export demand equations: a cross-country analysis. IMF Staff Papers, v.46, n.3, p.259-273, Sep./Dec. 1999. 
STALDER, S.H.G. Análise da participação do Brasil no mercado internacional de açúcar. Piracicaba, 1997. 121p. Dissertação (MS) - Escola Superior de Agricultura "Luiz de Queiroz", Universidade de São Paulo.

STALDER, S.H.G.; BURNQUIST, H.L. A importância dos subprodutos da cana-deaçúcar no desempenho do setor agroindustrial. Revista de Economia e Sociologia Rural, v.34, n.3/4, p.103-119, jul./dez. 1996.

STALDER, S.H.G.; BURNQUIST, H.L. Exportações de açúcar no Brasil: uma abordagem de elasticidade (compact disc). In: CONGRESSO BRASILEIRO DE ECONOMIA E SOCIOLOGIA RURAL, 35., Natal, 1997. Anais. Brasília: SOBER, 1997.

SOUZA, Z.J.; BURNQUIST, H.L. O potencial sucroalcooleiro de co-geração e a questão da comercialização. Preços Agrícolas, v.14, n.158, p.17-20, dez. 1999.

STOCK, J.; WATSON, M. Testing for commom trends. Journal of the American Statistical Association, v.83, n.2, p.1097-1107, 1988.

TOMICH, F.A.; MAGALHÃES, L.C.G.; SILVEIRA, F.G. Desempenho do comércio internacional e competitividade do agronegócio brasileiro: avaliação da década de 90 e cenários. In: GASQUES, J.G.; CONCEIÇÃO, J.C.P.R. (Org.). Transformações da agricultura e políticas. Rio de Janeiro: IPEA, 2001. Cap.9, p.340-372.

UNIÃO DA AGROINDÚSTRIA CANAVIEIRA DO ESTADO DE SÃO PAULO (UNICA). Biblioteca. http://www.portalunica.com.br/files/publicacoes/2 (15 jul. 2004)

UNIÃO DA AGROINDÚSTRIA CANAVIEIRA DO ESTADO DE SÃO PAULO (UNICA). Estatística. http://www.portalunica.com.br/referencia/estatisticas.jsp (14 jan. 2005)

UNITED STATES DEPARTMENT OF AGRICULTURE (USDA). Sugar: world markets and trade. http://www.fas.usda.gov/htp/sugar/sugar.html (15 Nov. 2004) VEIGA FILHO, A. O dilema da "escolha de sofia" nas exportações de açúcar pelo Brasil. Informações Econômicas, v.30, n.9, p.53-59, set. 2000. 
ZINI JUNIOR, A.A. Funções de exportação e de importação para o Brasil. Pesquisa e Planejamento Econômico, v.18, n.3, p.615-662, dez. 1988. 